Boletín de la Sociedad Geológica Mexicana

Volumen Conmemorativo del Centenario

Temas Selectos de la Geología Mexicana

Toмo LVII, NúM. 3, 2005, P. 285-318

\title{
La Mesa Central de México: estratigrafía, estructura y evolución tectónica cenozoica
}

\author{
Ángel Francisco Nieto-Samaniego*, Susana Alicia Alaniz-Álvarez, \\ Antoni Camprubí í Cano
}

Centro de Geociencias, Universidad Nacional Autónoma de México, Apartado postal 1-742, Querétaro, Qro. 76230, México

*afns@geociencias.unam.mx

\begin{abstract}
Resumen
La Mesa Central es una provincia fisiográfica caracterizada por ser una región elevada que internamente puede subdividirse en dos regiones. La región sur tiene cotas que se encuentran por encima de los $2000 \mathrm{msnm}$, con excepción del valle de Aguascalientes, es una zona montañosa cubierta en su mayor parte por rocas volcánicas cenozoicas. La región norte, que es de mayor extensión, muestra un estado de erosión más avanzado que la región sur, tiene grandes cuencas continentales rellenas de sedimentos aluviales y lacustres, y presenta cotas por debajo de los $2000 \mathrm{msnm}$. La configuración de la corteza en la Mesa Central muestra un espesor de $c a .32 \mathrm{~km}$ y está flanqueada por la Sierra Madre Oriental con espesor de $c a .37$ $\mathrm{km}$ y la Sierra Madre Occidental de $c a .40 \mathrm{~km}$. Bajo la corteza se infiere la presencia de cuerpos parcialmente fundidos de material mantélico atrapados en la zona adelgazada, sugiriendo que la adición de materiales fundidos en la base produjo el levantamiento y calentamiento de la parte inferior y media de la corteza.

Las rocas más antiguas que afloran en la Mesa Central son facies marinas de edad triásica y delimitan burdamente la zona del margen continental para ese tiempo. Yaciendo sobre esas rocas aparecen distribuidas en toda la Mesa Central rocas continentales de edad jurásica. A partir del Oxfordiano y hasta finales del Cretácico prevalecieron condiciones marinas. Durante ese lapso se depositaron tres conjuntos litológicos muy distintos, hacia el margen oriental se encuentra una secuencia de plataforma, denominada Plataforma Valles-San Luis Potosí que en su mayor parte queda comprendida en la Sierra Madre Oriental, pero hacia la Mesa Central está representada por facies arrecifales y principalmente de talud; hacia el centro de la Mesa Central aparecen rocas de cuenca marina que constituyen secuencias potentes de lutita y arenisca calcáreas y culminan con arenisca que contiene clastos de rocas volcánicas, a este conjunto se lo denomina Cuenca Mesozoica del Centro de México. Hacia los límites occidental y sur aparecen conjuntos volcanosedimentarios marinos en los que se reconocen espesores grandes de basaltos almohadillados con componentes sedimentarios que consisten principalmente en lutita, arenisca y caliza; en algunas localidades las lavas y los sedimentos se encuentran intercalados. Todas estas rocas muestran deformación plicativa y fallamiento inverso, los cuales fueron producidos durante la orogenia Laramide. Sobre estos conjuntos litológicos aparecen en contacto por una gran discordancia angular las rocas de edad cenozoica, todas de origen continental y que hacia la base de la secuencia consisten de conglomerados y rocas volcánicas de composiciones andesíticas a riolíticas. Hacia la parte superior la secuencia volcánica cenozoica consiste de un gran apilamiento de rocas de composición riolítica caracterizadas por una composición química peculiar que las identifica como riolitas "topacíferas" y cuyo origen fue mayoritariamente por fusión de la corteza. Hacia la cima de la secuencia cenozoica aparecen basaltos alcalinos de edad Mioceno y Cuaternario, volumétricamente modestos.
\end{abstract}


El límite norte de la Mesa Central lo constituye el Sector Transversal de Parras de la Sierra Madre Oriental. Los otros tres límites, este, oeste y sur están formados por sistemas de fallas regionales en los que se ha documentado actividad cenozoica. El límite este lo forma el sistema de fallas Taxco-San Miguel de Allende cuya edad de actividad varía de norte a sur de Oligoceno en la región central (San Luis Potosí) a Mioceno hacia el límite sur (San Miguel de Allende). El límite sur lo forma la falla del Bajío cuya actividad documentada abarca del Oligoceno al Mioceno medio, al igual que el graben de Aguascalientes que constituye la parte sur del límite poniente de la Mesa Central. Hay una gran estructura que constituye el límite de las regiones norte y sur de la Mesa Central y buena parte de su límite occidental. Ese gran sistema de fallas denominado San Luis-Tepehuanes muestra evidencias de actividad durante el Eoceno y Oligoceno, y se puede documentar actividad Plioceno-cuaternaria solamente en su porción NW.

Los yacimientos minerales, en especial epitermales, que se conocen en la Mesa Central están localizados, en su gran mayoría, sobre las trazas de esos grandes sistemas de falla. La información disponible permite establecer que esas estructuras ejercieron un control para el emplazamiento de rocas volcánicas, hipabisales y depósitos minerales a lo largo de sus trazas, sin que se pueda precisar los mecanismos por los que se dio ese control.

Palabras clave: México, Mesa Central, Estratigrafía cenozoica, Tectónica de México.

\section{Abstract}

The Mesa Central is a physipographic province in central Mexico that it is characterized by being an elevated plateau and that can be divided in two regions. In the southern region, the topography is higher than 2 000 masl, except for the Aguascalientes valley. This region is mountainous, and mostly covered by Cenozoic volcanic rocks. The northern region is larger than the southern, it shows an advanced degree of erosion, contains several continental basins filled with lacustrine and fluvial sediments, and its topography is lower than 2000 masl. The crust in the Mesa Central is about $32 \mathrm{~km}$ thick, and it is bordered by the Sierra Madre Oriental, with average crustal thickness of $\sim 37 \mathrm{~km}$, and the Sierra Madre Occidental, with average crustal thickness of $40 \mathrm{~km}$. The presence of magmas from mantle wedges below the crust is inferred, trapped at the bottom of the crust. This suggests that an underplating process produced heating and uplifting of the base and middle portions of the crust. The oldest rocks that outcrop at the Mesa Central are Triassic marine facies that formed approximately along the continental margin at that time. These rocks are overlain by Jurassic continental rocks that are widely distributed within the Mesa Central. Marine deposition in the area prevailed between the Oxfordian and the Cretaceous. During that period of time three distinctive lithological sequences formed. A marine platform formed at the eastern continental margin, and it is named Valles-San Luis Potosí Platform. It is mostly part of the Sierra Madre Oriental, but it is distinctively constituted by reef and talus facies towards the Mesa Central. In the middle part of the Mesa Central marine rocks outcrop and are made up of a very thick sequence of calcareous lutites and sandstones that are topped by sandstones with clasts of volcanic rocks, a suite that is known as the Mesozoic Basin of Central Mexico. In the western and southern borders of the Mesa Central, marine volcanosedimentary Mesozoic rocks crop out, that are made up of a thick sequence of pillow lava with intercalated lutite, sandstone and limestone. All of the above rocks have plicative deformation and inverse faulting, both produced during the Laramide orogeny. An angular unconformity separates these lithological sequences from the continental Cenozoic rocks. The bottom of the Cenozoic sequence consists of conglomerate, and andesitic and rhyolitic volcanic rocks. These were followed by Oligocene topaz-bearing rhyolites that formed by crustal melting. The uppermost part of the Cenozoic sequence contains scarce Miocene-Quaternary alkaline basalts.

The northern boundary of the Mesa Central is the so-called Sector Transversal de Parras, that is part of the Sierra Madre Oriental. The east, west and south boundaries of the Mesa Central are constituted by major fault systems that were active during the Cenozoic. The eastern boundary is constituted by the Taxco-San Miguel de Allende fault system, whose activity peaked from north to south, during the Oligocene in San Luis Potosi and during the Miocene in the southern boundary of the Mesa Central (San Miguel de Allende). The southern boundary is constituted by the El Bajio fault that was active between the Oligocene and the middle Miocene, simultaneously to the Aguascalientes graben, south of the western boundary of the Mesa Central. The major structure that separates the northern and southern regions of the Mesa Central is named San Luis-Tepehuanes fault system in this paper. It was active mostly between the Eocene and the Oligocene, but also during the Pliocene-Quaternary in its northwestern segment. The majority of the mineral deposits found in the Mesa Central or in its vicinities, especially epithermal deposits, are located on the traces of the major fault systems described above. The available information suggests that the structures associated with the major fault systems controlled the emplacement of both volcanic-hypabyssal rocks and mineral deposits, although the actual mechanisms that drove the association between faulting, volcanism, and metallogenesis remain unknown.

Key words: Mexico, Mesa Central, Cenozoic stratigraphy, Tectonics of Mexico. 


\section{Introducción}

La Mesa Central (MC) se localiza en la parte centronorte de México, en una región semidesértica del país, donde la mayor parte de los estudios del territorio se han llevado a cabo con el fin de localizar y explotar yacimientos minerales, principalmente de metales preciosos. Existen algunos trabajos del siglo XIX e inicios del siglo $\mathrm{XX}$ en los que se describe la estratigrafía de esos lugares debido a la presencia de algunos distritos mineros de importancia como Zacatecas, Fresnillo, Guanajuato o Real de Catorce, por mencionar algunos (e. g., López-Monroy, 1888; Botsford, 1909). El conocimiento de la constitución geológica cenozoica de esa región del país, así como de los procesos que la originaron, fue muy escaso hasta bien entrada la segunda mitad del siglo XX, lo que se refleja en la Carta Geológica de la República Mexicana escala 1:2 000 000, publicada en 1968 (Hernández-Sánchez Mejorada y López-Ramos, 1968). En ella, la parte meridional de la MC está cubierta por una unidad denominada "Cenozoico medio volcánico", que representa una cubierta volcánica cenozoica indiferenciada, ya que para ese tiempo esas rocas no habían sido divididas en formaciones. En la parte septentrional de la MC aparecen rocas del Cretácico, además de afloramientos locales de rocas más antiguas en Zacatecas, Catorce, Ojo Caliente y Charcas. El resto de la superficie está cubierta por una extensa unidad denominada "tobas y material residual" del Pleistoceno y Reciente, de la cual tampoco existía una división formacional.

La cartografía sistemática topográfica y geológica iniciada en la década de 1970 por el Instituto Nacional de Estadística, Geografía e Informática (INEGI, 2004), constituyó una base importantísima que permitió el desarrollo de las investigaciones geológicas modernas. Hay otras dos series de mapas geológicos de cobertura regional que constituyen el mayor núcleo de información geológica básica sobre la MC con que contamos actualmente: el primero de ellos es la cartografía geológica en escala 1:50 000 realizada por el Instituto de Geología de la Universidad Autónoma de San Luis Potosí y publicada en su serie "Folletos Técnicos". Esa cartografía cubre el estado de San Luis Potosí y algunas regiones vecinas, y fue editada por el mismo Instituto en tirajes muy reducidos y en formato pequeño. La segunda serie de mapas geológicos fueron publicados por el Servicio Geológico Mexicano, antes Consejo de Recursos Minerales (Coremi), cubre la totalidad de la MC con mapas geológicos en escala 1:250 000 y cuenta con cartas geológicas en escala 1:50 000 en numerosos lugares de interés minero. Esta información cartográfica estuvo paulatinamente disponible al público durante las décadas de 1970, 1980 y 1990. Actualmente el programa de cartografía sistemática que realiza el Servicio Geológico Mexicano se mantiene vigente. El estudio geológico de la MC durante las últimas décadas del siglo XX ha sido enfocado principalmente a su parte meridional y a las rocas cenozoicas, contándose actualmente con una estratigrafía bastante completa, así como edades isotópicas de rocas volcánicas y algunos estudios estructurales, lo que ha permitido que se hayan propuesto algunos modelos de su evolución tectónica.

En este trabajo presentamos un análisis crítico del conocimiento geológico de la MC, principalmente enfocado a su evolución cenozoica. Se aborda la definición misma de esta provincia fisiográfica y se presenta una revisión de los conjuntos litológicos y sus posibles interpretaciones. $\mathrm{Su}$ configuración estructural se aborda analizando la localización, geometría y edad de las estructuras mayores desde un punto de vista cinemático. Adicionalmente, se presenta una discusión sobre las principales interpretaciones tectónicas que se han hecho de su evolución cenozoica y a manera de conclusión, una propuesta de los eventos tectónicos que pudieron darle origen. Por último, presentamos una síntesis de los trabajos de investigación que se consideran necesarios para resolver los principales problemas científicos vigentes.

\section{Localización y extensión de la Mesa Central}

La Mesa Central de México fue reconocida como provincia fisiográfica por Raisz (1959), quien la definió como: "una cuenca rodeada por montañas más elevadas. Más alta y más plana que la provincia Cuencas y Sierras (localizada al norte). En lugar de sierras elongadas, ésta tiene áreas poco elevadas, principalmente disectando rocas volcánicas antiguas". Al observar la configuración orográfica de la República Mexicana es evidente la existencia de dicha provincia, localizada hacia la región central del país (Figura 1). Sin embargo, el conocimiento que actualmente se ha alcanzado de la orografía y geología de esa región, así como la posibilidad de observar la república en su conjunto en imágenes de satélite y en modelos digitales de elevación, imponen una redefinición de sus límites como provincia fisiográfica.

Los límites de la MC mostrados en la Figura 1 fueron trazados considerando tanto las características morfológicas como geológicas y buscando los límites con las regiones aledañas de morfología y geología contrastante, con el fin de ajustarse a las definiciones de provincia fisiográfica propuestas por Bates y Jackson (1987) y Lugo-Hubp (1989). La configuración que nosotros hemos obtenido para la MC es igual a la propuesta en el Mapa Digital de México, del Instituto de Nacional de Estadística, Geografía e Informática. La MC es una planicie elevada que se localiza en la parte central de México, más de la mitad de su superficie se encuentra por encima de la cota 2000 y las elevaciones topográficas en su interior son moderadas, la mayoría forman desniveles inferiores a los $600 \mathrm{~m}$ (Figura 1). Se encuentra limitada al norte y oriente por la Sierra Madre Oriental (SMOr), hacia el occidente por la Sierra Madre Occidental (SMOc) y al sur por la depresión conocida como El Bajío. Una característica distintiva es que 


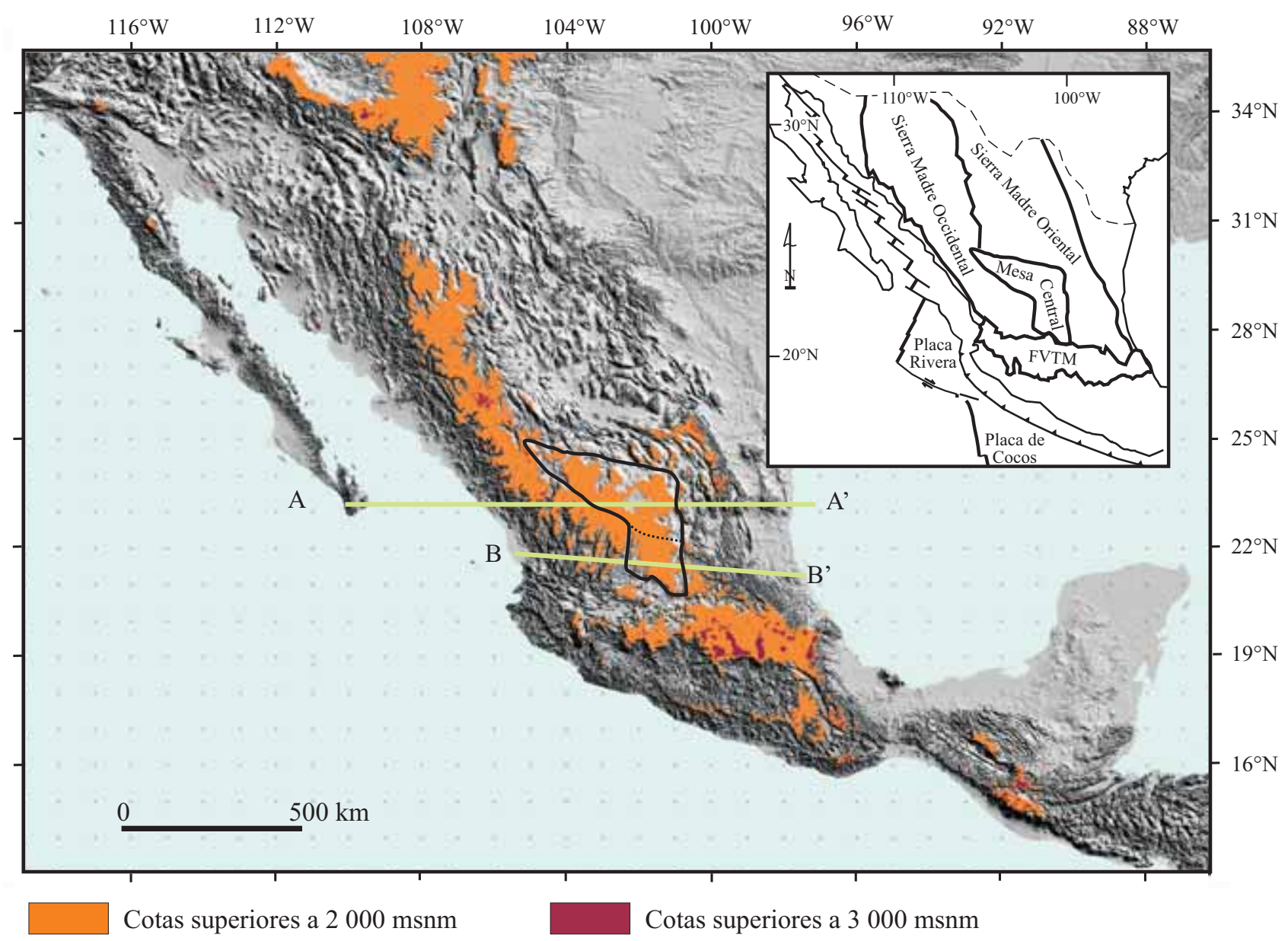

Figura 1. Modelo de elevación digital de la República Mexicana indicando la ubicación de la Mesa Central. FVTM: Faja Volcánica Transmexicana. La línea punteada indica la división entre la parte sur y norte de la Mesa Central. Las líneas verdes muestran la ubicación de los perfiles mostrados en la Figura 2.

las provincias fisiográficas circundantes tienen, en general, relieves más pronunciados. Hacia el norte y oriente aparece la Sierra Madre Oriental, que es una cadena montañosa originada por la deformación contractiva de la orogenia Laramide (e. g., Eguiluz-de Antuñano et al., 2000). En la parte oriental esta cadena montañosa muestra cotas por debajo de los $2000 \mathrm{msnm}$ mientras que hacia la zona y nororiente la hipsografía es más elevada, rebasando los 2800 msnm en las montañas más altas (Figura 1). Hacia el occidente, la MC limita con la Sierra Madre Occidental, que es una cadena montañosa de origen volcánico $(e . g$., Aranda-Gómez et al., 2000), en la parte en que esa provincia colinda con la MC aparece un cordón de $c a .130 \mathrm{~km}$ de ancho en promedio, con elevaciones que rebasan en numerosos lugares los $2800 \mathrm{msnm}$ (Figura 1) y a partir del cual, hacia el occidente, las elevaciones son menores a 2000 msnm y decrecen paulatinamente por un espacio superior a $400 \mathrm{~km}$ hasta llegar a la costa. Hacia el sur, la MC colinda con una depresión topográfica conocida como El Bajío, las elevaciones pasan abruptamente de cotas superiores a los $2000 \mathrm{msnm}$ a una cota promedio de $1800 \mathrm{msnm}$.
Dentro de la MC se pueden reconocer dos regiones. $\mathrm{La}$ región sur, donde se localizan las cotas más elevadas, se encuentra por encima de los $2000 \mathrm{msnm}$ con excepción del valle de Aguascalientes. Esa región de la MC es una región montañosa, cubierta en su mayor parte por rocas volcánicas cenozoicas (Nieto-Samaniego et al., 1999), muestra un estado de erosión mucho más activo que la región norte, con desniveles más pronunciados y los rasgos estructurales, principalmente fallas normales, se observan menos erosionados. Si se traza un perfil aproximadamente este-oeste que atraviese la región meridional de la MC y se extienda fuera de los límites de ésta, se podrá observar que las cotas promedio de la SMOc y la SMOr están por debajo de la cota promedio de la MC, también es notable que los desniveles dentro de la MC son menores a los observados dentro de la SMOc y SMOr, lo que le confiere su carácter de una meseta elevada y relativamente más alta que las regiones circundantes (Figura 1). En contraste, la región norte, que es la de mayor tamaño, muestra un estado de erosión más avanzado con grandes cuencas continentales rellenas de sedimentos aluviales y lacustres, algunas de 
ellas endorreicas. Esa región tiene las cotas más bajas y los desniveles menores, la parte más septentrional se encuentra por debajo de la cota 2000 (Figura 1). A diferencia de la porción meridional, si se traza un perfil E-W en la parte norte se observa que la MC constituye una zona relativamente deprimida y más plana que las sierras que la limitan (Figura 1), constituyendo así una meseta elevada, pero relativamente más baja que las regiones colindantes.

El límite entre las dos regiones de la MC descritas en el párrafo anterior lo constituye un gran lineamiento de más de $1600 \mathrm{~km}$ de longitud con rumbo NW, que ha sido documentado como un sistema de fallas normales de edad cenozoica en San Luis Potosí-San Luis de la Paz (AlanizAlvarez et al., 2001), Salinas de Hidalgo (La Ballena, Silva-Romo, 1996) y Nazas-Rodeo (Aranda-Gómez et al., 2003); existen además otros reportes locales de fallas normales paralelas al lineamiento sobre su traza en las zonas mineras de Zacatecas y Fresnillo (De Cserna, 1976; Ponce y Clark, 1988; Albinson, 1988).

\section{La corteza y la litósfera de la Mesa Central}

La estructura de la corteza en la MC y Sierra Madre Occidental ha sido interpretada a partir de la estructura sísmica reportada por distintos autores (Meyer et al., 1958; Fix, 1975; Rivera y Ponce, 1986). Adicionalmente Kerdan (1992) realizó la interpretación de la estructura cortical basándose en el estudio de un perfil gravimétrico a lo largo del Trópico de Cáncer, abarcando desde la península de Baja California hasta el Golfo de México. En su modelo utilizó como condicionantes las densidades propuestas por los modelos sísmicos mencionados arriba. El espesor más probable para la corteza de la MC es de ca. $32 \mathrm{~km}$ y contrasta con los espesores de la SMOr y SMOc que tienen espesores de ca. 37 y $40 \mathrm{~km}$ respectivamente (Kerdan, 1992; Campos-Enriquez et al., 1992; Nieto-Samaniego et al., 1999) (Figura 2). Fix (1975) interpreta en su modelo sísmico que bajo el bloque adelgazado de la MC existe una zona de fusión parcial cercana a $20 \%$, que inicia alrededor

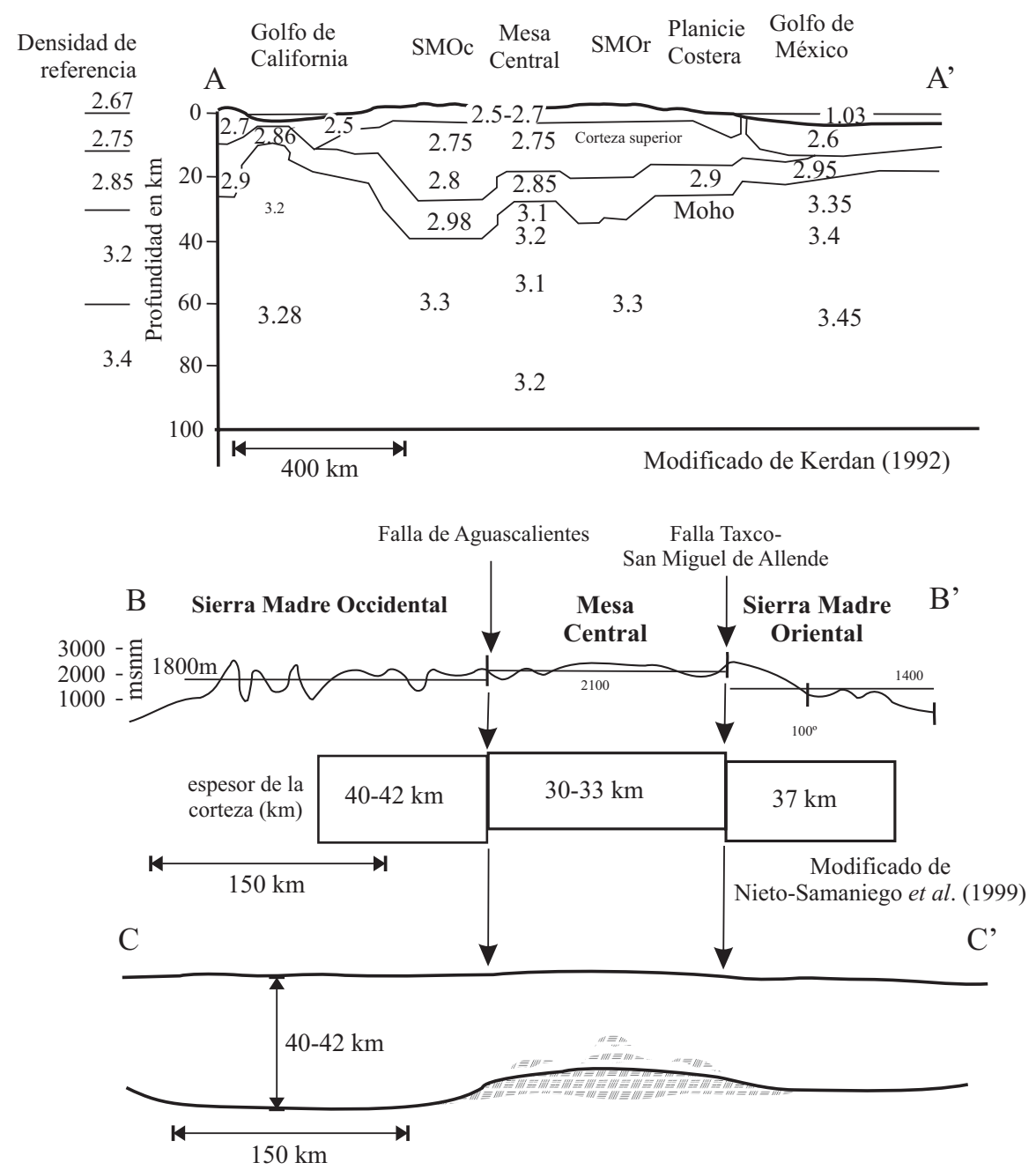

Figura 2. Perfiles que muestran la estructura de la corteza en la Mesa Central, su ubicación se muestra en la Figura 1. El perfil A-A' corresponde al modelo obtenido por inversión de datos gravimétricos y el perfil B-B' está basado en la hipsografía y espesores de la corteza publicados por diversos autores (véase discusión completa en texto). El perfil C-C' muestra un modelo idealizado de la estructura de la corteza en la Mesa Central propuesto en este trabajo. 
de los $34 \mathrm{~km}$ de profundidad y se extiende hasta los 260 $\mathrm{km}$, disminuyendo paulatinamente el porcentaje de fusión parcial. Esto es apoyado por la presencia de basanitas cuaternarias portadoras de xenolitos del manto y de la base de la corteza, que han sido reportadas por ArandaGómez et al. (1993a). Información indirecta acerca de la temperatura en la base de la corteza fue obtenida por Hayob et al. (1989), los datos se basan en las temperaturas de granulitización $\left(950-1125^{\circ} \mathrm{C}\right.$ ) y en las temperaturas de exsolución de feldespato y homogenización de plagioclasa (850-900 $\left.{ }^{\circ} \mathrm{C}\right)$, calculadas para xenolitos de la base de la corteza colectados en la parte meridional de la MC. Esos autores propusieron la existencia de un proceso de granulitización en la corteza inferior de la MC que ha tenido lugar durante el Oligoceno-Cuaternario, también deducen que la temperatura actual más probable en la base de la corteza es de al menos $850{ }^{\circ} \mathrm{C}$.

Con la información disponible, la configuración más probable de la corteza en la Mesa Central y la parte más superior del manto es como se ilustra en la Figura 2c. La MC muestra una corteza adelgazada y elevada, que está bordeada por dos bloques corticales relativamente más gruesos y deprimidos. Bajo la corteza de la MC aparecen "atrapados" cuerpos parcialmente fundidos de material mantélico. Esta configuración es típica en procesos de adición de base cortical, lo cual sugiere ese mecanismo como probablemente responsable del levantamiento de la corteza sobreyacente debido a la presencia de material parcialmente fundido bajo la zona elevada. Asociado a este fenómeno se espera que ocurra el calentamiento de la parte inferior y media de la corteza produciendo una elevación de las isotermas.

\section{Estratigrafía}

Dentro de la MC no hay afloramientos documentados de rocas paleozoicas, sólo al suroccidente de San Juan del Río, Dgo. se han reportado afloramientos pequeños de esquistos de muscovita (Figura 3) cuyo metamorfismo fue fechado en $c a$. $252 \mathrm{Ma}\left({ }^{40} \mathrm{Ar} /{ }^{39} \mathrm{Ar}\right.$ en muscovita; Iriondo, 2003). En contraste, las rocas paleozoicas afloran hacia los bordes de la MC y dentro de la Sierra Madre Oriental (Ortega-Gutiérrez et al., 1992; Sánchez-Zavala et al., 1999). Hay trabajos en los que se consideró la presencia de rocas paleozoicas dentro de la MC, pero sin que exista una evidencia contundente: en Zacatecas, Burckhardt y Scalia (1906) consideraron una posible edad paleozoica para los esquistos y filitas que subyacen discordantemente a una secuencia de filitas con contenido fósil del Cárnico; la edad paleozoica fue cuestionada por McGehee (1976), dado que en su sección estratigráfica no identifica dicha discordancia, sin que exista a la fecha evidencia adicional que apunte hacia una edad paleozoica. En la Sierra de Catorce, Zárate-del Valle (1982), Bacon (1978) y FrancoRubio (1999) consideraron una edad paleozoica para la base de la secuencia estratigráfica, principalmente apoyados en la presencia de unas esporas pensilvánicas (Bacon, 1978) y de restos de plantas fósiles (Franco-Rubio, 1999); esas edades han sido cuestionadas por Hoppe et al. (2002) y Barboza-Gudiño et al. (2004), quienes presentan argumentos sedimentológicos y estratigráficos que indican una edad más probable del Triásico Superior para las rocas que afloran en la base de la secuencia estratigráfica de la Sierra de Catorce.

\subsection{Mesozoico}

\subsubsection{Triásico}

Dentro de la MC han sido reportados afloramientos de rocas del Triásico Superior, cuya edad fue establecida por su contenido fósil, las localidades son: la sierra de Salinas (Peñón Blanco, Silva-Romo, 1996), Charcas, S. L. P. (Cantú-Chapa, 1969), Zacatecas, Zac. (Burckhardt y Scalia, 1906), y adicionalmente en la Sierra de Catorce, donde la secuencia turbidítica que aflora en la base de la columna expuesta fue asignada al Triásico por correlación litológica con las localidades mencionadas (Barboza-Gudiño et al., 2004) (Figura 3). En la sierra de Salinas, Charcas y la Sierra de Catorce, las rocas triásicas consisten principalmente de secuencias potentes de arenisca y lutita, y muestran características que las identifican como secuencias turbidíticas (Silva-Romo, 1996; Silva-Romo et al., 2000; CentenoGarcía y Silva-Romo, 1997). En Zacatecas, las rocas triásicas son sedimentos clásticos con grados bajos de metamorfismo, hacia la base predominan esquisto y filita con intercalaciones de arenisca y conglomerado; encima de esas rocas hay una secuencia de filita con arenisca y mármol. Entre ambas secuencias se ha propuesto la existencia de una discordancia, pero no hay acuerdo sobre su existencia (McGehee, 1976; Ranson et al., 1982; Monod y Calvet, 1991; Quintero-Legorreta, 1992). Aparecen también rocas ígneas de composición básica denominadas por varios autores como "roca verde" cuya relación con los sedimentos es principalmente de carácter intrusivo (diques, sills y otros cuerpos intrusivos), esas rocas son de edad más reciente y han sido interpretadas cretácicas (Centeno-García y Silva-Romo, 1997). Sin embargo, se han reportado afloramientos de rocas con estructuras que sugieren ser lavas almohadilladas intercaladas con los sedimentos triásicos (Burckhardt y Scalia, 1906; McGehee, 1976).

El carácter turbidítico de las secuencias triásicas en la sierra de Salinas, en la Sierra de Catorce y en Charcas, S. L. P., ha sido interpretado como evidencia de que en esa región existió un margen continental. La zona continental aportadora de clásticos estaría localizada hacia el ENE. Hacia el W-SW se localizaría una región oceánica, representada por las rocas sedimentarias clásticas de Zacatecas, Zac. (Figura 4).

Hay localidades de rocas volcanosedimentarias que algunos autores correlacionan con las rocas triásicas de 


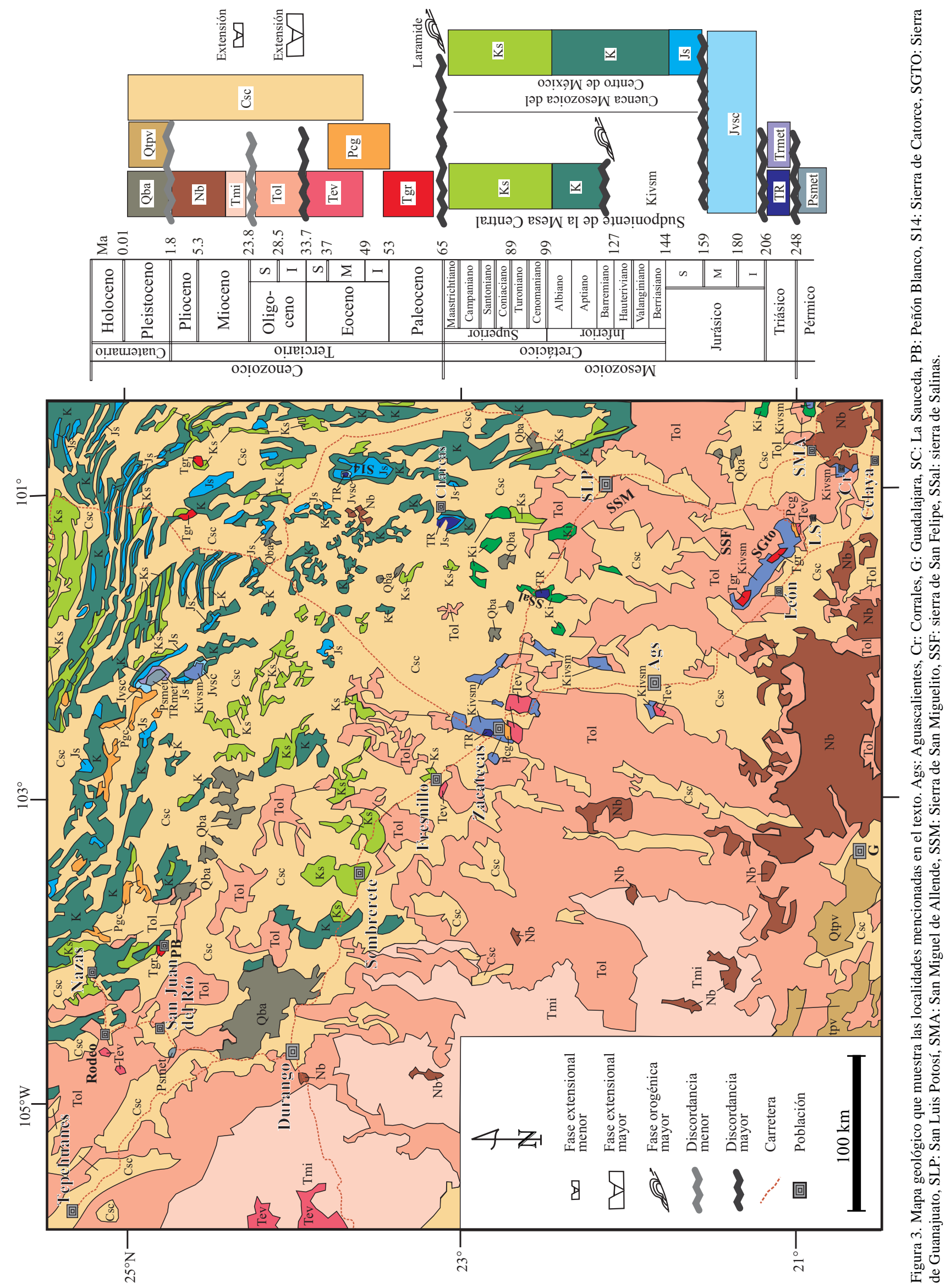


Zacatecas, pero que su edad es materia de debate. Su presencia en Fresnillo fue propuesta por De Cserna (1976), pero no hay acuerdo en la literatura acerca de su edad y algunos indicios aislados indican que las rocas señaladas por ese autor pudieran ser en realidad cretácicas (CentenoGarcía y Silva-Romo, 1997). En la Manganita, localizada $80 \mathrm{~km}$ al NW de Zacatecas, también han sido reportadas estas rocas con intercalaciones de "tobas híbridas" (LópezInfanzón, 1986), pero no existe información publicada donde se documente su edad y composición. En la Sierra de Guanajuato se ha documentado rocas con características de secuencias de cuenca, pero los fechamientos hasta ahora apuntan a una edad Jurásico Tardío-Cretácico Temprano; Freydier et al. (1996) las consideraron de esa edad por su cercanía a la secuencia de arco volcánico conocida como secuencia magmática de Guanajuato que aflora al oriente y cuya edad fue determinada con fechamientos K-Ar, la mayoría en roca total, realizados en basaltos, dioritas, tonalitas y gabros (Lapierre et al., 1992) así como una edad $\mathrm{U}-\mathrm{Pb}$ de 146.1 Ma en circón (Mortensen et al., 2003). En las cercanías de León, Gto., se conoce un registro estratigráfico directo de la relación entre la secuencia volcánica con sedimentos de cuenca y rocas calcáreas, en ese lugar las rocas volcánicas yacen en discordancia angular bajo calizas que contienen una gran cantidad de fauna fósil de edad Aptiano-Cenomaniano (Quintero-Legorreta, 1992; Chiodi et al., 1988). Las rocas volcánicas presentan metamorfismo en facies esquistos verdes y alteración hidrotermal y tienen el registro de dos deformaciones penetrativas y han sido correlacionadas por su similitud litológica con las rocas triásicas de Zacatecas por Quintero-Legorreta (1992), pero ese autor no cuenta con edades isotópicas ni paleontológicas. También se conoce de la existencia en Corrales, Gto., de secuencias sedimentarias con rocas basálticas marinas semejantes a las de Guanajuato y Zacatecas, de edad Cretácico Temprano (Freydier et al., 1996).

\subsubsection{Discordancia del Triásico Superior-Jurásico Inferior}

Sobre las rocas de edad triásica de la Mesa Central aparece una discordancia, la cual se puede observar en los afloramientos de rocas triásicas marinas de Zacatecas, Zac., sierra de Salinas, Sierra de Catorce y Charcas, S. L. $P$. Las rocas continentales que se encuentran encima de esta discordancia y que están distribuidas ampliamente dentro y fuera de la MC, en la Sierra Madre Oriental (CarilloBravo, 1971; Barboza-Gudiño et al. 1999) y en el sur de México (Morán-Zenteno et al., 1993), indican claramente una extensión muy amplia de esa discordancia.

\subsubsection{Jurásico}

Se han reconocido dos conjuntos litológicos y una discordancia con edades jurásicas:

Jurásico Temprano-Medio. El conjunto de rocas más antiguo de edad jurásica registra una etapa en la cual la Mesa Central estuvo emergida, está constituido de rocas continentales, conglomerado y arenisca con rocas volcánicas intercaladas. Su edad queda definida del Jurásico Temprano-Medio por yacer discordantemente sobre las rocas triásicas marinas y ser cubiertas, también discordantemente, por rocas marinas del Jurásico Superior (SilvaRomo, 1996; Barboza-Gudiño et al., 2004). La presencia del Jurásico Inferior-Medio atestigua el fin de la acumulación de rocas marinas clásticas depositadas en el margen del cratón norteamericano. En su lugar ocurrió el depósito de sedimentos clásticos en un ambiente continental y con la presencia de actividad volcánica subaérea, durante un lapso cuya duración no se tiene bien definida, pero durante el cual la MC se mantuvo emergida.

Discordancia del Jurásico Medio. Encima de las rocas continentales de edad Jurásico Temprano-Medio aparece una discordancia cuya extensión cubre toda la Mesa Central

\section{Triásico Tardío}
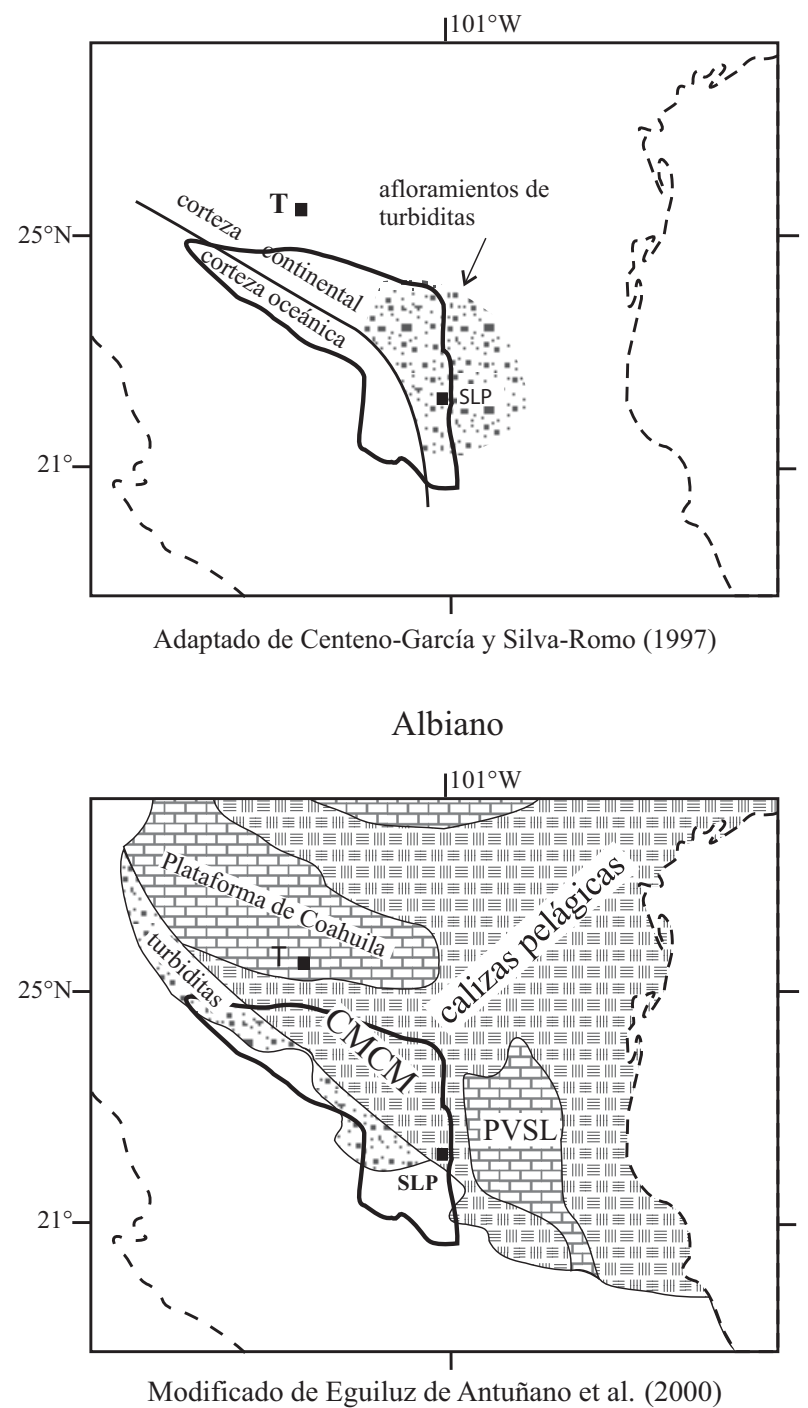

Figura 4. Reconstrucciones paleogeográficas para el Triásico y Cretácico de la Mesa Central. PVSL: Plataforma Valle-San Luis, CMCM: Cuenca Mesozoica del Centro de México, T: Torreón, SLP: San Luis Potosí. 
(Pantoja-Alor, 1963; López-Infanzón, 1986; Silva Romo, 1996). El alcance estratigráfico de esta discordancia no está bien definido por la imprecisión que se tiene de la edad de los sedimentos continentales que la subyacen, pero se localiza entre la parte superior del Jurásico Medio y la base del Jurásico Superior.

No obstante haber sido descrita esta discordancia en detalle en varias localidades (Bacon, 1978; Silva-Romo, 1996), la presencia de esta discordancia en la Sierra de Catorce ha sido cuestionada por Barboza-Gudiño et al. (2004). El registro estratigráfico pre-Oxfordiano en la MC ha sido ampliamente discutido en la literatura; sin embargo persisten aún numerosas dudas con referencia principalmente a la edad de varias unidades litoestratigráficas, así como incertidumbre en la correlación entre las distintas unidades reportadas en la literatura. Para una revisión completa de este tema consúltese a Barboza-Gudiño et al. (1999) y Bartolini et al. (1999).

Jurásico Superior. El segundo conjunto litológico de edad jurásica está formado por rocas marinas calcáreas, cuya parte inferior está compuesta de caliza y caliza dolomítica de plataforma (Formación Zuloaga), mientras que la parte superior la constituye principalmente limolita calcárea que presenta estratos de pedernal (Formación La Caja). La edad de este conjunto ha sido definida por el contenido fósil y abarca del Oxfordiano al Tithoniano (Imlay, 1938). La presencia de estas rocas documenta, para ese tiempo, el paso de un ambiente continental a un ambiente de sedimentación marina en toda la MC. Las condiciones marinas permanecerán a partir del Oxfordiano hasta la parte superior del Cretácico (Formación Caracol), abarcando un lapso cercano a los $90 \mathrm{Ma}$.

\subsubsection{Cretácico}

El advenimiento de un ambiente de sedimentación marina iniciado en el Jurásico Tardío se manifiesta en la MC y sus alrededores en tres ambientes marinos claramente distinguibles:

(1) En el borde oriental de la MC y más hacia el oriente se depositaron los sedimentos de la Plataforma Valles-San Luis Potosí (PVSLP), formando una acumulación con espesores superiores a $4000 \mathrm{~m}$ (Carrillo-Bravo, 1971). Ese depósito inició en el Jurásico Tardío sobre lechos rojos continentales, y se extiende en el Cretácico con los sedimentos de la PVSLP, que consisten de evaporitas y mayormente, de caliza tipo arrecifal, prearrecifal y postarrecifal. Todo este conjunto de rocas se encuentra plegado (Carrillo-Bravo, 1971; López-Doncel, 2003).

(2) Hacia el occidente de la PVSLP y ocupando casi la totalidad de la MC se localiza un paquete muy grueso de sedimentos marinos, depositados en mar abierto y aguas profundas, en lo que se ha denominado Cuenca Mesozoica del Centro de México (Carrillo-Bravo, 1971). El registro estratigráfico indica una subsidencia rápida, con una acumulación superior a $6000 \mathrm{~m}$ de sedimentos, que inicia con el depósito de la caliza de plataforma del
Jurásico Superior sobre lechos rojos y rocas volcánicas continentales. Hacia el Cretácico, pasa a caliza arcillosa y a lutita calcárea, culminando hacia la cima en rocas clásticas, principalmente arenisca con numerosos clastos de rocas volcánicas (Formación Caracol), que marcan la regresión marina que puso fin a las condiciones marinas en la MC hacia el Cretácico Tardío. La edad de la Formación Caracol está pobremente establecida, en Durango se le asignó un alcance hasta el Coniaciano por correlación litológica y posición estratigráfica (Roldán-Quintana, 1968) y en San Luis Potosí, Carrillo-Bravo (1971) le asigna su máximo alcance a la mitad del Maastrichtiano, sin especificar los criterios que lo conducen a asignarle esa edad. Estas rocas comparten la deformación contráctil de las rocas calcáreas de la PVSLP.

(3) Hacia el occidente de la Cuenca Mesozoica del Centro de México y localizándose en el margen occidental y sur de la MC, aparece una secuencia volcanosedimentaria marina, formada por un apilamiento grueso de basalto almohadillado, derrames, y cuerpos intrusivos de diabasa, que se encuentran intercalados con capas de toba, pizarra, pedernal y radiolarita. El componente sedimentario más importante consiste principalmente en lutita, arenisca y algunas calizas (Ranson et al. 1982; Centeno-García y Silva Romo, 1997, Martínez-Reyes, 1992). Este conjunto litológico se extiende ampliamente en la parte occidental de México hacia el norte y sur de la MC (Freydier et al., 1996). Las rocas de este conjunto litológico tienen una fuerte deformación contractiva y, a diferencia de las rocas de la Cuenca Mesozoica del Centro de México y de la Plataforma Valles-San Luis Potosí, muestran una facies metamórfica de esquistos verdes, principalmente en los componentes volcánicos. Estas rocas han sido interpretadas como una secuencia de arco volcánico marino, cuya edad no está definida con precisión, pero las evidencias conocidas indican una edad Jurásico Tardío-Cretácico Temprano (Corona-Chávez y López-Picos, 1988; Freydier et al., 1996; Mortensen et al., 2003).

Es muy notable que el límite entre la Plataforma VallesSan Luis Potosí y la Cuenca Mesozoica del Centro de México coincide con el límite oriental de la MC y con la traza del sistema de fallas Taxco-San Miguel de Allende (Alaniz-Álvarez et al., 2002). Por otra parte, el límite entre de la Cuenca Mesozoica del Centro de México y la secuencia volcanosedimentaria mesozoica, sigue burdamente la mayor parte del borde occidental de la Mesa Central y el sistema de fallas San Luis-Tepehuanes el cual se describe más adelante.

Discordancia del Neocomiano. Sobre las rocas volcanosedimentarias que afloran en el límite oeste de la MC, cuya edad va del Jurásico Tardío al Cretácico Temprano, aparece una discordancia cuya extensión y alcance estratigráfico no han sido definidos. Fue documentada por Quintero-Legorreta (1992) en las cercanías de León, Gto., quién la describe como una discordancia angular localizada entre rocas sedimentarias clásticas asociadas con 
rocas volcánicas marinas de edad pobremente definida del Jurásico Superior-Neocomiano y rocas calcáreas fosilíferas de edad Aptiano-Cenomaniano. Esta discordancia no ha sido documentada en las rocas pertenecientes a la Cuenca Mesozoica del Centro de México, donde la sedimentación marina abarca del Oxfordiano hasta el CampanianoMaastrichtiano. De esta manera, es posible inferir que la discordancia se extienda solamente en la parte occidental de la MC entre los conjuntos volcanosedimentarios y las rocas calcáreas de la Cuenca Mesozoica del Centro de México y abarcaría la parte superior del Neocomiano. La presencia de metamorfismo de grado bajo y de dos fases de deformación en el conjunto volcanosedimentario, en contraste con las rocas de la Cuenca del Mesozoica Centro de México que no muestran metamorfismo y tienen solamente evidencias de la fase de acortamiento laramídico, han llevado a algunos autores a inferir una fase orogénica Nevadiana (Quintero-Legorreta, 1992), probablemente responsable de la yuxtaposición y transporte del conjunto volcanosedimentario hacia el E-NE, que quedaría representada estratigráficamente en la discordancia descrita.

\subsection{Cenozoico}

Encima de las rocas mesozoicas se encuentran rocas continentales, sedimentarias y volcánicas que marcan el cambio del medio marino a uno continental, el cual perdurará en la MC hasta el presente. Dentro del registro estratigráfico se identifican tres discordancias regionales.

\subsubsection{Discordancia Mesozoico-Terciario}

Sobre los conjuntos litológicos mesozoicos, deformados y en algunos casos metamorfizados en grados bajos, aparece una discordancia angular y erosional que se extiende en toda la MC y en la mayor parte de México. Dentro de la MC dicha discordancia abarca un lapso que va del Cretácico Superior al Paleoceno en la parte occidental, y del Maastrichtiano al Paleoceno en la parte oriental, sin que sus límites temporales estén definidos con precisión; Munguía-Rojas et al. (2000) la delimitan abarcando el Santoniano en $26^{\circ}$ latitud N y $104^{\circ}$ longitud W, haciéndose más antigua hacia el oeste. Esta discordancia representa el hiatus sedimentario ocurrido durante la fase orogénica laramídica.

\subsubsection{Sedimentos continentales del Paleoceno-Eoceno medio}

Estas rocas afloran en zonas extensas en la parte $\mathrm{N}$ y NW de la MC y en localidades aisladas en el centro, sur y este (Figura 3). Consisten principalmente de conglomerado y arenisca, que presentan también, aunque no en todos los afloramientos, rocas volcánicas intercaladas principalmente máficas; en algunos lugares contienen material piroclástico de composición félsica. Los espesores de esta unidad son muy variables pasando de decenas a cientos de metros en distancias cortas, lo que evidencia su depósito en una superficie con relieve topográfico abrupto, al parecer asociado al desarrollo de fosas tectónicas como fue documentado en Guanajuato, Gto., en donde existe uno de sus afloramientos mejor estudiados (Edwards, 1955; Aranda-Gómez y McDowell, 1998). Otras localidades donde ha sido documentada esta unidad son: León, Gto. (Martínez-Reyes, 1992), Zacatecas, Zac. (Edwards, 1955), Fresnillo, Zac. y Sombrerete, Zac. (Albinson, 1988), en distintas localidades del estado de San Luis Potosí (Labarthe-Hernández et al. 1982), en los alrededores de Durango, Dgo. (Córdoba, 1988), en la región de Rodeo, Dgo. (Aguirre Díaz y McDowell, 1991) y en Peñón Blanco, Dgo. (Roldán-Quintana, 1968). En todos los casos estos depósitos posfechan la deformación contráctil laramídica. La edad de estas rocas ha sido definida del PaleocenoEoceno por su posición estratigráfica, y en tres localidades se han logrado obtener edades de los sedimentos: la primera localidad es Guanajuato, donde se le asigna una edad del Eoceno porque contiene fósiles de vertebrados con alcance estratigráfico del Paleoceno-Eoceno (Edwards, 1955) y por un fechamiento isotópico realizado en un derrame de andesita intercalado hacia la parte baja de la secuencia, que arrojó una edad de 49.3ะ1 Ma (K-Ar, plagioclasa, ArandaGómez y McDowell, 1998). Esa fecha permite ubicar el inicio de este depósito a finales del Eoceno temprano y la roca más antigua depositada en discordancia sobre

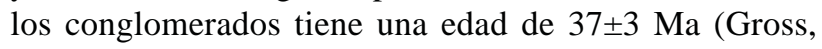
1975). La segunda localidad es San Luis Potosí, donde análisis palinológicos ubican a esta unidad en el rango Paleoceno-Eoceno (Labarthe-Hernández et al., 1982). La tercera localidad es Zacatecas, donde la parte superior del conglomerado está intercalada con rocas piroclásticas de 46.8 Ma (K-Ar en biotita; Ponce y Clark, 1988) denominada ignimbrita Los Alamitos por Loza-Aguirre (2005). La información disponible indica como más probable que el depósito de los conglomerados continentales ocurrió en el Eoceno temprano y parte del Eoceno medio, sin que se pueda descartar que parte de ellos sean del Paleoceno.

\subsubsection{Discordancia del Eoceno medio}

Encima de los sedimentos continentales del PaleocenoEoceno medio, descritos arriba, aparecen discordancias locales de carácter litológico y en ocasiones angular, que yacen bajo una cubierta de rocas volcánicas. Se las observa en buena parte de la MC, apareciendo de manera discontinua. En la parte sur, centro y oeste de la MC, su posición estratigráfica la localiza en la parte superior del Eoceno medio, mientras que en las localidades donde están ausentes los sedimentos del Paleoceno-Eoceno inferior, la discordancia del Eoceno medio se une con la discordancia Mesozoico-Terciario ya descrita. En la Sierra de Guanajuato la discordancia del Eoceno medio alcanza hasta el Oligoceno y hacia la parte noreste de la MC su alcance estratigráfico se extiende hasta tiempos recientes, dada la ausencia de la cubierta volcánica. 


\subsubsection{Rocas volcánicas del Eoceno medio}

Yaciendo sobre el conglomerado del Paleoceno-Eoceno aparecen rocas volcánicas, mayormente máficas, pero también se encuentran rocas de composiciones félsicas. Las localidades donde han sido documentadas son: Guanajuato, Aguascalientes, Zacatecas, Fresnillo, San Luis Potosí (Nieto-Samaniego et al., 1996), Sombrerete-Colorada (Albinson, 1988), Durango (Swanson et al., 1978), Nazas, y se extienden fuera de la MC hacia el norte (Aguirre-Díaz y McDowell, 1991) y hacia el sur (Morán-Zenteno, et al., 2000), formando un cinturón volcánico discontinuo en el occidente de México cuyas edades abarca del Paleoceno tardío al Eoceno (Ferrari et al., 2005). En algunas localidades las rocas volcánicas aparecen discordantes sobre los conglomerados del Paleoceno-Eoceno, como el caso de Guanajuato y en otras aparecen concordantes, como en el caso de Zacatecas.

Dentro de la Mesa Central, las edades isotópicas de la mayoría de las rocas que conforman esta unidad varían entre 37 y $49 \mathrm{Ma}$, lo que las ubica principalmente en el Eoceno medio (Tabla 1).

\subsubsection{Discordancia del Eoceno superior-Oligoceno}

Entre las rocas del Eoceno medio y las rocas del Oligoceno se aprecia una discordancia angular que ha sido documentada en la región localizada entre Zacatecas, Fresnillo y Sombrerete, en el estado de Zacatecas (Albinson, 1988). En la Sierra de Guanajuato su presencia se hace evidente por la posición estratigráfica de la cubierta volcánica oligocénica, la cual comúnmente cubre directamente a las rocas sedimentarias del Eoceno inferior, o a las rocas mesozoicas. Esta posición también se observa comúnmente en la región comprendida entre San Luis Potosí y Salinas de Hidalgo. La discordancia representa también un hiatus en la actividad volcánica y marca un cambio en la composición de los magmas, ya que se pasa del volcanismo eocénico que presenta ambas composiciones, andesíticas y riolíticas, a un volcanismo preponderantemente riolítico en el Oligoceno.

\subsubsection{Rocas volcánicas del Oligoceno}

Este grupo de rocas constituye el conjunto litológico más distintivo de las partes meridional y occidental de la MC. En la parte meridional de la MC es donde se cuenta con mejor información cartográfica y estratigráfica, teniéndose ya establecida la litoestratigrafía de este conjunto de rocas (Labarthe-Hernández et al., 1982, Nieto-Samaniego et al., 1996 y referencias en esos trabajos). Está conformado casi exclusivamente por rocas volcánicas de composición riolítica, con variaciones composicionales a latita y dacita. La parte inferior está formada mayormente de rocas de volcanismo efusivo: derrames y domos, conteniendo algunas rocas piroclásticas intercaladas. Los domos y derrames forman complejos volcánicos muy grandes que constituyen los núcleos de las sierras más elevadas de la parte sur de la $\mathrm{MC}$, formando apilamientos con espesores que superan los
400 m, por ejemplo en la Sierra de San Miguelito, la Sierra de Guanajuato, la sierra de Codornices, o la sierra de San Felipe (Figura 3). Los fechamientos que se tienen de las riolitas en la parte sur de la MC indican que se emplazaron hacia la parte superior del Oligoceno temprano entre 32 y $29 \mathrm{Ma}$ (Nieto-Samaniego et al., 1996). En la región de Fresnillo y Sombrerete, no se cuenta con información detallada de su estratigrafía, pero los fechamientos isotópicos reportados indican edades entre 27 y 30 Ma para la mayor parte de estas rocas (Huspeni et al., 1984).

La parte superior del conjunto de rocas oligocénicas corresponde a depósitos de actividad volcánica explosiva, se trata de una cubierta de ignimbritas y otras rocas piroclásticas de composición riolítica que aparecen cubriendo a los domos y derrames riolíticos. Las formaciones que constituyen a este conjunto rocoso fueron formalizadas por Labarthe-Hernández et al. (1982). En conjunto se observa a las ignimbritas cubriendo grandes extensiones pero su espesor es moderado superando sólo ocasionalmente los $250 \mathrm{~m}$. Las edades reportadas en San Luis Potosí por Labarthe-Hernández et al. (1982) son de 29 a 27 Ma. En la región SE de la Sierra de Guanajuato y en la sierra de Codornices, Nieto-Samaniego et al. (1996) reportaron una ignimbrita de $\sim 25$ Ma que es la unidad más joven de esta secuencia piroclástica. Esas edades han sido corroboradas para afloramientos de esa unidad hasta las cercanías de Celaya, Gto. (Ojeda-García, 2004) (Tabla 2).

En la parte meridional de la MC es notable la ausencia de estructuras tipo caldera que se asocien a este conjunto volcánico, no así en la parte occidental de la MC, donde este tipo de estructuras han sido documentadas (Swanson et al., 1978; Ponce y Clark, 1988). La ausencia de estas estructuras en la parte sur de la MC y su escasez en el límite oriental de la Sierra Madre Occidental, han llevado a proponer que las emisiones de rocas piroclásticas riolíticas en esta región se originaron a partir de actividad fisural, lo que se ve sustentado por la observación de numerosos diques piroclásticos localizados en las unidades infrayacentes de la cubierta ignimbrítica (Labarthe-Hernández et al., 1982; Aguirre-Díaz y Labarthe-Hernández, 2003).

Basados en la distribución geográfica, posición estratigráfica, composición química e isotópica, Orozco-Esquivel et al. (2002) distinguieron dos grupos de rocas que tuvieron un origen diferente, un grupo inferior que queda incluido en el volcanismo efusivo descrito arriba, el cual está formado por derrames, algunos domos y material piroclástico de composición riolítica, cuyo origen asocian a magmas derivados del manto. El segundo grupo lo constituyen un grupo muy voluminoso de domos y derrames riolíticos que forman la parte superior de la secuencia del volcanismo efusivo y la totalidad de la cubierta piroclástica. A este segundo conjunto de rocas las consideran originadas principalmente por procesos de fusión parcial en desequilibrio de rocas corticales, teniendo un escaso aporte de magmas mantélicos. Al parecer el cambio en la composición de los magmas que constituyeron estos dos grupos de rocas 
Tabla 1. Edades isotópicas de la Mesa Central.

\begin{tabular}{|c|c|c|c|c|c|c|c|c|c|c|}
\hline Muestra & $\begin{array}{c}\text { Unidad } \\
\text { Cronoestratigráfica }\end{array}$ & Estado & Longitud & Latitud & Roca & Método & $\begin{array}{l}\text { Material } \\
\text { fechado }\end{array}$ & Edad & Error & Referencia \\
\hline H90-9 & Plioceno y Cuaternario & Durango & -105.33 & 24.91 & Basalto & $\mathrm{K} / \mathrm{Ar}$ & Roca entera & 2.3 & 0.2 & Aranda-Gómez et al. 1997 \\
\hline H90-13 & Plioceno y Cuaternario & Durango & -105.33 & 24.91 & Basalto & $\mathrm{K} / \mathrm{Ar}$ & Roca entera & 2.5 & 0.2 & Aranda-Gómez et al., 1997 \\
\hline H90-15a & Plioceno y Cuaternario & Durango & -105.33 & 24.91 & Basalto & $\mathrm{K} / \mathrm{Ar}$ & Roca entera & 2.3 & 0.2 & Aranda-Gómez et al., 1997 \\
\hline- & Mioceno medio y superior & Guanajuato & -100.76 & 21 & Basalto & $\mathrm{K} / \mathrm{Ar}$ & Roca entera & 10.7 & 0.7 & $\begin{array}{l}\text { Carranza-Castañeda et al., } \\
1994\end{array}$ \\
\hline ZA 8 & Mioceno medio y superior & Querétaro & -100.18 & 20.91 & Andesita & $\mathrm{K} / \mathrm{Ar}$ & Roca entera & 10.9 & 0.5 & Carrasco-Núñez et al., 1989 \\
\hline ES 135 & Mioceno medio y superior & $\begin{array}{l}\text { San Luis } \\
\text { Potosí }\end{array}$ & -100.75 & 22.39 & Basalto & $\mathrm{K} / \mathrm{Ar}$ & Roca entera & 11 & 1 & $\begin{array}{l}\text { Murillo-Muñetón y Torres- } \\
\text { Vargas, } 1987\end{array}$ \\
\hline H96-9 & Mioceno medio y superior & Durango & -104.87 & 23.93 & Basalto & $\mathrm{Ar} / \mathrm{Ar}$ & Hornblenda & 11.59 & 0.05 & Henry y Aranda-Gomez, 2000 \\
\hline H96-6 & Mioceno medio y superior & Durango & -104.85 & 23.95 & Basalto & $\mathrm{Ar} / \mathrm{Ar}$ & Plagioclasa & 11.6 & 0.07 & Henry y Aranda-Gomez, 2000 \\
\hline RK 12 & Mioceno medio y superior & Durango & -104.87 & 23.92 & Basalto & $\mathrm{K} / \mathrm{Ar}$ & Anfíbol & 11.7 & 0.3 & McDowell y Keizer, 1977 \\
\hline H96-8 & Mioceno medio y superior & Durango & -104.86 & 23.94 & Basalto & $\mathrm{Ar} / \mathrm{Ar}$ & Hornblenda & 11.9 & 0.5 & Henry y Aranda-Gómez, 2000 \\
\hline- & Mioceno medio y superior & Guanajuato & -101.37 & 21.02 & Basalto & $\mathrm{K} / \mathrm{Ar}$ & Roca entera & 12.1 & 0.2 & Aguirre-Díaz et al., 1997 \\
\hline RK 24 & Mioceno medio y superior & Durango & -104.86 & 23.93 & Basalto & $\mathrm{K} / \mathrm{Ar}$ & Anfíbol & 12.4 & 0.4 & McDowell y Keizer, 1977 \\
\hline- & Mioceno medio y superior & Guanajuato & -100.76 & 21 & Basalto & $\mathrm{K} / \mathrm{Ar}$ & Roca entera & 12.5 & 0.9 & $\begin{array}{l}\text { Carranza-Castaneda et al., } \\
1994\end{array}$ \\
\hline NA 41 & Mioceno medio y superior & Durango & -104.3 & 25.42 & Basalto & $\mathrm{K} / \mathrm{Ar}$ & Roca entera & 20.3 & 0.4 & $\begin{array}{l}\text { Aguirre- Díaz y McDowell, } \\
1993\end{array}$ \\
\hline NA 41 & Mioceno medio y superior & Durango & -104.3 & 25.42 & Basalto & $\mathrm{K} / \mathrm{Ar}$ & Roca entera & 20.3 & 0.4 & $\begin{array}{l}\text { Aguirre-Díaz y McDowell, } \\
1993\end{array}$ \\
\hline PZ 3 & Mioceno medio y superior & Zacatecas & -101.53 & 22.4 & Riolita & $\mathrm{K} / \mathrm{Ar}$ & Sanidino & 22 & 4 & $\begin{array}{l}\text { Murillo-Muñetón y Torres- } \\
\text { Vargas, } 1987\end{array}$ \\
\hline $\mathrm{Na} 55$ a & Mioceno medio y superior & Durango & -104.2 & 25.19 & Basalto & $\mathrm{K} / \mathrm{Ar}$ & Roca entera & 22.1 & 0.4 & $\begin{array}{l}\text { Aguirre-Díaz y McDowell, } \\
1993\end{array}$ \\
\hline $\mathrm{Na} 55$ a & Mioceno medio y superior & Durango & -104.2 & 25.19 & Basalto & $\mathrm{K} / \mathrm{Ar}$ & Roca entera & 22.1 & 0.4 & $\begin{array}{l}\text { Aguirre-Díaz y McDowell, } \\
1993\end{array}$ \\
\hline R 14 & Mioceno medio y superior & Durango & -104.49 & 25.12 & Basalto & $\mathrm{K} / \mathrm{Ar}$ & Roca entera & 22.4 & 0.4 & $\begin{array}{l}\text { Aguirre-Díaz y McDowell, } \\
1993\end{array}$ \\
\hline R 14 & Mioceno medio y superior & Durango & -104.49 & 25.12 & Basalto & $\mathrm{K} / \mathrm{Ar}$ & Roca entera & 22.4 & 0.4 & $\begin{array}{l}\text { Aguirre-Díaz y McDowell, } \\
1993\end{array}$ \\
\hline $\begin{array}{l}\mathrm{Mx} \\
88-38\end{array}$ & $\begin{array}{l}\text { Rocas volcánicas del } \\
\text { Oligoceno }\end{array}$ & Guanajuato & -101.22 & 20.93 & Riolita & $\mathrm{K} / \mathrm{Ar}$ & Sanidino & 23 & 1 & Pasquarè et al., 1991 \\
\hline PZ 2 & $\begin{array}{l}\text { Rocas volcánicas del } \\
\text { Oligoceno }\end{array}$ & Zacatecas & -101.68 & 22.45 & Riolita & $\mathrm{K} / \mathrm{Ar}$ & Sanidino & 23 & 2 & $\begin{array}{l}\text { Murillo-Muñetón y Torres- } \\
\text { Vargas, } 1987\end{array}$ \\
\hline FM291 & $\begin{array}{l}\text { Rocas volcánicas del } \\
\text { Oligoceno }\end{array}$ & Zacatecas & -103.02 & 21.43 & Ignimbrita & $\mathrm{K} / \mathrm{Ar}$ & Roca entera & 23.7 & 1.4 & Webber et al., 1994 \\
\hline PZ 1 & $\begin{array}{l}\text { Rocas volcánicas del } \\
\text { Oligoceno }\end{array}$ & Zacatecas & -101.44 & 22.22 & Riolita & $\mathrm{K} / \mathrm{Ar}$ & Sanidino & 24 & 3 & $\begin{array}{l}\text { Murillo-Muñetón y Torres- } \\
\text { Vargas, } 1987\end{array}$ \\
\hline SL29 & $\begin{array}{l}\text { Rocas volcánicas del } \\
\text { Oligoceno }\end{array}$ & Durango & -104.2 & 25.26 & Basalto & $\mathrm{K} / \mathrm{Ar}$ & Roca entera & 24.3 & 0.5 & $\begin{array}{l}\text { Aguirre-Díaz y McDowell, } \\
1993\end{array}$ \\
\hline SL29 & $\begin{array}{l}\text { Rocas volcánicas del } \\
\text { Oligoceno }\end{array}$ & Durango & -104.2 & 25.26 & Basalto & $\mathrm{K} / \mathrm{Ar}$ & Roca entera & 24.3 & 0.5 & $\begin{array}{l}\text { Aguirre-Díaz y McDowell, } \\
1993\end{array}$ \\
\hline SLP 9 & $\begin{array}{l}\text { Rocas volcánicas del } \\
\text { Oligoceno }\end{array}$ & $\begin{array}{l}\text { San Luis } \\
\text { Potosí }\end{array}$ & -100.75 & 23.25 & Riolita & $\mathrm{K} / \mathrm{Ar}$ & Sanidino & 24.38 & 1.2 & Ferrari inédito \\
\hline SOM-3 & $\begin{array}{l}\text { Rocas volcánicas del } \\
\text { Oligoceno }\end{array}$ & Zacatecas & -103.47 & 23.47 & Toba & $\mathrm{K} / \mathrm{Ar}$ & Sanidino & 24.6 & 0.3 & Tuta et al., 1988 \\
\hline HR460 & $\begin{array}{l}\text { Rocas volcánicas del } \\
\text { Oligoceno }\end{array}$ & Zacatecas & -103.17 & 21.5 & Ignimbrita & FT & Circón & 24.9 & 2.7 & Webber et al., 1994 \\
\hline BQ483 & $\begin{array}{l}\text { Rocas volcánicas del } \\
\text { Oligoceno }\end{array}$ & Zacatecas & -103.3 & 21.45 & Ignimbrita & FT & Circón & 25.2 & 2.2 & Webber et al., 1994 \\
\hline HR467 & $\begin{array}{l}\text { Rocas volcánicas del } \\
\text { Oligoceno }\end{array}$ & Zacatecas & -103.18 & 21.5 & Ignimbrita & FT & Circón & 25.3 & 2.4 & Webber et al., 1994 \\
\hline SOM-6 & $\begin{array}{l}\text { Rocas volcánicas del } \\
\text { Oligoceno }\end{array}$ & Zacatecas & -103.48 & 23.43 & Toba & $\mathrm{K} / \mathrm{Ar}$ & Sanidino & 25.6 & 0.3 & Tuta et al., 1988 \\
\hline LP476 & $\begin{array}{l}\text { Rocas volcánicas del } \\
\text { Oligoceno }\end{array}$ & Zacatecas & -103 & 21.51 & Ignimbrita & FT & Circón & 25.9 & 2.5 & Webber et al., 1994 \\
\hline SA 5 & $\begin{array}{l}\text { Rocas volcánicas del } \\
\text { Oligoceno }\end{array}$ & Zacatecas & -103.13 & 23.55 & Riolita & $\mathrm{K} / \mathrm{Ar}$ & Sanidino & 26 & 2 & $\begin{array}{l}\text { Murillo-Muñetón y Torres- } \\
\text { Vargas, } 1987\end{array}$ \\
\hline
\end{tabular}


Tabla 1. Continuación.

\begin{tabular}{|c|c|c|c|c|c|c|c|c|c|c|}
\hline Muestra & $\begin{array}{c}\text { Unidad } \\
\text { Cronoestratigráfica }\end{array}$ & Estado & Longitud & Latitud & d Roca & Método & $\begin{array}{c}\text { Material } \\
\text { fechado }\end{array}$ & Edad & Error & Referencia \\
\hline REA-5 & $\begin{array}{c}\text { Rocas volcánicas del } \\
\text { Oligoceno }\end{array}$ & Guanajuato & -100 & 21.467 & Riolita & $\mathrm{K} / \mathrm{Ar}$ & Sanidino & 26.7 & 0.3 & Tuta et al., 1988 \\
\hline * & $\begin{array}{c}\text { Rocas volcánicas del } \\
\text { Oligoceno }\end{array}$ & $\begin{array}{l}\text { San Luis } \\
\text { Potosí }\end{array}$ & -101.16 & 21.82 & Ignimbrita & $\mathrm{K} / \mathrm{Ar}$ & Roca entera & 26.8 & 1.3 & $\begin{array}{l}\text { Labarthe-Hernández et al., } \\
1982\end{array}$ \\
\hline IL 895 & $\begin{array}{l}\text { Rocas volcánicas del } \\
\text { Oligoceno }\end{array}$ & Zacatecas & -103.48 & 21.42 & Ignimbrita & $\mathrm{K} / \mathrm{Ar}$ & Sanidino & 27.11 & 0.05 & Moore et al., 1994 \\
\hline REA-7 & $\begin{array}{c}\text { Rocas volcánicas del } \\
\text { Oligoceno }\end{array}$ & Guanajuato & -100 & 21.467 & Riolita & $\mathrm{K} / \mathrm{Ar}$ & Sanidino & 27.5 & 0.3 & Tuta et al., 1988 \\
\hline SS-227 & $\begin{array}{l}\text { Rocas volcánicas del } \\
\text { Oligoceno }\end{array}$ & Zacatecas & -102.94 & 23.12 & Ignimbrita & $\mathrm{K} / \mathrm{Ar}$ & Roca entera & 27.5 & 1.2 & Lang et al., 1988 \\
\hline SS-149 & $\begin{array}{c}\text { Rocas volcánicas del } \\
\text { Oligoceno }\end{array}$ & Zacatecas & -102.93 & 23.06 & Ignimbrita & $\mathrm{K} / \mathrm{Ar}$ & Roca entera & 27.7 & 0.6 & Lang et al., 1988 \\
\hline TS 15 & $\begin{array}{l}\text { Rocas volcánicas del } \\
\text { Oligoceno }\end{array}$ & Durango & -104.22 & 22.63 & Riolita & $\mathrm{Ar} / \mathrm{Ar}$ & Sanidino & 27.9 & 0.3 & Ferrari et al., 2002 \\
\hline IMP 619 & $\begin{array}{c}\text { Rocas volcánicas del } \\
\text { Oligoceno }\end{array}$ & $\begin{array}{l}\text { San Luis } \\
\text { Potosí }\end{array}$ & -100.38 & 22.62 & Granito & $\mathrm{K} / \mathrm{Ar}$ & Biotita & 28 & 2 & $\begin{array}{l}\text { Murillo-Muñetón y Torres- } \\
\text { Vargas, } 1987\end{array}$ \\
\hline TS 11 & $\begin{array}{c}\text { Rocas volcánicas del } \\
\text { Oligoceno }\end{array}$ & Jalisco & -103.99 & 22.66 & Ignimbrita & $\mathrm{Ar} / \mathrm{Ar}$ & Sanidino & 28 & 2 & Ferrari et al., 2002 \\
\hline $\mathrm{SN}-2$ & $\begin{array}{l}\text { Rocas volcánicas del } \\
\text { Oligoceno }\end{array}$ & $\begin{array}{l}\text { San Luis } \\
\text { Potosí }\end{array}$ & -100.28 & 22.667 & Granito & $\mathrm{Ar} / \mathrm{Ar}$ & Biotita & 28 & 0.4 & Tuta et al., 1988 \\
\hline SA 6 & $\begin{array}{c}\text { Rocas volcánicas del } \\
\text { Oligoceno }\end{array}$ & Zacatecas & -103.2 & 23.71 & Ignimbrita & $\mathrm{K} / \mathrm{Ar}$ & Sanidino & 28 & 2 & $\begin{array}{l}\text { Murillo-Muñetón y Torres- } \\
\text { Vargas, } 1987\end{array}$ \\
\hline AMC-01 & $\begin{array}{l}\text { Rocas volcánicas del } \\
\text { Oligoceno }\end{array}$ & Guanajuato & -101.53 & 21.33 & Ignimbrita & $\mathrm{K} / \mathrm{Ar}$ & Sanidino & 28.2 & 0.7 & Nieto-Samaniego et al., 1996 \\
\hline RK 4 P & $\begin{array}{l}\text { Rocas volcánicas del } \\
\text { Oligoceno }\end{array}$ & Durango & -104.67 & 23.83 & Ignimbrita & $\mathrm{K} / \mathrm{Ar}$ & Plagioclasa & 28.3 & 0.6 & McDowell y Keizer, 1977 \\
\hline RK $3 \mathrm{~F}$ & $\begin{array}{l}\text { Rocas volcánicas del } \\
\text { Oligoceno }\end{array}$ & Durango & -104.67 & 23.92 & Ignimbrita & $\mathrm{K} / \mathrm{Ar}$ & Feldespato & 28.3 & 0.6 & McDowell y Keizer, 1977 \\
\hline REM-2 & $\begin{array}{c}\text { Rocas volcánicas del } \\
\text { Oligoceno }\end{array}$ & Durango & -104.35 & 24.04 & Riolita & $\mathrm{K} / \mathrm{Ar}$ & Sanidino & 28.3 & 0.3 & Tuta et al., 1988 \\
\hline RK $1 \mathrm{~F}$ & $\begin{array}{l}\text { Rocas volcánicas del } \\
\text { Oligoceno }\end{array}$ & Durango & -104.88 & 23.93 & Ignimbrita & $\mathrm{K} / \mathrm{Ar}$ & Feldespato & 28.5 & 1.5 & McDowell y\& Keizer, 1977 \\
\hline TS 10 & $\begin{array}{c}\text { Rocas volcánicas del } \\
\text { Oligoceno }\end{array}$ & Jalisco & -103.99 & 22.67 & Ignimbrita & $\mathrm{Ar} / \mathrm{Ar}$ & Sanidino & 28.6 & 0.3 & Ferrari et al., 2002 \\
\hline RK $11 \mathrm{~F}$ & $\begin{array}{c}\text { Rocas volcánicas del } \\
\text { Oligoceno }\end{array}$ & Durango & -104.87 & 23.92 & Ignimbrita & $\mathrm{K} / \mathrm{Ar}$ & Feldespato & 28.6 & 0.6 & McDowell y Keizer, 1977 \\
\hline JL 1 R & $\begin{array}{l}\text { Rocas volcánicas del } \\
\text { Oligoceno }\end{array}$ & Durango & -104.59 & 24.12 & Basalto & $\mathrm{K} / \mathrm{Ar}$ & Roca entera & 28.6 & 0.5 & McDowell y Keizer, 1977 \\
\hline RK $2 \mathrm{~F}$ & $\begin{array}{c}\text { Rocas volcánicas del } \\
\text { Oligoceno }\end{array}$ & Durango & -104.77 & 23.97 & Ignimbrita & $\mathrm{K} / \mathrm{Ar}$ & Feldespato & 28.7 & 0.6 & McDowell y Keizer, 1977 \\
\hline RK $15 \mathrm{~F}$ & $\begin{array}{c}\text { Rocas volcánicas del } \\
\text { Oligoceno }\end{array}$ & Durango & -104.95 & 23.9 & Ignimbrita & $\mathrm{K} / \mathrm{Ar}$ & Feldespato & 28.8 & 1.1 & McDowell y Keizer, 1977 \\
\hline Na.4 & $\begin{array}{c}\text { Rocas volcánicas del } \\
\text { Oligoceno }\end{array}$ & Durango & -104.187 & 25.208 & Toba & $\mathrm{K} / \mathrm{Ar}$ & Feldespato & 28.8 & 1.9 & $\begin{array}{l}\text { Aguirre-Díaz y\& McDowell, } \\
1993\end{array}$ \\
\hline $3-71-1 \mathrm{~F}$ & $\begin{array}{l}\text { Rocas volcánicas del } \\
\text { Oligoceno }\end{array}$ & Durango & -104.97 & 23.89 & Ignimbrita & $\mathrm{K} / \mathrm{Ar}$ & Feldespato & 28.9 & 0.6 & McDowell y Keizer, 1977 \\
\hline$*$ & $\begin{array}{l}\text { Rocas volcánicas del } \\
\text { Oligoceno }\end{array}$ & $\begin{array}{l}\text { San Luis } \\
\text { Potosí }\end{array}$ & -101.03 & 21.91 & Ignimbrita & $\mathrm{K} / \mathrm{Ar}$ & Roca entera & 29 & 1.5 & $\begin{array}{l}\text { Labarthe-Hernández et al., } \\
1982\end{array}$ \\
\hline $2-71-2 \mathrm{~F}$ & $\begin{array}{c}\text { Rocas volcánicas del } \\
\text { Oligoceno }\end{array}$ & Durango & -104.97 & 23.89 & Ignimbrita & $\mathrm{K} / \mathrm{Ar}$ & Feldespato & 29.1 & 0.6 & McDowell y Keizer, 1977 \\
\hline Sl-56 & $\begin{array}{c}\text { Rocas volcánicas del } \\
\text { Oligoceno }\end{array}$ & Durango & -104.325 & 25.383 & Toba & $\mathrm{K} / \mathrm{Ar}$ & Feldespato & 29.1 & 1.8 & $\begin{array}{l}\text { Aguirre Díaz y McDowell, } \\
1993\end{array}$ \\
\hline $\begin{array}{l}\text { Ped } \\
\text { Zac } 3\end{array}$ & $\begin{array}{c}\text { Rocas volcánicas del } \\
\text { Oligoceno }\end{array}$ & Zacatecas & -103.18 & 21.77 & Ignimbrita & $\mathrm{K} / \mathrm{Ar}$ & Sanidino & 29.15 & 0.6 & Nieto-Obregón et al. 1981 \\
\hline JAG 1 & $\begin{array}{l}\text { Rocas volcánicas del } \\
\text { Oligoceno }\end{array}$ & $\begin{array}{c}\text { San Luis } \\
\text { Potosí }\end{array}$ & -101.27 & 22.04 & Riolita & $\mathrm{K} / \mathrm{Ar}$ & Biotita & 29.2 & 0.8 & Aguillón-Robles et al., 1994 \\
\hline JAG 1 & $\begin{array}{c}\text { Rocas volcánicas del } \\
\text { Oligoceno }\end{array}$ & $\begin{array}{c}\text { San Luis } \\
\text { Potosí }\end{array}$ & -101.27 & 22.04 & Riolita & $\mathrm{K} / \mathrm{Ar}$ & Biotita & 29.2 & 0.8 & Aguillón-Robles et al., 1994 \\
\hline RK $14 \mathrm{~F}$ & $\begin{array}{c}\text { Rocas volcánicas del } \\
\text { Oligoceno }\end{array}$ & Durango & -104.95 & 23.9 & Ignimbrita & $\mathrm{K} / \mathrm{Ar}$ & Feldespato & 29.2 & 0.7 & McDowell y Keizer, 1977 \\
\hline
\end{tabular}


Tabla 1. Continuación.

\begin{tabular}{|c|c|c|c|c|c|c|c|c|c|c|}
\hline Muestra & $\begin{array}{c}\text { Unidad } \\
\text { Cronoestratigráfica }\end{array}$ & Estado & Longitud & Latitud & Roca & Método & $\begin{array}{l}\text { Material } \\
\text { fechado }\end{array}$ & Edad & Error & Referencia \\
\hline$*$ & $\begin{array}{l}\text { Rocas volcánicas del } \\
\text { Oligoceno }\end{array}$ & $\begin{array}{l}\text { San Luis } \\
\text { Potosí }\end{array}$ & -100.7 & 21.8 & Ignimbrita & $\mathrm{K} / \mathrm{Ar}$ & Roca entera & 29.5 & 1.5 & $\begin{array}{l}\text { Labarthe-Hernández et al., } \\
1982\end{array}$ \\
\hline $\begin{array}{l}\text { JL BR } \\
\text { SI R }\end{array}$ & $\begin{array}{l}\text { Rocas volcánicas del } \\
\text { Oligoceno }\end{array}$ & Durango & -104.57 & 24.08 & Basalto & $\mathrm{K} / \mathrm{Ar}$ & Roca entera & 29.5 & 0.6 & McDowell y Keizer, 1977 \\
\hline $\mathrm{Na}-33$ & $\begin{array}{l}\text { Rocas volcánicas del } \\
\text { Oligoceno }\end{array}$ & Durango & -104.386 & 25.409 & Toba & $\mathrm{K} / \mathrm{Ar}$ & Feldespato & 29.5 & 0.6 & $\begin{array}{l}\text { Aguirre-Díaz y McDowell, } \\
1993\end{array}$ \\
\hline $\mathrm{OCH}-5$ & $\begin{array}{l}\text { Rocas volcánicas del } \\
\text { Oligoceno }\end{array}$ & Durango & -103.92 & 24.03 & Toba & $\mathrm{K} / \mathrm{Ar}$ & Sanidino & 29.6 & 0.4 & Tuta et al., 1988 \\
\hline SOM-6 & $\begin{array}{l}\text { Rocas volcánicas del } \\
\text { Oligoceno }\end{array}$ & Zacatecas & -103.48 & 23.43 & Toba & $\mathrm{K} / \mathrm{Ar}$ & Roca entera & 29.7 & 0.3 & Tuta et al., 1988 \\
\hline $\begin{array}{l}\text { JL BM } \\
\text { LBR }\end{array}$ & $\begin{array}{l}\text { Rocas volcánicas del } \\
\text { Oligoceno }\end{array}$ & Durango & -104.22 & 24.53 & Basalto & $\mathrm{K} / \mathrm{Ar}$ & Roca entera & 29.8 & 0.6 & McDowell y Keizer, 1977 \\
\hline RK 6 F & $\begin{array}{l}\text { Rocas volcánicas del } \\
\text { Oligoceno }\end{array}$ & Durango & -104.67 & 23.95 & Ignimbrita & $\mathrm{K} / \mathrm{Ar}$ & Feldespato & 29.9 & 0.7 & McDowell y Keizer, 1977 \\
\hline$*$ & $\begin{array}{l}\text { Rocas volcánicas del } \\
\text { Oligoceno }\end{array}$ & $\begin{array}{l}\text { San Luis } \\
\text { Potosí }\end{array}$ & -101.15 & 21.85 & Riolita & $\mathrm{K} / \mathrm{Ar}$ & Roca entera & 30 & 1.5 & $\begin{array}{l}\text { Labarthe-Hernández et al., } \\
1982\end{array}$ \\
\hline RK $5 \mathrm{~F}$ & $\begin{array}{l}\text { Rocas volcánicas del } \\
\text { Oligoceno }\end{array}$ & Durango & -104.67 & 23.93 & Ignimbrita & $\mathrm{K} / \mathrm{Ar}$ & Feldespato & 30 & 0.7 & McDowell y Keizer, 1977 \\
\hline AMC-06 & $\begin{array}{l}\text { Rocas volcánicas del } \\
\text { Oligoceno }\end{array}$ & Guanajuato & -101.02 & 21.08 & Riolita & $\mathrm{K} / \mathrm{Ar}$ & Sanidino & 30.1 & 0.8 & Nieto-Samaniego et al., 1996 \\
\hline SOM-3 & $\begin{array}{l}\text { Rocas volcánicas del } \\
\text { Oligoceno }\end{array}$ & Zacatecas & -103.47 & 23.47 & Toba & $\mathrm{K} / \mathrm{Ar}$ & Roca entera & 30.1 & 0.4 & Tuta et al., 1988 \\
\hline SOM-1 & $\begin{array}{l}\text { Rocas volcánicas del } \\
\text { Oligoceno }\end{array}$ & Zacatecas & -103.47 & 23.47 & Toba & $\mathrm{K} / \mathrm{Ar}$ & $\begin{array}{l}\text { Sanidino+ } \\
\text { Plagioclasa }\end{array}$ & 30.2 & 0.4 & Tuta et al., 1988 \\
\hline 77.4 & $\begin{array}{l}\text { Rocas volcánicas del } \\
\text { Oligoceno }\end{array}$ & Durango & -104.567 & 24.35 & Ignimbrita & $\mathrm{K} / \mathrm{Ar}$ & Feldespato & 30.4 & 0.9 & Magonthier, 1988 \\
\hline REA-7 & $\begin{array}{l}\text { Rocas volcánicas del } \\
\text { Oligoceno }\end{array}$ & Guanajuato & -100 & 21.467 & Riolita & $\mathrm{K} / \mathrm{Ar}$ & Roca entera & 30.5 & 0.4 & Tuta et al., 1988 \\
\hline$*$ & $\begin{array}{l}\text { Rocas volcánicas del } \\
\text { Oligoceno }\end{array}$ & $\begin{array}{l}\text { San Luis } \\
\text { Potosí }\end{array}$ & -100.68 & 21.9 & Riodacita & $\mathrm{K} / \mathrm{Ar}$ & Roca entera & 30.6 & 1.5 & $\begin{array}{l}\text { Labarthe-Hernández et al., } \\
1982\end{array}$ \\
\hline $2-71-1 \mathrm{~F}$ & $\begin{array}{l}\text { Rocas volcánicas del } \\
\text { Oligoceno }\end{array}$ & Durango & -104.67 & 24.05 & Ignimbrita & $\mathrm{K} / \mathrm{Ar}$ & Feldespato & 30.6 & 0.9 & McDowell y Keizer, 1977 \\
\hline AMC-08 & $\begin{array}{l}\text { Rocas volcánicas del } \\
\text { Oligoceno }\end{array}$ & Guanajuato & -101.27 & 21.45 & Riolita & $\mathrm{K} / \mathrm{Ar}$ & Sanidino & 30.7 & 0.8 & Nieto-Samaniego et al., 1996 \\
\hline RK 23 B & $\begin{array}{l}\text { Rocas volcánicas del } \\
\text { Oligoceno }\end{array}$ & Durango & -104.83 & 23.99 & Riolita & $\mathrm{K} / \mathrm{Ar}$ & Biotita & 30.7 & 0.5 & McDowell y Keizer, 1977 \\
\hline $\begin{array}{l}\text { JL-RD- } \\
\text { A P }\end{array}$ & $\begin{array}{l}\text { Rocas volcánicas del } \\
\text { Oligoceno }\end{array}$ & Durango & -104.65 & 24.63 & $\begin{array}{l}\text { Riolita } \\
\text { dique }\end{array}$ & $\mathrm{K} / \mathrm{Ar}$ & Plagioclasa & 30.7 & 0.7 & McDowell y Keizer, 1977 \\
\hline REA-5 & $\begin{array}{l}\text { Rocas volcánicas del } \\
\text { Oligoceno }\end{array}$ & Guanajuato & -100 & 21.467 & Riolita & $\mathrm{K} / \mathrm{Ar}$ & Roca entera & 30.8 & 0.3 & Tuta et al., 1988 \\
\hline REA-8 & $\begin{array}{l}\text { Rocas volcánicas del } \\
\text { Oligoceno }\end{array}$ & Guanajuato & -100 & 21.467 & Riolita & $\mathrm{K} / \mathrm{Ar}$ & Roca entera & 30.9 & 0.4 & Tuta et al., 1988 \\
\hline M-3 & $\begin{array}{l}\text { Rocas volcánicas del } \\
\text { Oligoceno }\end{array}$ & $\begin{array}{l}\text { San Luis } \\
\text { Potosí }\end{array}$ & -100.38 & 22.66 & Granito & $\mathrm{K} / \mathrm{Ar}$ & Biotita & 31 & 2.0 & $\begin{array}{l}\text { Murillo-Muñetón y Torres- } \\
\text { Vargas, } 1987\end{array}$ \\
\hline OCH-1 & $\begin{array}{l}\text { Rocas volcánicas del } \\
\text { Oligoceno }\end{array}$ & Durango & -103.92 & 24.03 & Riolita & $\mathrm{K} / \mathrm{Ar}$ & Roca entera & 31 & 0.4 & Tuta et al., 1988 \\
\hline REM-2 & $\begin{array}{l}\text { Rocas volcánicas del } \\
\text { Oligoceno }\end{array}$ & Durango & -104.35 & 24.04 & Riolita & $\mathrm{K} / \mathrm{Ar}$ & Matriz & 31 & 0.4 & Tuta et al., 1988 \\
\hline RK $20 \mathrm{~F}$ & $\begin{array}{l}\text { Rocas volcánicas del } \\
\text { Oligoceno }\end{array}$ & Durango & -104.74 & 24.07 & Ignimbrita & $\mathrm{K} / \mathrm{Ar}$ & Feldespato & 31 & 0.7 & McDowell y Keizer, 1977 \\
\hline $\begin{array}{l}\text { CUEVS- } \\
\text { TF }\end{array}$ & $\begin{array}{l}\text { Rocas volcánicas del } \\
\text { Oligoceno }\end{array}$ & $\begin{array}{l}\text { San Luis } \\
\text { Potosí }\end{array}$ & -100.6 & 21.95 & Riolita & $\mathrm{K} / \mathrm{Ar}$ & Roca entera & 31.1 & 0.3 & Tuta et al., 1988 \\
\hline TS 5 & $\begin{array}{l}\text { Rocas volcánicas del } \\
\text { Oligoceno }\end{array}$ & Jalisco & -103.99 & 22.66 & Ignimbrita & $\mathrm{Ar} / \mathrm{Ar}$ & Sanidino & 31.1 & 0.4 & Ferrari et al., 2002 \\
\hline $\mathrm{OCH}-5$ & $\begin{array}{l}\text { Rocas volcánicas del } \\
\text { Oligoceno }\end{array}$ & Durango & -103.92 & 24.03 & Toba & $\mathrm{K}-\mathrm{Ar}$ & Matriz & 31.1 & 0.3 & Tuta et al., 1988 \\
\hline RK $10 \mathrm{P}$ & $\begin{array}{l}\text { Rocas volcánicas del } \\
\text { Oligoceno }\end{array}$ & Durango & -104.67 & 23.83 & Ignimbrita & $\mathrm{K} / \mathrm{Ar}$ & Plagioclasa & 31.2 & 1.5 & McDowell y Keizer, 1977 \\
\hline RK $17 \mathrm{~F}$ & $\begin{array}{l}\text { Rocas volcánicas del } \\
\text { Oligoceno }\end{array}$ & Durango & -104.75 & 23.96 & Ignimbrita & $\mathrm{K} / \mathrm{Ar}$ & Feldespato & 31.2 & 0.7 & McDowell y Keizer, 1977 \\
\hline
\end{tabular}


Tabla 1. Continuación.

\begin{tabular}{|c|c|c|c|c|c|c|c|c|c|c|}
\hline \multirow{2}{*}{$\begin{array}{l}\text { Muestra } \\
\text { RK } 22 \mathrm{~F}\end{array}$} & \multirow{2}{*}{$\begin{array}{c}\text { Unidad } \\
\text { Cronoestratigráfica } \\
\begin{array}{c}\text { Rocas volcánicas del } \\
\text { Oligoceno }\end{array}\end{array}$} & \multirow{2}{*}{$\begin{array}{c}\text { Estado } \\
\text { Durango }\end{array}$} & \multirow{2}{*}{$\begin{array}{c}\text { Longitud } \\
-104.5\end{array}$} & \multirow{2}{*}{$\begin{array}{l}\text { Latitud } \\
23.87\end{array}$} & \multirow{2}{*}{$\begin{array}{c}\text { Roca } \\
\text { Ignimbrita }\end{array}$} & \multirow{2}{*}{\begin{tabular}{|l} 
Método \\
$\mathrm{K} / \mathrm{Ar}$
\end{tabular}} & \multirow{2}{*}{$\begin{array}{c}\begin{array}{c}\text { Material } \\
\text { fechado }\end{array} \\
\text { Feldespato }\end{array}$} & \multicolumn{2}{|c|}{ Edad Error } & \multirow{2}{*}{$\begin{array}{c}\text { Referencia } \\
\text { McDowell y Keizer, } 1977\end{array}$} \\
\hline & & & & & & & & 31.4 & 0.7 & \\
\hline $\begin{array}{l}\text { K-LP- } \\
\text { T F }\end{array}$ & $\begin{array}{c}\text { Rocas volcánicas del } \\
\text { Oligoceno }\end{array}$ & Durango & -104.63 & 24.12 & Ignimbrita & $\mathrm{K} / \mathrm{Ar}$ & Feldespato & 31.4 & 0.7 & McDowell y Keizer, 1977 \\
\hline 77.9 & $\begin{array}{l}\text { Rocas volcánicas del } \\
\text { Oligoceno }\end{array}$ & Durango & -104.421 & 24.593 & Ignimbrita & $\mathrm{K} / \mathrm{Ar}$ & Feldespato & 31.5 & 1.0 & Magonthier, 1988 \\
\hline TS 56 & $\begin{array}{l}\text { Rocas volcánicas del } \\
\text { Oligoceno }\end{array}$ & Zacatecas & -103.72 & 22.89 & Ignimbrita & $\mathrm{Ar} / \mathrm{Ar}$ & Sanidino & 31.6 & 0.3 & Ferrari et al., 2002 \\
\hline$*$ & $\begin{array}{l}\text { Rocas volcánicas del } \\
\text { Oligoceno }\end{array}$ & Guanajuato & -101.25 & 21.25 & Riolita & $\mathrm{K} / \mathrm{Ar}$ & Roca entera & 32 & 1.0 & Gross, 1975 \\
\hline $\begin{array}{l}\text { JL-JE- } \\
\text { A F }\end{array}$ & $\begin{array}{l}\text { Rocas volcánicas del } \\
\text { Oligoceno }\end{array}$ & Durango & -104.63 & 24.12 & Ignimbrita & $\mathrm{K} / \mathrm{Ar}$ & Feldespato & 32.1 & 1.9 & McDowell y Keizer, 1977 \\
\hline $\mathrm{Na}-81 \mathrm{a}$ & $\begin{array}{l}\text { Rocas volcánicas del } \\
\text { Oligoceno }\end{array}$ & Durango & -104.270 & 25.157 & Toba & $\mathrm{K} / \mathrm{Ar}$ & Feldespato & 32.2 & 0.7 & $\begin{array}{l}\text { Aguirre-Díaz y McDowell, } \\
1993\end{array}$ \\
\hline SOM-1 & $\begin{array}{l}\text { Rocas volcánicas del } \\
\text { Oligoceno }\end{array}$ & Zacatecas & -103.47 & 23.47 & Toba & $\mathrm{Ar} / \mathrm{Ar}$ & Biotita & 32.3 & 0.5 & Tuta et al., 1988 \\
\hline SLP 1 & $\begin{array}{l}\text { Rocas volcánicas del } \\
\text { Oligoceno }\end{array}$ & $\begin{array}{l}\text { San Luis } \\
\text { Potosí }\end{array}$ & -101.12 & 22.08 & Ignimbrita & $\mathrm{K} / \mathrm{Ar}$ & Sanidino & 33.4 & 1.7 & Ferrari, inédito \\
\hline $\begin{array}{l}\text { Uaka } \\
79-21\end{array}$ & $\begin{array}{c}\text { Rocas volcánicas Eoceno } \\
\text { medio. }\end{array}$ & Zacatecas & -102.55 & 22.75 & Ignimbrita & $\mathrm{K} / \mathrm{Ar}$ & Sanidino & 36.8 & 0.8 & Clark et al., 1981 \\
\hline - & $\begin{array}{c}\text { Rocas volcánicas Eoceno } \\
\text { medio. }\end{array}$ & Guanajuato & -101.25 & 21.25 & Ignimbrita & $\mathrm{K} / \mathrm{Ar}$ & Roca entera & 37 & 3 & Gross, 1975 \\
\hline SLP 7 & $\begin{array}{c}\text { Rocas volcánicas Eoceno } \\
\text { medio. }\end{array}$ & $\begin{array}{l}\text { San Luis } \\
\text { Potosí }\end{array}$ & -100.68 & 22.43 & Andesita & $\mathrm{K} / \mathrm{Ar}$ & Hornblenda & 37.7 & 1.9 & Ferrari, inédito \\
\hline S-2 & $\begin{array}{c}\text { Rocas volcánicas Eoceno } \\
\text { medio. }\end{array}$ & Zacatecas & -102.82 & 23.13 & Ignimbrita & $\mathrm{K} / \mathrm{Ar}$ & Roca entera & 38.3 & 0.8 & Lang et al., 1988 \\
\hline TOM-02 & $\begin{array}{c}\text { Rocas volcánicas Eoceno } \\
\text { medio. }\end{array}$ & Aguascalientes & -102.41 & 21.88 & Riolita & $\mathrm{K} / \mathrm{Ar}$ & Sanidino & 40.6 & 1.0 & Nieto-Samaniego et al., 1996 \\
\hline \multirow[t]{2}{*}{ na } & $\begin{array}{c}\text { Rocas volcánicas Eoceno } \\
\text { medio. }\end{array}$ & Durango & -104.19 & 25.21 & Toba & $\mathrm{K} / \mathrm{Ar}$ & $\begin{array}{l}\text { Feldespato } \\
\text { +Biotita }\end{array}$ & 43 & & $\begin{array}{l}\text { Aguirre-Díaz y McDowell, } \\
1991\end{array}$ \\
\hline & $\begin{array}{c}\text { Rocas volcánicas Eoceno } \\
\text { medio. }\end{array}$ & $\begin{array}{l}\text { San Luis } \\
\text { Potosí }\end{array}$ & -101.17 & 22.27 & Andesita & $\mathrm{K} / \mathrm{Ar}$ & Roca entera & 44.1 & 2.2 & $\begin{array}{l}\text { Labarthe-Hernández et al., } \\
1982\end{array}$ \\
\hline CTO-01 & $\begin{array}{c}\text { Rocas volcánicas Eoceno } \\
\text { medio. }\end{array}$ & Aguascalientes & -102.41 & 21.9 & Ignimbrita & $\mathrm{K} / \mathrm{Ar}$ & Sanidino & 47.2 & 1.2 & Nieto-Samaniego et al., 1996 \\
\hline \multirow[t]{2}{*}{ BFA } & $\begin{array}{c}\text { Rocas volcánicas Eoceno } \\
\text { medio. }\end{array}$ & Zacatecas & -103.15 & 21.65 & Andesita & $\mathrm{K} / \mathrm{Ar}$ & Feldespato & 48.1 & 2.6 & Webber et al., 1994 \\
\hline & $\begin{array}{c}\text { Rocas volcánicas Eoceno } \\
\text { medio. }\end{array}$ & Guanajuato & -101.29 & 20.98 & Andesita & $\mathrm{K} / \mathrm{Ar}$ & Roca entera & 49.3 & 1.0 & $\begin{array}{l}\text { Aranda-Gómez y McDowell, } \\
1998\end{array}$ \\
\hline- & $\begin{array}{c}\text { Secuencia } \\
\text { volcanosedimentaria }\end{array}$ & Guanajuato & -101.55 & 21.117 & Ultramáfica & $\mathrm{K} / \mathrm{Ar}$ & Roca entera & 112 & - & Lapierre et al., 1992 \\
\hline- & $\begin{array}{c}\text { Secuencia } \\
\text { volcanosedimentaria }\end{array}$ & Guanajuato & -101.55 & 21.117 & Ultramáfica & $\mathrm{K} / \mathrm{Ar}$ & Actinolita & 82 & - & Lapierre et al., 1992 \\
\hline- & $\begin{array}{c}\text { Secuencia } \\
\text { volcanosedimentaria }\end{array}$ & Guanajuato & -101.402 & 21.027 & Diorita & $\mathrm{K} / \mathrm{Ar}$ & Hornblenda & 122 & - & Lapierre et al., 1992 \\
\hline- & $\begin{array}{c}\text { Secuencia } \\
\text { volcanosedimentaria }\end{array}$ & Guanajuato & -101.402 & 21.027 & Diorita & $\mathrm{K} / \mathrm{Ar}$ & Roca entera & 120 & - & Lapierre et al., 1992 \\
\hline- & $\begin{array}{c}\text { Secuencia } \\
\text { volcanosedimentaria }\end{array}$ & Guanajuato & -101.354 & 21.024 & $\begin{array}{c}\text { Dolerita } \\
\text { (dique) }\end{array}$ & $\mathrm{K} / \mathrm{Ar}$ & Roca entera & $\begin{array}{l}157- \\
143\end{array}$ & - & Lapierre et al., 1992 \\
\hline - & $\begin{array}{c}\text { Secuencia } \\
\text { volcanosedimentaria }\end{array}$ & Guanajuato & -101.356 & 21.027 & Basalto & $\mathrm{K} / \mathrm{Ar}$ & Roca entera & $\begin{array}{l}108- \\
66\end{array}$ & - & Lapierre et al., 1992 \\
\hline $\mathrm{SN}-2$ & Cuerpos intrusivos & $\begin{array}{l}\text { San Luis } \\
\text { Potosí }\end{array}$ & -100.28 & 22.667 & Granito & $\mathrm{K} / \mathrm{Ar}$ & Roca entera & 32 & 0.4 & Tuta et al., 1988 \\
\hline ES 323 & Cuerpos intrusivos & $\begin{array}{c}\text { San Luis } \\
\text { Potosí }\end{array}$ & -100.73 & 22.7 & Granito & $\mathrm{K} / \mathrm{Ar}$ & Biotita & 36 & 3.0 & $\begin{array}{l}\text { Murillo-Muñetón y Torres- } \\
\text { Vargas, } 1987\end{array}$ \\
\hline $2 \mathrm{M}-200$ & Cuerpos intrusivos & $\begin{array}{l}\text { San Luis } \\
\text { Potosí }\end{array}$ & -100.71 & 23.66 & $\begin{array}{l}\text { Grano- } \\
\text { diorita }\end{array}$ & $\mathrm{K} / \mathrm{Ar}$ & Biotita & 36 & 3.0 & $\begin{array}{l}\text { Murillo-Muñetón y Torres- } \\
\text { Vargas, } 1987\end{array}$ \\
\hline
\end{tabular}

Nota: Algunas edades referidas en el texto no aparecen en esta tabla por carecer de la información completa; esas edades deberán ser consultadas en la fuente original citada en el texto. 
Tabla 2. Edades isotópicas de las ignimbritas San Nicolás y El Salto en el Edo. de Guanajuato.

\begin{tabular}{|c|c|c|c|c|c|c|}
\hline $\begin{array}{l}\text { Coordenadas } \\
\text { UTM }\end{array}$ & $\begin{array}{c}\text { Unidad } \\
\text { Litoestratigráfica }\end{array}$ & $\begin{array}{l}\text { Mineral } \\
\text { fechado }\end{array}$ & $\% \mathrm{~K}$ & $\begin{array}{l}{ }^{40} \mathrm{Ar} * \\
\text { moles/g }\end{array}$ & $\%{ }^{40} \mathrm{Ar} *$ & $\begin{array}{c}\text { Edad } \\
\text { Ma }\end{array}$ \\
\hline \multicolumn{7}{|c|}{ Muestra A029MDA173 } \\
\hline $\begin{array}{l}\text { 14Q285018 } \\
2295393\end{array}$ & $\begin{array}{c}\text { Ignimbrita } \\
\text { San Nicolás }{ }^{\dagger \#}\end{array}$ & Sanidino & 5.93 & $2.560^{-10}$ & 99 & $24.7 \pm 1.1$ \\
\hline \multicolumn{7}{|c|}{ Muestra A029MDA172 } \\
\hline $\begin{array}{l}14 \mathrm{Q} 284842 \\
2295584\end{array}$ & $\begin{array}{l}\text { Ignimbrita } \\
\text { El Salto }\end{array}$ & Sanidino & 8.03 & $3.919^{-10}$ & 95.9 & $28.0 \pm 1.1$ \\
\hline
\end{tabular}

La separación de minerales fue realizada en el Centro de Geociencias y los análisis en el Laboratorio Universitario de Geoquímica Isotópica del Instituto de Geología, ambos de la Universidad Nacional Autónoma de México. * Argón radiogénico; ${ }^{\dagger}$ Nieto-Samaniego (1992); \# Ojeda-García (2004).

ocurrió alrededor de los $30 \mathrm{Ma}$.

En numerosos reportes privados y en algunos trabajos publicados se documenta que algunas rocas volcánicas aparecen intercaladas con los depósitos sedimentarios que rellenan cuencas continentales en la porción sur de la MC (Jiménez-Nava, 1993, Martínez-Ruiz y Cuellar-González, 1978); intercalaciones similares fueron reportadas por Córdoba (1988) para la Formación San Pablo, en las localidades ubicadas $\sim 20 \mathrm{~km}$ al norte de San Juan del Río, Dgo. Presumiblemente esas rocas volcánicas corresponden al conjunto oligocénico por tratarse de ignimbritas de composición riolítica. Sin embargo, sólo se han reportado fechas isotópicas de esas rocas para la región de San Miguel de Allende-Guanajuato (Nieto-Samaniego et al., 1996). Aunque para establecer los alcances estratigráficos de las rocas volcánicas intercaladas con los sedimentos continentales resulta indispensable contar con un mayor número de fechamientos, la información con que se cuenta hasta este momento hace suponer que durante el Oligoceno, sincrónicamente con el volcanismo, se depositaron sedimentos continentales en buena parte de la MC.

\subsubsection{Rocas volcánicas del Mioceno medio y superior}

Yaciendo discordantemente sobre el conjunto volcánico oligocénico, o bien intercaladas con los sedimentos que rellenan las cuencas continentales cenozoicas, aparecen rocas volcánicas de composición máfica y de edad miocénica. Este conjunto de rocas ha sido reportado aisladamente en numerosas localidades de la MC, especialmente en sus porciones centro, sur y occidente.

Córdoba-Méndez (1988) define la Formación Metates, localizada en el extremo NW de la MC, la describe como derrames de basalto de olivino y basalto andesítico, que comúnmente contienen xenolitos de peridotita, gneis y otras rocas metamórficas. La Formación Metates fue fechada fuera de la MC en su localidad tipo, la cual está ubicada hacia el occidente de la ciudad de Durango, en ese lugar se obtuvieron edades de $\sim 12 \mathrm{Ma}$ (McDowell y Keizer, 1977; Henry y Aranda-Gómez, 2000).

En la región de Los Encinos (Figura 3) aflora un campo volcánico de basaltos alcalinos con edades que varían entre 10.6-13.6 Ma (Luhr et al., 1995). Dentro de la porción sur de la MC, en el estado de San Luis Potosí, Labarthe-Henández et al. (1982) establecen una unidad litoestratigráfica denominada Basalto Cabras cuya edad desconocen, pero la asignaron al Oligoceno tardío por yacer sobre ignimbritas fechadas en $27 \mathrm{Ma}$. Sin embargo, un fechamiento en andesitas que afloran en la parte NE del estado de San Luis Potosí, y que presumiblemente corresponden al Basalto Cabras, fue reportado por Nieto-Samaniego et al. (1999), obteniendo una edad K-Ar en plagioclasas de 13.2 $\pm 0.6 \mathrm{Ma}$.

Al sur de San Luis Potosí, en la Sierra de Guanajuato, afloran basaltos y andesitas que coronan las partes elevadas que fueron denominados Basalto El Cubilete por Martínez-Reyes (1992); esas rocas fueron fechadas en 13.5 Ma por Aguirre-Díaz et al. (1997). En los alrededores de San Miguel de Allende, en la esquina SE de la MC, hay derrames de lava y estratovolcanes de composición andesítica y basáltica cuyas edades varían de 16 a 10 Ma (Pérez-Venzor et al., 1996, Verma y Carrasco-Núñez, 2003). Estas rocas volcánicas se extienden ampliamente fuera de la MC a todo lo largo del límite norte de la Faja Volcánica Transmexicana.

\subsubsection{Rocas volcánicas pliocénicas y cuaternarias}

Se han reconocido rocas volcánicas de edad PliocenoCuaternario en el centro de la MC, afloran principalmente en pequeños conjuntos de aparatos volcánicos como conos cineríticos y maares en el estado de San Luis Potosí (Labarthe-Hernández et al., 1982). En Durango forman un campo volcánico extenso de aproximadamente 2000 $\mathrm{km}^{2}$ donde se han documentado más de 100 conos cineríticos y de lava, y han sido reportados algunos maares (Swanson 1989; Aranda-Gómez et al., 2003) cuya edad es cuaternaria. En conjunto las rocas volcánicas pliocénicas y cuaternarias de la Mesa Central se caracterizan porque la composición de sus lavas es alcalina y porque comúnmente son portadoras de xenolitos de lerzolita provenientes del manto y de granulita procedentes de la base de la corteza. Una descripción de su distribución geográfica, de las estructuras volcánicas, así como de la química de las lavas y los xenolitos, puede encontrarse en Swanson (1989) y Aranda-Gómez et al. (1993a, 1993b). 
Para una descripción completa de los conjuntos volcánicos que afloran en la MC y sus alrededores, cuyas edades van del Mioceno al Cuaternario, así como una amplia discusión sobre su génesis, consúltese Aranda-Gómez et al. (2005).

\subsubsection{Rocas sedimentarias del Oligoceno-Cuaternario}

Dentro de la Mesa Central y principalmente en su porción sur y occidente, la topografía muestra un conjunto de sierras de poca elevación rodeadas de cuencas continentales con rellenos fluvio-lacustres. Las rocas que forman esta unidad estratigráfica son poco conocidas, pero es evidente que su alcance estratigráfico varía en distintos lugares. En la región de Durango su parte inferior ha sido reportada con el nombre de formación San Pablo y su parte superior como Formación Los Llanos o formación Guadiana (CórdobaMéndez, 1988) conteniendo intercaladas rocas volcánicas de composición félsica y rocas volcánicas máficas pertenecientes a los conjuntos volcánicos del Oligoceno y del Plioceno-Cuaternario respectivamente. En San Luis Potosí, Zacatecas y Guanajuato las rocas sedimentarias muestran intercalaciones de rocas volcánicas félsicas y máficas de edades oligocénicas o del Mioceno medio y se sabe que las partes superiores de los sedimentos que constituyen este grupo de rocas tienen edades que alcanzan el Cuaternario, dado su contenido fósil (Montellano-Ballesteros, 1990; Carranza-Castañeda et al., 1994).

\subsection{Cuerpos intrusivos}

En la Mesa Central afloran numerosos cuerpos intrusivos de dimensiones pequeñas, la mayoría son de edad terciaria. Existen pocos estudios específicos sobre ellos y en general se encuentran dispersos en literatura no convencional (tesis, informes y reportes de empresas privadas o de dependencias gubernamentales). La principal fuente de información sobre su distribución y edad proviene de las cartas geológicas editadas por el Servicio Geológico Mexicano, las cuales se encuentran en acceso gratuito en la dirección electrónica http://www.coremisgm.gob.mx/. A continuación se describen solamente tres de los más importantes cuerpos plutónicos que afloran en la Mesa Central.

\subsubsection{Granito de Comanja, Guanajuato}

Fue definido por Quintero-Legorreta (1992), aflora de manera intermitente en la mayor parte de la Sierra de Guanajuato (Figura 5). De acuerdo con este autor, el cuerpo de granito ocupa un área de aproximadamente $160 \mathrm{~km}^{2} \mathrm{y}$ presenta una mineralogía formada por cristales de feldespato potásico dentro de una masa de cristales de cuarzo y plagioclasa de menor tamaño. La mica presente es biotita en cantidades subordinadas.

El granito corta a las unidades mesozoicas plegadas y muestra su carácter postorogénico al no observarse deformado y producir contactos intrusivos produciendo metamorfismo de contacto en las rocas mesozoicas en las que está emplazado. El granito es cubierto discordantemente por las rocas terciarias, yace bajo conglomerados continentales pertenecientes al grupo "Sedimentos continentales del Paleoceno-Eoceno medio" ya descritos, y bajo ignimbritas riolíticas de edad Oligoceno (28.2 \pm 0.7 Ma, K-Ar en sanidino; Nieto-Samaniego et al., 1996). Dos edades K-Ar en biotitas obtenidas por Mujica-Mondragón y Albarrán-Jacobo (1983; referido en Quintero-Legorreta, 1992) dieron edades de $55 \pm 4$ y $58 \pm 5 \mathrm{Ma}$, por lo que su edad se ubica en el Paleoceno tardío.

\subsubsection{Intrusivo Peñón Blanco, Zacatecas}

Aflora en la sierra de Salinas, a manera de varios cuerpos plutónicos e hipabisales, el mayor de ellos conforma el denominado Peñón Blanco. Su textura es porfídica, con fenocristales en una matriz equigranular. Presentan una mineralogía de cuarzo (ca. 35\%), ortoclasa (10-15\%), oligoclasa $(c a .10 \%)$ y muscovita $(3.5-4 \%)$ y presenta turmalina negra como mineral accesorio; su composición química y mineralógica indica una composición granítica peraluminosa (Silva- Romo, 1996). Los cuerpos graníticos están emplazados en la secuencia sedimentaria triásica, comúnmente sobre fallas normales. Se conoce el reporte de un fechamiento K-Ar en muscovita en el Peñón Blanco que dio una edad 48 \pm 4 Ma (Mujica-Mondragón y AlbarránJacobo, 1983; referido en Silva-Romo, 1996).

\subsubsection{Intrusivo Palo Verde (El Realito-El Refugio)}

Está conformado por dos cuerpos principales y numerosos cuerpos intrusivos menores, es denominado Intrusivo Palo Verde por Labarthe-H. et al. (1989), quienes lo describen como una roca subvolcánica, de color gris a café claro, holocristalina, inequigranular, con $20 \%$ de fenocristales de ortoclasa o sanidino, plagioclasa y cuarzo en tamaños de entre 2 y $3 \mathrm{~mm}$. La matriz es un agregado de feldespato y cuarzo, con minerales ferromagnesianos (biotita, hastingsita y riebeckita) de $1 \mathrm{~mm}$, dispersos, que constituyen de un 3 a un 5\% de la matriz. Se observa que en los cuerpos mayores pasa transicionalmente a riodacita. Su edad no ha sido determinada, pero sus relaciones estratigráficas indican una edad oligocénica ya que intrusiona a ignimbritas de $29.1 \pm 0.3 \mathrm{Ma}$ (K-Ar, roca total, Labarthe-H. et al., 1989) y pasa transicionalmente a unidades que por correlación litológica es ubicada por estos mismos autores al Oligoceno.

\section{Estructuras cenozoicas mayores}

\subsection{Fallas mayores que limitan la Mesa Central}

\subsubsection{La falla del Bajío}

El límite sur de la Mesa Central lo constituye una falla normal que muestra dos segmentos mayores, el más 
oriental se extiende desde Celaya hasta Irapuato en el estado de Guanajuato, donde la zona de falla tiene dirección $\sim$ E-W (Figura 5). En el bloque levantado se aprecian dos grupos de fallas con direcciones NW-SE y ENE a NE, en conjunto ambos grupos de estructuras le dan en ese sector una forma aserrada al borde norte de El Bajío, que es una planicie de relleno aluvial de escala regional. En esa zona los desplazamientos mínimos pueden estimarse a partir de los desniveles en el escarpe de la sierra, que son de entre 150 y $250 \mathrm{~m}$ y los espesores del relleno reportados en los alrededores de Celaya que son cercanos a los 100 m (Trujillo-Candelaria, 1985). Debe considerarse también, que en zonas donde hay fallas transversales cubiertas por los depósitos aluviales dentro del bloque caído, los espesores de los sedimentos llegan a alcanzar los $250 \mathrm{~m}$ (Trujillo-Candelaria, 1985). De la información anterior podemos considerar como una estimación general que el hundimiento (rechazo vertical) producido por la falla del Bajío en esa zona es del orden de 350 a $500 \mathrm{~m}$.

El segundo segmento de la falla del Bajío forma el escarpe SW de la Sierra de Guanajuato, siendo ésta el bloque levantado de la falla, tiene $80 \mathrm{~km}$ de largo y se extiende desde Irapuato hasta León, ambos en el estado de Guanajuato. La falla hace aflorar la secuencia volca-

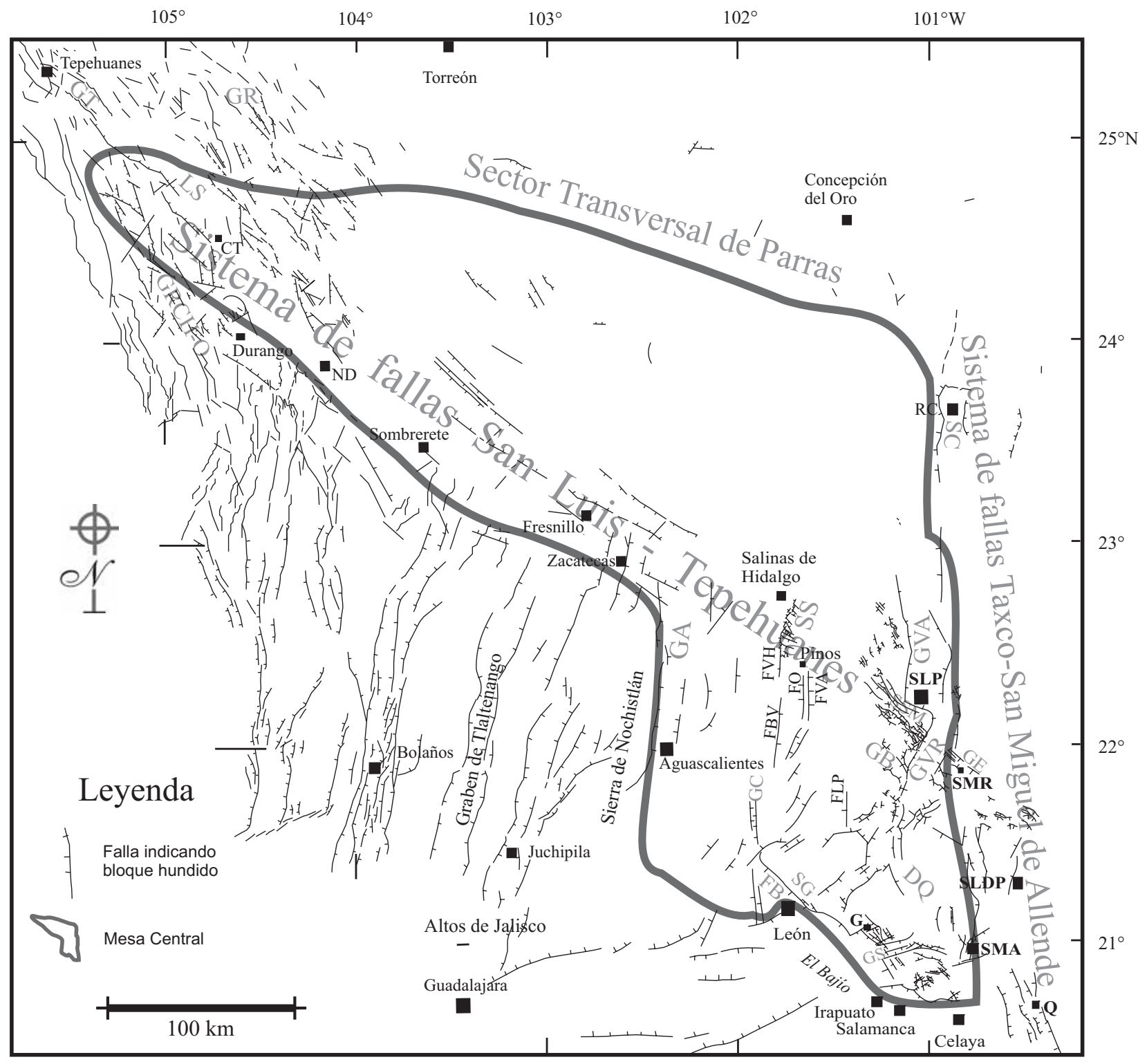

Figura 5. Mapa que muestra la localización de las estructuras mayores de la Mesa Central. GT: graben de Tepehuanes, GR: graben de Rodeo, LS: laguna de Santiaguillo, GRCH-O: graben Río Chico-Otinapa, GA: graben de Aguascalientes, FVH: falla Villa Hidalgo, FBV: falla Buena Vista, FO: falla El Obraje, FVA: falla Villa de Arriaga, FLP: falla Los Pájaros, GC: graben El Cuarenta, FB: falla del Bajío, GS: graben de la Sauceda, GB: graben de Bledos, GVR: graben Villa de Reyes, GVA: graben de Villa de Arista, GE: graben de Enramadas, DQ: depresión de La Quemada, SSM: Sierra de San Miguelito, SG: Sierra de Guanajuato, SC: Sierra de Catorce, SS: sierra de Salinas, RC: Real de Catorce, G: Guanajuato, SLP: San Luis Potosí, SMR: Santa María del Río, SLDP: San Luis de la Paz, ND: Nombre de Dios, SMA: San Miguel de Allende, Q: Querétaro. 
nosedimentaria marina de edad cretácica, ya descrita en el apartado de Estratigrafía. La estructura está formada por una serie de fallas normales de ángulo alto, escalonadas y con bloque hundido al SW. Los desplazamientos de $850 \mathrm{~m}$ medidos en las unidades volcánicas oligocénicas (QuinteroLegorreta, 1992) y los espesores de los rellenos aluviales en las cercanías de León (Hernández-Laloth, 1991), permiten asignarle un rechazo vertical acumulado que supera los 1 $200 \mathrm{~m}$, y que ocurrió posterior al Oligoceno. Conviene hacer notar que el rechazo vertical posterior al Mioceno medio fue posible estimarlo en $\mathrm{ca}$. $500 \mathrm{~m}$ en el Cerro del Cubilete, localizado $20 \mathrm{~km}$ al SE de León, por medio del desplazamiento del Basalto El Cubilete de edad 13.5 Ma (Aguirre-Díaz et al., 1997). En la ciudad de Guanajuato se ha estudiado la falla de la Veta Madre, que es una estructura de tipo normal de rumbo NW-SE, paralela a la falla del Bajío y localizada a menos de $10 \mathrm{~km}$ al oriente de ella. Dicha falla tiene un desplazamiento medido superior a $1500 \mathrm{~m}$, ocurrido posterior al Oligoceno; si se suma este desplazamiento y los de fallas paralelas cercanas a la falla del Bajío tendríamos en la región de Guanajuato un desplazamiento total que supera los $2 \mathrm{~km}$ y un rechazo vertical cercano a los $800 \mathrm{~m}$.

Los conglomerados rojos de edad Paleoceno-Eoceno temprano que afloran a lo largo de la traza de la falla del Bajío son indicio de su posible actividad en el Eoceno, aunque dicha actividad no ha sido bien documentada. No se puede descartar que la falla del Bajío tenga un origen mucho más antiguo, pero su individualización se hace evidente hasta el Oligoceno, durante el cual tuvo lugar su actividad mayor y a partir de entonces ha tenido fases sucesivas de reactivación que abarcan por lo menos hasta el Mioceno tardío. A lo largo de su traza afecta a rocas del Mioceno medio, tanto en la región de Guanajuato (Basaltos El Cubilete), como en las cercanías de Salamanca (andesita La Ordeña; Ojeda-García, 2004). No hay evidencias claras de que la falla del Bajío o fallas asociadas hayan tenido actividad pliocénica o más joven. Rocas volcánicas y aparatos volcánicos de esa edad afloran en la región de Salamanca-Celaya y no se observan cortados por fallas.

\subsubsection{Sistema de fallas Taxco-San Miguel de Allende}

El límite oriental de la Mesa Central lo constituye un sistema de fallas normales de dirección N-S que se extiende desde San Miguel de Allende y Querétaro hasta más al norte de la Sierra de Catorce, formando el límite entre la Mesa Central y la Sierra Madre Oriental. Estas fallas corresponden también a la parte septentrional del sistema de fallas Taxco-San Miguel de Allende (SFTSMA) (AlanizÁlvarez et al., 2002, Alaniz-Álvarez y Nieto-Samaniego, 2005). Este sistema de fallas coincide también con el límite paleogeográfico, entre la Plataforma Valles-San Luis Potosí, localizada al este, y la Cuenca Mesozoica del Centro de México, localizada al oeste. Estos elementos paleogeográficos ya fueron descritos en el apartado de Estratigrafía; la importancia de la coincidencia de esa tran- sición con el SFTSMA radica en la diferencia batimétrica y posiblemente de espesor cortical de esos paleoelementos, ya que actualmente existen también diferencias similares en los espesores de la corteza a ambos lados del SFTSMA. Esto nos conduce a pensar que tanto las fallas como las diferencias en los espesores corticales actuales, son rasgos heredados de una zona antigua, al menos mesozoica, de transición plataforma marina-cuenca marina y en donde probablemente hubo un sistema de fallas normales semejante al SFTSMA.

Dentro de la MC el rasgo morfológico del SFTSMA se observa segmentado por varios lineamientos NW-SE, algunos de los cuales han sido documentados como sistemas de fallas, los mayores de ellos son el sistema de fallas San Luis-Tepehuanes y la falla del Bajío (Figura 5). Las fallas que forman el SFTSMA han sido reconocidas en las siguientes localidades:

- En la Sierra de Catorce (Barboza-Gudiño et al., 2004), donde se reconocen fallas de dirección $\sim \mathrm{N}-\mathrm{S}$ que se localizan en el costado oeste de la Sierra de Catorce y buzan hacia el oeste. No se tiene información detallada sobre las magnitudes y edad del desplazamiento ya que no afloran rocas terciarias que permitan cuantificarlos, pero considerando el escarpe que forman las fallas suponemos que su desplazamiento fue preponderantemente de tipo normal. La edad probable de actividad de las fallas es el Paleógeno, ya que cortan a estructuras de dirección NW-SE que tienen emplazados sobre ellas diques cuarzo-monzoníticos de 53 44 Ma (Mujica-Mondragón y Jacobo-Albarrán, 1983). En cuanto a la magnitud de los desplazamientos sólo se sabe que el escarpe alcanza los $1000 \mathrm{~m}$ de desnivel. Al oriente de la Sierra de Catorce hay una falla normal, con el bloque oriental caído, que regionalmente se localiza sobre el lineamiento del margen occidental de la Plataforma Valles-San Luis Potosí (Barboza-Gudiño et al., 2004).

- Graben de Villa de Arista (continuación norte del graben de Villa de Reyes). Se trata de una serie de fallas normales bastante erosionadas que forman un graben con relleno fluvial (Moreira-Rivera et al., 1998). En la ciudad de San Luis Potosí el desplazamiento vertical del graben es de $c a .500$ m (Tristán-González, 1986) y las fallas estuvieron activas durante el Oligoceno (Nieto-Samaniego et al., 1997).

- En la región de San Miguel de Allende y Querétaro han sido mejor estudiadas estas fallas, en ambos casos se trata de grupos de fallas normales, paralelas, con dirección de alargamiento este-oeste. En San Miguel de Allende se documentó que la zona de falla principal tiene un rechazo vertical de $450 \mathrm{~m}$ y dos fases de actividad ocurridas entre el Oligoceno y el Mioceno medio; en Querétaro las fallas tienen rechazos verticales cercanos a $100 \mathrm{~m}$ y edades de actividad del Mioceno tardío (Alaniz-Alvarez et al., 2001).

\subsubsection{Sistema de fallas San Luis-Tepehuanes}

Este sistema de fallas se observa en imágenes de satélite y modelos digitales de elevación como un gran 
lineamiento de dirección NW-SE que se extiende desde San Luis de la Paz, Gto., hasta Tepehuanes, Dgo. Su traza coincide burdamente con el límite de los afloramientos de rocas volcánicas cenozoicas pertenecientes a la Sierra Madre Occidental, con los afloramientos de las secuencias volcanosedimentarias mesozoicas y con el límite norte de los grábenes de la Sierra Madre Occidental (Figuras 3 y 5). En el sistema de fallas San Luis-Tepehuanes (FSLT) podemos reconocer dos segmentos:

- Su porción oriental se extiende de San Luis de la Paz hasta Salinas de Hidalgo y constituye el límite de las regiones meridional y septentrional de la Mesa Central. Dentro de este segmento, entre San Luis de la Paz y Santa María del Río, se ha cartografiado un sistema formado de numerosas fallas normales con rumbo NW-SE y buzamiento principalmente al SW, que en algunos lugares forman fosas tectónicas y desplazan principalmente a rocas del Oligoceno temprano (Labarthe-Hernández y Tristán-González, 1980; Tristán-González, 1987; Alvarado-Méndez et al., 1997), lo que indica una edad máxima de actividad en el Oligoceno tardío. No se cuenta con información sobre las magnitudes de los desplazamientos producidos a lo largo de esas fallas.

Inmediatamente al occidente del graben de Villa de Reyes, en la Sierra de San Miguelito (Figuras 3 y 5), este sistema de fallas ha sido exhaustivamente estudiado (Labarthe-Hernández y Jiménez-López, 1992, 1993, 1994; Nieto-Samaniego et al,. 1997; Xu et al., 2004), allí está formado por numerosas fallas de rumbos que varían de $\mathrm{N} 60^{\circ} \mathrm{W}$ a $\mathrm{N} 20^{\circ} \mathrm{W}$ y echados de $45^{\circ}$ a $75^{\circ}$ al SW, formando un arreglo tipo dominó que causó un basculamiento promedio de $20^{\circ}$ al $\mathrm{NE}$ en las capas de rocas volcánicas oligocénicas. Esa deformación produjo una extensión de $0.2(20 \%)$ con dirección $\sim$ NE-SW, perpendicular al rumbode las fallas (Xu et al., 2004). La edad más antigua de actividad de estas fallas que se logró determinar es previa al Oligoceno, sin poder precisarla, posteriormente ocurrieron varias reactivaciones, la de mayor magnitud ocurrió en el Oligoceno temprano y una segunda de menor magnitud en el Oligoceno tardío, la cual pudo haberse extendido hasta el Mioceno temprano (Nieto-Samaniego et al., 1997).

Continuando sobre la traza del FSLT, la siguiente localidad en que se tienen bien documentadas fallas normales de este sistema es en la sierra de Salinas, localizada $10 \mathrm{~km}$ al SSE de Salinas de Hidalgo (Figuras 3 y 5). Esa sierra es alargada en dirección N-S, de aproximadamente $30 \mathrm{~km}$ de largo y entre 5 y $10 \mathrm{~km}$ de ancho, su flanco oeste es una falla bastante erosionada. El FSLT corta la sierra de manera oblicua, sus fallas tienen dirección promedio $\mathrm{N} 50^{\circ} \mathrm{W}$ con direcciones de estría que indican un movimiento preponderantemente normal y formando un sistema de horst y graben (Silva-Romo, 1996); ese autor reconoce tres fases de deformación frágil extensional, la más antigua activó fallas $\sim \mathrm{N}-\mathrm{S}$ y WNW; la segunda fase es responsable de la reactivación de las fallas WNW que cortan la sierra y que pertenecen al FSLT, a estas dos fases les asigna una edad Eoceno temprano-medio, argumentando que fueron contemporáneas o anteriores al emplazamiento de cuerpos graníticos fechados en $48 \mathrm{Ma}$, ya que hay numerosos diques emplazados en las fallas; por último, tuvo lugar una fase de deformación que activó las fallas $\sim \mathrm{N}-\mathrm{S}$ que limitan a la sierra hacia el occidente (Silva-Romo, 1996), la edad de esta deformación no es esclarecida por este autor, pero es más joven que las fases anteriores, probablemente del Oligoceno tardío o Mioceno temprano, ya que afecta a la Ignimbrita Villa Hidalgo que parece correlacionarse con ignimbritas oligocénicas de la Mesa Central (LabartheHernández et al., 1982). No se cuenta con información acerca de las magnitudes de desplazamiento producido por estas fallas.

Aproximadamente $60 \mathrm{~km}$ al occidente de la sierra de Salinas ya descrita, el FSLT se cruza con el graben de Aguascalientes, observándose que dicho graben termina en la intersección y no continúa hacia el norte. Hay un salto izquierdo aparente en el hombro oeste del graben de Aguascalientes, ya que se lo vuelve a reconocer hasta Guadalupe, población localizada aproximadamente $15 \mathrm{~km}$ al occidente (Figuras 3 y 5). En esa zona hay numerosas estructuras de rumbo $\mathrm{N} 70^{\circ} \mathrm{W}$, de movimiento principalmente normal, que se localizan sobre la traza del FSLT. Aunque se observaron algunas fallas menores con desplazamientos laterales, no se tiene evidencias de fallas importantes con ese tipo de desplazamiento.

En Zacatecas, y sobre la traza del FSLT, se han cartografiado dos sistemas mayores de fallas (Ponce y Clark, 1988; Caballero-Martínez et al., 1999). Las fallas más antiguas tienen dirección NW-SE, en su mayoría con echados de $50^{\circ}-70^{\circ}$ al SW. Sus longitudes varían entre 4 y $16 \mathrm{~km}$ y alojan vetas mineralizadas, de ellas, las más grandes y mejor conocidas son: La Plomosa, Tajos de Pánuco, Veta Grande, Mala Noche, Bote, Cantera y San Rafael (Ponce y Clark, 1988). La edad de los desplazamientos sobre estas fallas no se conoce con exactitud, ya que están emplazadas en rocas mesozoicas. Las fallas NW-SE son cortadas por fallas $\sim \mathrm{N}-\mathrm{S}$ que limitan la sierra de Zacatecas, y la configuran como un pilar tectónico. No hay información detallada de las edades y magnitudes de los desplazamientos de estas fallas; pero considerando el desnivel que se observa en la sierra, deben de superar en conjunto los $400 \mathrm{~m}$ de rechazo vertical y cortan a unidades volcánicas del Eoceno medio (ignimbrita Los Alamitos de 46.8 Ma y formación La Virgen de $36.8 \mathrm{Ma}$; Ponce y Clark, 1988) y no afectan a las rocas volcánicas oligocénicas (ignimbrita Garabato de 28.0 0.8

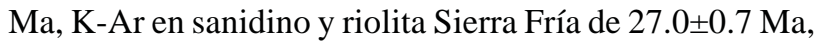
K-Ar en sanidino; Loza-Aguirre, 2005), por lo que su edad se ubica entre el Eoceno tardío y el Oligoceno temprano. Estas fallas $\sim \mathrm{N}-\mathrm{S}$ se observan cortadas por fallas NW-SE, lo que se interpreta como una reactivación del sistema FSLT ocurrida a finales del Oligoceno tardío o posterior, ya que cortan a la ignimbrita Garabato y la riolita Sierra Fría mencionadas arriba. 
Por lo descrito en el párrafo anterior, se visualizan dos fases de actividad del FSLT en Zacatecas, una ocurrida en el Eoceno tardío-Oligoceno temprano que es sincrónica con la discordancia descrita en el apartado de Estratigrafía, y la segunda ocurrida hacia finales del Oligoceno o en el Mioceno.

Siguiendo hacia el occidente, sobre la traza del FSLT se localizan los distritos mineros de Fresnillo y Sombrerete, a 50 y $150 \mathrm{~km}$ al NW de Zacatecas respectivamente, en ambos casos están documentadas fallas normales cenozoicas. En Fresnillo, las fallas más grandes son las fallas Fresnillo y Laguna Blanca, de dirección $\mathrm{N} 30^{\circ}-60^{\circ} \mathrm{W}$ con inclinación al NE; en esa misma zona hay otras fallas normales con esa misma orientación (véase figura 2 en De Cserna, 1976). Los desplazamientos de las fallas no están bien documentados, como un indicio de las magnitudes podemos considerar la falla Laguna Blanca, a la que De Cserna (1976) le supone al menos $1000 \mathrm{~m}$ de desplazamiento. La edad de actividad de las fallas en Frenillo es posterior al Conglomerado Fresnillo, el cual yace en discordancia angular sobre las rocas cretácicas, no presenta deformación plicativa y subyace a rocas volcánicas de $38.3 \mathrm{Ma}$ (Albinson, 1988). Aparecen también fallas con alteración hidrotermal dentro de estas rocas volcánicas y se tienen edades de feldespatos hidrotermales en esas fallas que fueron fechados en 29.1 Ma (Albinson, 1988). Estas relaciones nos llevan a suponer que la actividad de las fallas en la región de Fresnillo ocurrió en el Eoceno tardío-Oligoceno temprano, sin que se puedan descartar eventos previos de actividad en el lapso Paleoceno-Eoceno medio.

En la zona de Sombrerete hay dos grupos de fallas NW-SE de distinta edad, también hay fallas de rumbos E-W y NE-SW, aunque en menor número. Las fallas más antiguas alojan vetas cuya edad de mineralización se ubica entre el Eoceno tardío y el Oligoceno temprano (Albinson 1988), esas fallas cortan rocas en las que se han obtenido edades del Eoceno temprano-medio, sin que haya un control preciso de los niveles estratigráficos dentro de la secuencia volcánica a los que corresponden esas edades. Lo anterior indica una edad de actividad de las fallas del Eoceno medio-tardío. Las fallas más jóvenes desplazan a las vetas y cortan a rocas riolíticas presumiblemente de edad Oligoceno (30-25 Ma) correlacionables con las riolitas oligocénicas de Fresnillo (Albinson 1988).

Hacia el NW de Sombrerete, Zacatecas y siempre sobre la traza del FSLT se sigue un tren de fallas normales que configuran una serie de cuencas continentales con relleno aluvial que sigue hasta las cercanías de Tepehuanes, Durango. No se tiene información detallada de estas fallas pero aparecen en mapas publicados (Cartas GeológicoMineras del Consejo de Recursos Minerales: Fresnillo, Durango y El Salto, escala 1:250 000, y Tepehuanes, escala 1:50 000). Entre Villa Unión y Canatlán aparece sobre la traza del FSLT el campo volcánico de Durango cuya edad es del Cuaternario, en él se han documentado fallas normales de orientación NW-SE que cortan esas rocas volcánicas (Aranda-Gómez et al., 2003). Más hacia el NW el sistema de fallas continúa formando los grábenes que contienen la laguna de Santiaguillo, de dirección NW-SE, la cual supera los $40 \mathrm{~km}$ de longitud y donde han sido documentados sismos históricos y sismicidad instrumental local (Yamamoto, 1993). El extremo NW del FSLT lo constituye el graben de Tepehuanes, cartografiado en escala 1:50 000 (Carta Geológico-Minera del Consejo de Recursos Minerales, Tepehuanes), sin que se cuente con información detallada de las fallas que lo forman. En la región de Durango, el FSLT está bordeado por grandes grábenes y fallas normales de dirección NNW: al oriente el graben de Rodeo en el que se han documentado dos fases de deformación, una de edad Oligoceno temprano entre 32.3 y 30.6 Ma y una segunda de edad Mioceno temprano ( 24 Ma); al occidente se localiza el graben de Río Chico-Otinapa que tuvo actividad entre 12 y $2.5 \mathrm{Ma}$ (Aranda-Gómez et al., 2003).

\subsubsection{Graben de Aguascalientes}

Este sistema de fallas limita al occidente el sector sur de la MC separándola de la Sierra Madre Occidental (Figura 5), consiste de un graben asimétrico (semigraben) cuya falla principal está ubicada al occidente. Esa falla se extiende con dirección N-S por $150 \mathrm{~km}$, desde los Altos de Jalisco hasta su intersección con el FSLT, cerca de Zacatecas. El desplazamiento de la falla mayor en Aguascalientes es de aproximadamente $900 \mathrm{~m}$, fue obtenido por el desnivel de $\sim 400 \mathrm{~m}$ entre las rocas volcánicas que afloran en el bloque levantado (occidental) y el nivel del valle, más el espesor de $\sim 500 \mathrm{~m}$ de los sedimentos que rellenan ese valle, dicho espesor fue estimado a partir del registro de un pozo profundo para agua (Jiménez-Nava, 1993). La falla occidental desplaza rocas volcánicas, principalmente ignimbritas de composición félsica, cuyo alcance estratigráfico no está definido con precisión. Se tienen fechadas las rocas más antiguas al occidente de la ciudad de Aguascalientes que son de edad Eoceno medio y las ignimbritas que coronan la Sierra de Nochistlán localizada inmediatamente al occidente, de edad Oligoceno tardío (Nieto-Samaniego et al., 1997). Adicionalmente, en los registros del pozo profundo en Aguascalientes se describen rocas basálticas intercaladas con los sedimentos cuya edad no está determinada, pero los basaltos más cercanos que yacen sobre la secuencia ignimbrítica, localizados al occidente, en el graben de Tlaltenango y dentro ya de la Sierra Madre Occidental, tienen edades Mioceno temprano (21.8 $\pm 1.0 \mathrm{Ma}, \mathrm{K}-\mathrm{Ar}$ en matriz, Moore et al., 1994). La edad de actividad de la falla principal del graben de Aguascalientes es posterior al Oligoceno temprano, sin que se pueda precisar cuántos eventos de deformación han tenido lugar en ella.

La cubierta volcánica cenozoica está presente tanto en la MC como en la Sierra Madre Occidental, sin embargo la morfología y el estilo estructural de ambas provincias fisiográficas es contrastante, la Sierra Madre Occidental presenta en estas latitudes fosas y pilares tectónicos de 
rumbos que varían de NNE a NNW, muy largos y paralelos y con poco relleno aluvial, mientras que la MC muestra un arreglo complejo de fallas normales con distintos rumbos, pilares tectónicos y fosas con rellenos gruesos de sedimentos continentales aluviales y lacustres que comúnmente forman arreglos romboédricos, siendo el graben de Aguascalientes la estructura que claramente limita ambas provincias.

\subsection{Sector Transversal de Parras de la Sierra Madre} Oriental.

La MC se encuentra limitada al norte por un sistema montañoso de dirección aproximadamente E-W, el cual se observa que es más alto hacia su parte este, superando los 2000 msnm, mientras que en la parte norte es un poco más bajo, sin alcanzar esa cota. Está constituido por pliegues en rocas mesozoicas que forman parte de la Sierra Madre Oriental y es conocida como Sector Transversal de Parras. Los pliegues tienen dirección $\mathrm{N} 70^{\circ} \mathrm{W}$ y se caracterizan por ser angostos y alargados, la mayoría de ellos son vergentes al NNE, pero los hay con vergencia opuesta (Eguiluz-de Antuñano et al., 2000). En las cercanías con el límite de la MC los pliegues no se aprecian afectados por las fallas Caballo, Almagre y Juárez de dirección $\sim \mathrm{N}-\mathrm{S}$ y de edad oligocénica propuestas por Eguiluz-de Antuñano (1984). Por otra parte, se ha documentado la falla de San Marcos y fallas paralelas o asociadas a ella, que se localizan al norte del límite de la MC y que son paralelas al Sector Transversal de Parras, esas fallas han tenido actividad postlaramídica en el Mioceno tardío-Plioceno temprano (Aranda-Gómez et al., 2005; Chávez-Cabello et al., 2004). El rasgo morfológico del Sector Transversal de Parras sugiere la existencia una gran estructura cenozoica; sin embargo, no se han documentado fallas que constituyan el límite norte entre la Mesa Central y la Sierra Madre Oriental.

\subsection{Sistemas de fallas en el interior de la Mesa Central}

Dentro de la Mesa Central hay numerosas fallas cenozoicas que en muchos casos limitan cuencas continentales rellenas de sedimentos fluviales y lacustres. Estas estructuras se pueden reconocer principalmente en el sector meridional de la MC, donde afectan a rocas de edad oligocénica, se reconocen fallas de dirección N-S, E-W, NE-SW y NW-SE, lo que le imprime a la región una configuración estructural compleja (Figura 5); de ellas las más importantes son: el graben de Villa de Reyes de dirección NNE-SSW, con cerca de $100 \mathrm{~km}$ de longitud y rechazos verticales que alcanzan los 500 m (TristánGonzález, 1986). El graben de La Sauceda de dirección ENE, longitud de ca. $25 \mathrm{~km}$ y rechazo vertical que alcanza los 400 m (Nieto-Samaniego, 1992). El graben El
Cuarenta, de dirección N-S, 40 km de longitud y rechazo vertical que alcanza $1000 \mathrm{~m}$ (Quintero-Legorreta, 1992). Las fallas normales N-S más importantes son: El Obraje, Villa Hidalgo, Los Pájaros, Buenavista, Villa de Arriaga, y las estructuras NW más importantes son los grábenes de Bledos y Enramadas, así como la depresión de La Quemada (Figura 5).

\section{Evolución Geológica}

El registro litológico que permite inferir la evolución geológica de la Mesa Central inicia en el Triásico Tardío, por los afloramientos de sedimentos marinos. La característica más sobresaliente es la diferencia entre las secuencias turbidíticas de la parte oriental (sierras de Salinas, Catorce, Charcas) y las secuencias clásticas con metamorfismo de grado bajo (filitas) y con componente volcánico de la parte occidental (Zacatecas). Esta distribución de facies permite establecer la existencia de un margen continental localizado en la Mesa Central, con el océano hacia el occidente. La configuración de ese margen es una mera conjetura y su geometría no se puede reconstruir dada escasez de afloramientos.

Hay otras localidades donde afloran sedimentos mesozoicos de cuenca marina, en esos lugares aparecen con rocas volcánicas básicas intercaladas (Figura 3). La distribución de esos afloramientos muestra que las secuencias sedimentarias de cuenca marina con rocas volcánicas se extienden en dirección NW a lo largo del extremo oeste de la MC. Freydier et al. (1996) explican la presencia de estas rocas suponiendo la existencia de una cuenca formada en el Jurásico Tardío-Cretácico Temprano que denominan Cuenca de Arperos. Las rocas que constituirían esta cuenca incluyen los afloramientos de Zacatecas y Guanajuato. Es en este último estado donde se observa a rocas marinas de edad Aptiano-Albiano cubriendo discordantemente a la secuencia deformada de la Cuenca de Arperos, lo que es consistente con la edad asignada por Freydier et al. (1996) del Jurásico Tardío-Cretácico Temprano, y hace suponer a Quintero-Legorreta (1992) la existencia de una fase de deformación ocurrida hacia finales de Neocomiano. Sin embargo, debe considerarse que a $c a .100 \mathrm{~km}$ al norte de la Sierra de Guanajuato y ca. $40 \mathrm{~km}$ al este de los afloramientos orientales de Zacatecas, aflora la secuencia calcárea perteneciente a la Cuenca Mesozoica del Centro de México en la sierra de Salinas, con un alcance estratigráfico que va del Oxfordiano al Turoniano, sin discordancias ni componentes volcánicos documentados. Por ello, también resulta una opción razonable suponer una edad más antigua que el Cretácico Temprano para las rocas volcanosedimentarias de cuenca de Guanajuato. Este aspecto se mantiene como un problema a resolver en la estratigrafía y evolución tectónica de esta región de México.

Cabe hacer notar que hacia el oriente y nororiente de la MC hay capas rojas de edad Triásico Tardío (Carrillo- 
Bravo 1971; López-Infanzón, 1986) que no serán discutidas aquí. Dentro de la Mesa Central, la discordancia que aparece encima de las rocas triásicas, así como el carácter continental y la composición volcanosedimentaria de las rocas de edad Jurásico Medio sobreyacientes, indican un cambio fundamental en el ambiente geológico, evidencian la emersión de la Mesa Central, pasando de un ambiente marino a condiciones subaéreas que se mantienen durante el Jurásico Medio, así como la instauración de un arco volcánico continental. La discordancia que existe encima de las rocas volcanosedimentarias continentales del Jurásico Medio y la secuencia marina del Jurásico Superior (Oxfordiano-Tithoniano) en la que está ausente el componente volcánico, indican claramente que en la Mesa Central tuvo lugar una gran transgresión marina con el cese de la actividad volcánica. La inmersión de la Mesa Central fue sincrónica con la migración hacia el occidente de la zona con volcanismo a lo largo del límite continental. Lo anterior se evidencia porque en el margen surponiente de la Mesa Central están las secuencias volcanosedimentarias de edad Jurásico Tardío-Cretácico Temprano que descasan bajo las rocas Aptiano-Albiano; así como también existen secuencias de arco volcánico del Jurásico Tardío (Oxfordiano) en Sonora (Rangin, 1977) y en general el volcanismo de edad Cretácico bajo la Sierra Madre Occidental (Ferrari et al., 2005). Lo anterior sugiere, como la explicación más senci1la, que la placa en subducción experimentó un aumento en su ángulo de inclinación hacia finales del Jurásico Medio, pudiendo ese mecanismo dar lugar a la migración del arco volcánico hacia el occidente, al mismo tiempo que producir extensión y subsidencia en la placa continental.

Las condiciones marinas en la Mesa Central se mantuvieron por todo el Jurásico Tardío y Cretácico formando la secuencia de cuenca conocida como Cuenca Mesozoica del Centro de México. La secuencia no presenta discordancias mayores que evidencien fases orogénicas, es hasta las unidades superiores donde se presenta un cambio de facies pasando de una sedimentación de calizas a sedimentos terrígenos con materiales detríticos de origen volcánico. Las edades de las secuencias clásticas con material volcánico han sido determinadas paleontológicamente del Cenomaniano-Turoniano en la Mesa Central (Tardy y Mauri 1973, Silva-Romo, 1996); y en la región de Parras, Coahuila, alcanza el Maastrichtiano (Tardy y Maury, 1973). Lo anterior ha sido interpretado como un indicio del comienzo de la orogenia Laramide (Centeno-García y Silva-Romo 1997).

La gran discordancia que aparece sobre las rocas mesozoicas y que se distribuye en toda la Mesa Central registra el tiempo en que ocurrió la orogenia Laramide. El frente orogénico migró de occidente a oriente y la edad máxima de la deformación queda limitada por las edades de las rocas deformadas más jóvenes, que son turonianas en la parte oeste de la Mesa Central y son maastrichtianas en la parte este. Debe considerarse que una gran parte de las rocas deformadas por acortamiento en la Mesa Central están cubiertas por rocas más recientes, por ello es posible que los alcances de las rocas plegadas pudieran abarcar edades más jóvenes pero no hayan sido reconocidas por encontrarse sepultadas. La edad mínima de la deformación está definida por las edades de las rocas continentales o plutónicas no deformadas, en la Sierra de Guanajuato se han documentado cuerpos plutónicos postorogénicos de 54 Ma (Quintero-Legorreta, 1992), así como conglomerados continentales con lavas máficas intercaladas de $49 \mathrm{Ma}$ (Aranda-Gómez y McDowell, 1998). Hay también rocas volcánicas con edades que van de 51 a 37 Ma que ya no presentan la deformación contráctil Laramide. Estas rocas volcánicas eocénicas se presentan en la parte oeste de la Mesa Central constituyendo un arco volcánico continental, están localizadas burdamente a lo largo del sistema de fallas San Luis-Tepehuanes (Figura 3). Simultáneamente con ese volcanismo tuvo lugar una fase extensional en ese sistema de fallas, produciéndose alargamiento en dirección NE-SW. Es importante considerar que para ese tiempo el frente orogénico laramídico aún estaba activo en la Sierra Madre Oriental (Eguiluz-de Antuñano et al., 2000), lo que muestra que ocurría acortamiento en dirección NE-SW en el norte y oriente de México de manera sincrónica, o cuasisincrónica, con extensión en esa misma dirección a lo largo del extremo oeste de la Mesa Central. La distribución de los campos de deformación descritos no es sencilla de explicar, si se acepta que la fase orogénica estuvo asociada con un ángulo de subducción bajo, entonces el inicio de la extensión junto con volcanismo de arco, cuya composición no se conoce ya que no hay información geoquímica de esas rocas, requeriría que en esa zona la placa en subducción alcanzara la profundidad necesaria para propiciar fusión parcial en la cuña del manto. Quizá la opción más simple es que la placa en subducción se haya roto y el segmento más cercano a la trinchera, subduciendo con un ángulo más grande de inclinación que el segmento más alejado hacia el oriente, fuera el que propiciara la fusión parcial y el volcanismo. Un mecanismo y geometría semejante fue propuesto para esa región por van der Lee y Nolet (1997) para el Mioceno. Aunque esto es una simple especulación, dicha hipótesis explicaría el conocimiento actual que se tiene del registro geológico para ese tiempo y resultará interesante de explorar.

Suponemos que la localización de la extensión de edad eocénica a lo largo del FSLT responde a la existencia de una gran zona de debilidad antigua, esto se deduce al observar que a lo largo de una franja sobrepuesta a esa estructura existen sedimentos de cuenca oceánica, indicando ya sea una corteza adelgazada o bien el límite de la corteza continental para el Triásico Tardío, como indican los afloramientos de Zacatecas, o bien para el Cretácico Temprano de acuerdo con la interpretación de Freydier et al. (1996); también allí se localiza el límite de los arcos volcánicos marinos cretácicos, o sea es la zona de su yuxtaposición sobre las secuencias de cuenca marina. Aunque la extensión del Eoceno pudo haber afectado una región mayor de la 
Mesa Central, no se ha documentado dicha deformación en las partes centro y NE de ella y parece haberse concentrado a lo largo de ese gran lineamiento.

La discordancia que existe sobre las rocas eocénicas de la Mesa Central marca un cambio en la composición y localización del volcanismo, así como en la región afectada por la tectónica extensional y la dirección de alargamiento que prevaleció durante todo el Oligoceno. Las rocas volcánicas oligocénicas se presentan cubriendo el segmento sur de la Mesa Central, formando un enorme campo de domos riolíticos que tiene una cubierta relativamente delgada de ignimbritas, también de composición riolítica. En el segmento norte de la Mesa Central las rocas volcánicas oligocénicas están ausentes, salvo por la franja aledaña al límite oeste que constituye la frontera con la Sierra Madre Occidental y que se encuentra localizada a lo largo del FSLT. El volcanismo oligocénico tuvo lugar al mismo tiempo que deformación extensional con alargamiento principal cercano al $20 \%$ en dirección de E-W y de ca. $10 \%$ en dirección N-S. Durante este evento, que afectó al segmento sur de la MC, ocurrió: (1) el adelgazamiento y levantamiento de la corteza (Nieto-Samaniego et al., 1997), (2) el aumento de la temperatura en la corteza produciéndose la granulitización de su base (Hayob et al., 1989), (3) la emisión de grandes volúmenes de rocas efusivas de composición riolítica en un lapso cercano a 2 Ma que presentan características químicas indicativas de un origen a partir de fusión de la corteza (Orozco-Esquivel et al., 2002) y (4) la formación de numerosas cuencas sedimentarias continentales que fueron rellenadas por depósitos aluviales.

Nieto-Samaniego et al. (1999) propusieron que el mecanismo que produjo los eventos descritos fue el aumento en la tasa de subducción, produciéndose un diferencial entre las razones de subducción y convergencia, que al parecer alcanzó los valores críticos necesarios para producir extensión en la placa cabalgante. Las razones por las que el sector septentrional de la Mesa Central no fue afectado por este fenómeno son desconocidas, la única explicación que ha sido propuesta es que se relacione con la distinta tasa de expansión oceánica en la placa Pacífico al norte y sur de la zona de fractura Shirley. La tasa de expansión es $\sim 20 \%$ más alta al sur que al norte de la fractura Shirley durante el Oligoceno y Mioceno y se ubica alineada con la zona límite entre los segmentos norte y sur de la Mesa Central, si es restituida a su posición en el Oligoceno (Nieto-Samaniego et al., 1999).

Tanto el arco volcánico como la deformación extensional migraron hacia afuera de la Mesa Central durante el Mioceno, hacia el occidente y sur, localizándose hacia los márgenes de la Mesa Central. El volcanismo miocénico dentro de la Mesa Central está representado por dos conjuntos, uno localizado en el centro (San Luis Potosí y alrededores) y occidente (Durango) de la Mesa Central representado por basaltos fisurales que forman mesetas y que pertenecen a la Provincia Extensional del Norte de México, subprovincia Cuencas y Sierras meridional (véase Aranda-Gómez et al., 2005). El segundo conjunto de rocas volcánicas de edad miocénica aparece en el límite meridional de la Mesa Central representado tanto por aparatos centrales como por derrames fisurales, los cuales han sido considerados como parte de la Faja Volcánica Transmexicana. Todo este volcanismo estuvo asociado con fallamiento normal, aunque las tasas y magnitudes de deformación son mucho menores que el evento oligocénico (Alaniz-Alvarez et al., 2001).

El evento volcánico más reciente con el cual culmina la historia magmática en la Mesa Central y cuyas rocas aparecen discordantemente sobre las distintas unidades descritas, es un volcanismo alcalino de edad Plioceno-Cuaternario, que también forma parte de la Provincia Extensional del Norte de México, subprovincia Cuencas y Sierras meridional. Se trata de magmas provenientes del manto y que son portadores de xenolitos tanto del manto como de la corteza inferior. Sus características tanto en el estilo de volcanismo como petrológicas y geoquímicas, indican que debieron ascender rápidamente atravesando la corteza probablemente asociadas a zonas de fallas profundas que facilitaran su rápido ascenso (Aranda-Gómez et al., 2005), sin embargo no se ha podido documentar fallamiento con tasas y magnitudes de deformación grandes asociado a esos conjuntos volcánicos.

\section{Depósitos minerales en la Mesa Central}

Una de las particularidades de la Mesa Central es la cantidad y variedad de yacimientos minerales emplazados en esta provincia; entre ellos algunos de los depósitos más ricos de México. En este trabajo se ubican en el espacio y en el tiempo con el propósito de identificar posibles relaciones con los procesos geológicos ocurridos en la MC.

\subsection{Sulfuros masivos vulcanogénicos y Sedex}

En la Mesa Central de México, los depósitos minerales más antiguos con importancia económica son los cuerpos polimetálicos de sulfuros masivos de la región de Zacatecas, como Francisco I. Madero y El SalvadorSan Nicolás (Johnson et al., 1999; Miranda-Gasca, 2000; Olvera-Carranza et al., 2001). El depósito de Francisco I. Madero se ha interpretado como perteneciente a la tipología de depósitos sedimentario-exhalativos o Sedex, mineralizado en $\mathrm{Zn}-\mathrm{Pb}-\mathrm{Ag}-(\mathrm{Cu})$, mientras que El SalvadorSan Nicolás pertenece a la tipología de sulfuros masivos vulcanogénicos (o VMS), mineralizado en $\mathrm{Zn}-\mathrm{Cu}-(\mathrm{Ag}-$ $\mathrm{Au})$. En dichos distritos mineros también se encuentran skarns y vetas, posiblemente epitermales, formadas durante el Terciario. En un contexto análogo, en el distrito de Guanajuato también se encuentran pequeños depósitos de sulfuros masivos, de hasta $1 \mathrm{Mt}$, dentro del denominado complejo vulcanosedimentario de la Sierra de Guanajuato 
(Miranda-Gasca, 2000). Los depósitos de ambos tipos de sulfuros masivos se encuentran encajonados en las secuencias vulcanosedimentarias de arco submarino y de cuenca de trasarco del Jurásico Superior al Cretácico Inferior que afloran en la MC (Corona-Chávez y López-Picos, 1988; Freydier et al., 1996).

\subsection{Depósitos metalíferos en skarns}

Los depósitos metalíferos de tipo skarn son especialmente abundantes en los límites de la Mesa Central, que es donde se dan las condiciones esenciales para su formación. Cerca del límite noreste de la Mesa Central se hallan los depósitos de Providencia-Concepción del Oro, Zacatecas, con una edad de 26.6 Ma; cerca de su límite noroeste se hallan los de Mapimí, Durango, de 36.1 Ma; hacia su límite este los de Charcas (46.6 Ma) y Guadalcázar en San Luis Potosí, y en su límite suroeste se encuentra el distrito de San Martín, Zac. Las edades y principales características de estos depósitos fueron recopiladas por Megaw et al. (1988) a partir de numerosas fuentes. El distrito de San Martín contiene el mayor depósito de tipo skarn conocido en México (Aranda-Gómez, 1978; Rubin y Kyle, 1988), formado a raíz de la intrusión de un tronco cuarzo-monzonítico en las calizas cretácicas de la Formación Cuesta del Cura y con una edad K-Ar en biotita de 46.2 $\pm 1 \mathrm{Ma}$ (Damon et al., 1983). En la Formación Cuesta del Cura, así como en las Formaciones Soyatal y Tamaulipas (Coremi, 1996; Petersen et al., 2001), están encajonados los depósitos de Cerro San Pedro en San Luis Potosí. Los depósitos de tipo skarn de la Mesa Central y zonas aledañas, y los depósitos derivados, han sido históricamente fuente de $\mathrm{Ag}, \mathrm{Au}, \mathrm{Pb}$, $\mathrm{Zn}, \mathrm{Cu}, \mathrm{Sn}, \mathrm{Hg}, \mathrm{As}, \mathrm{Sb}, \mathrm{Bi}$ y fluorita.

\subsection{Depósitos epitermales}

En la Mesa Central, como en buena parte de la República Mexicana, la tipología de depósitos más notoria es la de los epitermales (Camprubí et al., 1998; 2003; Albinson et al., 2001; Camprubí y Albinson, en prensa), por ser la fuente más habitual de $\mathrm{Ag}$, así como también de $\mathrm{Au}, \mathrm{Bi}$, $\mathrm{Se}, \mathrm{Zn}, \mathrm{Pb}, \mathrm{Cu}, \mathrm{Hg}, \mathrm{As}, \mathrm{Sb}$, etc., y por pertenecer a dicha tipología muchos de los distritos mineros más famosos del país. Dentro de la Mesa Central, se encuentran, por ejemplo, Real de Asientos en Aguascalientes, Velardeña y Papanton en Dgo., Guanajuato y Pozos en Gto., Comanja de Corona en Jalisco, Santa María de la Paz y Real de Catorce en San Luis Potosí, Colorada, Fresnillo, Panuco, Pinos, Real de Ángeles, Saín Alto, Sombrerete y Zacatecas en Zac. (González-Reyna, 1956; Petruk y Owens, 1974; Salas, 1975; Buchanan, 1981; Albinson, 1985, 1988; Gemmell et al., 1988; Gilmer et al., 1988; Lang et al., 1988; Pearson et al., 1988; Ponce y Clark, 1988; Ruvalcaba-Ruiz y Thompson, 1988; Simmons et al, 1988; Mango et al.,
1991; Simmons, 1991; Coremi, 1992, 1996; Rivera, 1993; Gunnesch et al., 1994; Randall et al., 1994; Albinson et al., 2001). De las tipologías de depósitos minerales en la Mesa Central, los epitermales son posiblemente los más estudiados, dada su importancia económica.

Los depósitos epitermales conocidos hasta la fecha en México son de edad terciaria, desde el Luteciano (Eoceno medio) hasta el Aquitaniano (Mioceno temprano) (Camprubí et al., 2003), y su distribución espacial está en gran parte determinada por la evolución del vulcanismo de la Sierra Madre Occidental y de la Sierra Madre del Sur (ver Damon et al., 1981; Clark et al., 1982; Camprubí et al., 2003). La distribución de depósitos epitermales en México puede definirse según tres rangos de edades principales: (1) más antiguos de $\sim 40 \mathrm{Ma}$, entre los cuales se encuentra Real de Ángeles, (2) entre $\sim 40 \mathrm{y} \sim 27 \mathrm{Ma}$, que es el rango preferencial de formación de estos depósitos en México (entre 35 y 30 Ma, según Albinson, 1988) y que comprende el resto de depósitos de edad conocida en la Mesa Central, y (3) más recientes de $\sim 23 \mathrm{Ma}$.

Al sureste de la ciudad de Zacatecas se encuentra el distrito de Real de Ángeles, que contiene depósitos polimetálicos de $\mathrm{Pb}-\mathrm{Zn}-\mathrm{Ag}-(\mathrm{Cd})$ con una producción estimada de $85 \mathrm{Mt}$, lo que lo convierte en el depósito epitermal de mayor tonelaje en México. Sin embargo, no es el de mayor producción puesto que la mayor parte de la mineralización se halla como diseminaciones de baja ley en rocas carbonatadas, además de vetas y stockwork (Pearson et al., 1988; Megaw, 1999; Albinson et al., 2001). Su tonelaje es similar al de los depósitos de Pachuca-Real del Monte, Hgo., que tuvieron la mayor producción histórica del mundo, aunque en este distrito las leyes promedio son casi un orden de magnitud mayores que las de Real de Ángeles. Los otros depósitos epitermales de orden mayor y clase mundial en la Mesa Central son Guanajuato y Fresnillo, con producciones estimadas de 40 y $7 \mathrm{Mt}$, respectivamente, en vetas y mantos de alta ley (Albinson et al., 2001).

\subsection{Depósitos de óxidos de hierro tipo IOCG}

Uno de los depósitos minerales más conocidos de la Mesa Central es el depósito ferrífero Cerro de Mercado en Durango (Swanson et al., 1978; Lyons, 1988), mejor conocido mundialmente por sus apatitas de calidad gema. La formación de este depósito se produjo alrededor de 31.5 Ma, en las rocas volcánicas silícicas del Grupo Carpintero, cuya erupción se produjo a partir de la caldera de Chupaderos. La edad de este depósito se obtuvo mediante trazas de fisión y (U-Th)/He en apatita (Young et al., 1969; McDowell y Keizer, 1977; Farley, 2000), y la apatita de este depósito se usa habitualmente como estándar internacional en ambas técnicas. Lyons (1988) debatió ampliamente acerca del origen de este depósito, y argumentó su origen volcánico. Según la concepción actual de este tipo de depósitos, Cerro de Mercado pertenecería 
a la tipología de depósitos de óxidos de hierro-Cu-Au, o IOCG (Pollard, 2000), de los que sería un equivalente fanerozoico.

\subsection{Depósitos de reemplazamiento en carbonatos}

Bajo esta denominación se incluyen aquellos depósitos encajonados en carbonatos por medio de reemplazamiento que no corresponden a depósitos de tipo skarn, incluyendo tanto depósitos que se consideran como del tipo Mississippi Valley (MVT), como aquellos cuya filiación es aún incierta, si bien posiblemente deban considerarse también dentro de esa tipología. La mayoría de estos depósitos se encuentra ya en el límite este de la Mesa Central o ya dentro de la Sierra Madre Oriental, pero es conveniente incluirlos en esta relación. Estos depósitos son los de Las Cuevas y San José Tierras Negras (Wadley), S. L. P., y El Realito, Gto. (González-Reyna y White, 1947; González-Reyna, 1956; Ruiz et al., 1980; Coremi, 1992, 1996; Levresse et al., 2003). Los depósitos de fluorita de Las Cuevas, en concreto, son los mayores del mundo hasta la fecha: sólo el cuerpo "G" tiene más de $50 \mathrm{Mt}$, a casi $99 \%$ de fluorita y, en el global del distrito, más de 150 Mt con mineralización de alto grado. Además de las mineralizaciones de fluorita, dentro de la misma tipología, son notables las mineralizaciones antimoníferas, con algo de $\mathrm{Ag}, \mathrm{Pb}, \mathrm{Cu}, \mathrm{Hg}$ y $\mathrm{Zn}$, de Wadley, encajonadas en la Formación Zuloaga del Jurásico. La filiación de algunos de estos depósitos permanece un tanto incierta a espera de ser convenientemente estudiados.

\subsection{Otros tipos de depósitos}

En el margen noroeste de la Mesa Central se hallan numerosos yacimientos e indicios estanníferos en placeres aluviales del Cuaternario. Los depósitos más notables al respecto son posiblemente los de Sapiorís y América, Dgo., aunque la zona favorable abarca desde Sapiorís a Coneto de Comonfort. La mineralogía de los placeres de dicha zona se compone de casiterita, topacio, durangita $\mathrm{y}$, en menor medida, crisoberilo, esmeralda, oro y plata (Fabregat-G., 1966). Las áreas fuente de los depósitos de placer son las sierras aledañas conformadas por riolitas terciarias, en que se encuentran todavía algunas vetas estanníferas de origen neumatolítico a lo largo de zonas de brecha. La mayor parte de esas vetas se encuentra ya dentro de la Sierra Madre Occidental propiamente dicha. También se encuentran numerosos depósitos de $\mathrm{Sn}$ en vetas en Ahualulco, Villa de Arriaga y Villa de Reyes en San Luis Potosí, Ochoa en Dgo., en la sierra de Chapultepec en Zac., Cosío en Ags., y Tlaquicheros en Gto. (BrachoValle, 1960; Fabregat-G., 1966; Salas, 1975; Coremi, 1996). Las mineralizaciones más conocidas de topacio en domos riolíticos de la Mesa Central son las de Tepetate,
S. L. P. (Aguillón-Robles et al., 1994), mundialmente famosas por sus ejemplares de topacio de calidad gema. También son notables los placeres auríferos y estanníferos de Guadalcázar y El Realejo, S. L. P. (Coremi, 1996).

Como parte de la gran variedad de ambientes mineralogenéticos de la Mesa Central, cabe mencionar el distrito de Montaña de Manganeso, S. L. P. en que se encuentran vetas, stockworks y jasperoides hidrotermales mineralizados en manganeso, encajonados en la Formación Caracol del Cretácico Superior (Coremi, 1996). Igualmente, si bien su importancia es muy escasa, se encuentran depósitos supergénicos de alunita en Comonfort y Santa Cruz de Galeana, Gto. (GonzálezReyna, 1956). También se han hallado depósitos de fosfatos, esencialmente variscita, desarrollados por intemperismo sobre tobas riolíticas en La Herradura, S. L. P. (Coremi, 1996). Cabe destacar que no pocos depósitos metalíferos de cualquier tipo presentan zonas de gossan o alteración supergénica que incrementan el valor económico de los mismos, como en Real de Catorce, con clorargirita y bromargirita. Por último, es preciso mencionar que Salinas de Hidalgo, S. L. P., es una zona con abundantes prospectos de muy diversas sustancias de diferentes tipologías de depósito, son notorios los depósitos evaporíticos recientes de potasa, cloruros, sulfatos y carbonatos de sodio (Coremi, 1996).

\subsection{Consideraciones generales}

Teniendo en cuenta que el sistema de fallas San LuisTepehuanes (FSLT) ha sido funcional desde antes del Oligoceno, y que una gran parte de depósitos minerales en la Mesa Central o sus inmediaciones se hallan concentrados alrededor del FSLT (Figura 6), es razonable pensar que la formación de dichos depósitos puede estar fuertemente influenciada por el funcionamiento de este sistema de fallas. Una concentración similar, aunque de orden menor, se aprecia alrededor del sistema de fallas Taxco-San Miguel de Allende y de la falla del Bajío. En contraste, el sector septentrional de la Mesa Central aparece prácticamente vacío de depósitos minerales, salvo aquellos cuya formación no es directamente imputable a actividad magmática en ninguna forma. Además, visto que las tipologías de depósitos concentrados alrededor del FSLT (skarns, epitermales, IOCG, vetas de Sn) guardan una afinidad genética con fenómenos magmáticos, también es razonable pensar que el FSLT favoreció la canalización de magmas que, a su vez, conllevaron la formación de depósitos minerales. De forma no menos notoria, cabe considerar las sucesivas reactivaciones del FSLT identificadas, que ocurrieron en distintos segmentos de esta estructura y que abarcan desde el Eoceno medio hasta posiblemente el Mioceno temprano. Llama la atención que esas fases de reactivación del FSLT coinciden con el rango temporal preferencial para la formación de depósitos epitermales en la parte central de 


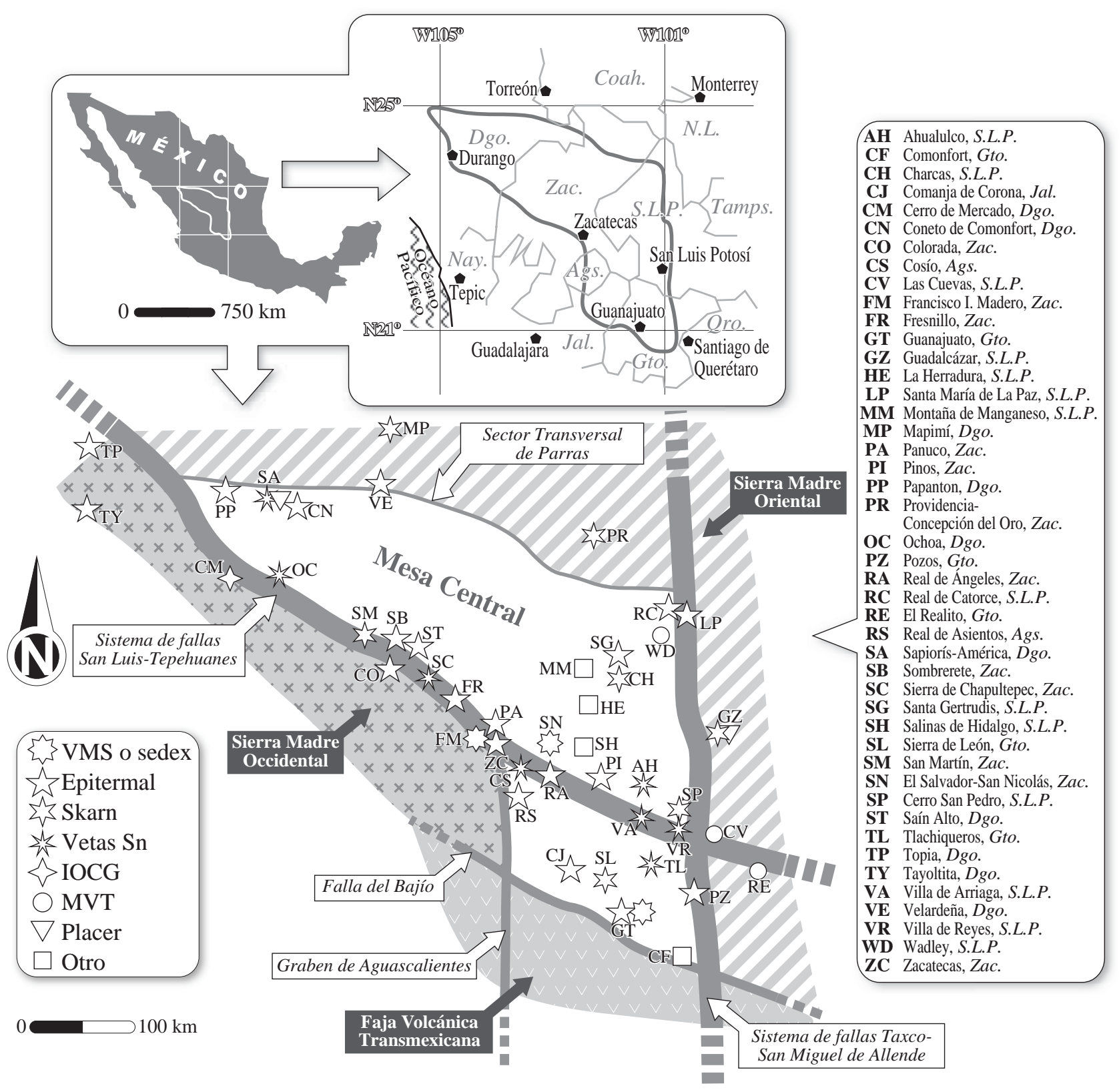

Figura 6. Mapa que muestra la localización de los principales depósitos minerales de la Mesa Central.

México (Albinson, 1988; Camprubí et al., 2003), así como de algunos depósitos metalíferos en skarns (Megaw et al., 1988) y del IOCG de Cerro de Mercado (Lyons, 1988). Cabe considerar que zonas de debilidad estructural de orden mayor como la FSLT, el sistema de fallas Taxco-San Miguel de Allende o la falla del Bajío pudieron favorecer altamente el emplazamiento de magmas, de fluidos de diversos tipos, y de depósitos minerales asociables a los mismos. De hecho, como ya se ha referido anteriormente, en los distritos mineros de las regiones de Zacatecas y Fresnillo, dentro del trazado de la FSLT, se ha documentado actividad de fallas normales y magmatismo durante el Eoceno tardío y el Oligoceno temprano, en el mismo tiempo en que se produjo la formación de los depósitos epitermales (Albinson, 1988; Lang et al., 1988; Ponce y Clark, 1988).

Sin embargo, todo ello no implica que el emplazamiento de magmas y depósitos minerales asociados se haya producido o deba producirse en las fallas principales propiamente dichas. En el caso de los depósitos epitermales, existe un importante control de los mismos por parte de fallas de escala regional en zonas con intensa fractura tensional (Mitchell y Balce, 1990; Nesbitt, 1990; Staude, 1993; Ponce y Glen, 2002). Dichas fallas determinan la localización de los depósitos y la guía para el emplazamiento de la fuente de calor magmática necesaria para la subsiguiente actividad hidrotermal que controla la duración de dicha actividad 
(Hedenquist, 1986; Fournier, 1987). Sin embargo, aunque las fallas de orden mayor ejercen un control directo sobre el emplazamiento de la mineralización, se ha observado que ésta suele disponerse de forma preferencial en fallas subsidiarias (White y Hedenquist, 1990). Acerca de los depósitos minerales de la Mesa Central, resta por evaluar el papel que juegan las fallas de orden menor caso por caso y cómo los depósitos se asocian a las fallas de orden mayor e, igualmente, determinar qué relación guardan las otras tipologías de depósitos minerales con dichas fallas. Por el momento sólo podemos señalar la coincidencia en edad y localización espacial, entre los depósitos minerales de la MC (especialmente los epitermales) y los sistemas de fallas mayores; haciendo hincapié en que estos grandes sistemas estructurales son regiones de la corteza a través de las cuales se canaliza la circulación de fluidos.

\section{Conclusiones}

La MC es una provincia fisiográfica que se reconoce por presentar una hipsografía con desniveles moderados, localizada en la parte centro-norte de México y que se encuentra rodeada por la Sierra Madre Occidental, Sierra Madre Oriental y Faja Volcánica Transmexicana. La deformación extensional cenozoica ha sido el principal factor que ha configurado esta provincia, los grandes sistemas de fallas que se localizan en ella han jugando un papel fundamental en su evolución geológica.

Los límites de la Mesa Central son, al norte el sistema Transversal de Parras de la Sierra Madre Oriental, al sur el sistemas de fallas del Bajío, al este el sistema de fallas Taxco-San Miguel de Allende y al oeste el graben de Aguascalientes y el sistema de fallas San Luis-Tepehuanes. En su interior se distinguen dos sectores, el septentrional, que se encuentra en un estado de erosión más avanzado y donde no se tienen evidencias de que haya ocurrido actividad tectónica significativa en el Neógeno; y el meridional, donde tuvieron lugar eventos tectónicos extensionales importantes en el Oligoceno y de menor magnitud del Mioceno al Cuaternario. El límite entre ambos segmentos es el sistema de fallas San Luis-Tepehuanes, el cual sigue burdamente el límite poniente de los afloramientos de rocas turbidíticas de edad triásica, los cuales han sido interpretados como la franja que delimitaba el continente en ese tiempo.

Se reconoce que la corteza de la Mesa Central se encuentra adelgazada con relación a las regiones colindantes al este y oeste, así como también la presencia en el Cuaternario-Reciente de zonas de fusión parcial en el manto superior que yace bajo la $\mathrm{MC}$, a las que se relaciona la emisión de basaltos alcalinos portadores de xenolitos del manto que se encuentran distribuidos en buena parte del segmento norte de la Mesa Central.

En el segmento sur se han realizado estudios más detallados que permiten establecer que la corteza de ese segmento experimentó un alargamiento cercano al $20 \%$ en dirección $\sim \mathrm{E}-\mathrm{W}$, ocurrido principalmente durante el Oligoceno temprano, pero abarcando deformaciones de intensidad menor hasta el Mioceno. En este sector ocurrió también magmatismo intenso de composición silícica durante el Oligoceno temprano, producido en gran medida por fusión parcial de la corteza

Dentro de la Mesa Central se observa que han tenido lugar fases de actividad magmática contemporáneas a la formación de depósitos minerales, eso ya había sido notado por otros autores para esta región y para otras regiones del país. Sin embargo, notamos que en la Mesa Central la distribución geográfica de los conjuntos volcánicos resulta mucho más amplia que la distribución de los depósitos minerales, y en el caso de las rocas volcánicas de la Sierra Madre Occidental, los depósitos se localizan mayoritariamente en su límite nororiental. Los depósitos minerales están ubicados preferentemente sobre las trazas de las estructuras mayores de la MC y sus edades coinciden con fases de actividad de esas estructuras. No obstante que estas relaciones espaciales y temporales son bastante evidentes, es muy poco lo que se ha estudiado sobre el papel que estos grandes sistemas de fallas han tenido en el emplazamiento de los depósitos minerales. Es razonable suponer que las zonas mas débiles de la corteza superior y más aún siendo estas zonas de fractura más intensa que sus alrededores, permitan una mayor circulación de fluidos, tanto magmáticos como hidrotermales, favoreciendo la localización de los depósitos minerales.

Por último, podemos señalar algunos problemas importantes que quedan por resolver:

- Es necesario obtener edades confiables de las secuencias volcanosedimentarias, para separar aquellas que corresponden a arcos volcánicos marinos de probable edad Jurásico Tardío-Cretácico Temprano, de rocas que pertenecen a las secuencias volcanosedimentarias triásicas, correlacionables con los afloramientos de Zacatecas.

- Los rellenos de las cuencas tectónicas cenozoicas no han sido estudiados desde un punto de vista sedimentológico; su estudio aportará sin duda información fundamental sobre temas diversos, considérese sólo como un ejemplo que contienen casi la totalidad de los acuíferos explotados actualmente en la Mesa Central, o bien que en ellas se encuentra el registro litológico y paleontológico para el tiempo de emplazamiento de las gigantescas secuencias ignimbríticas de la Sierra Madre Occidental.

- Aún falta mucho por refinar la estratigrafía volcánica cenozoica, para ello se requieren realizar fechamientos isotópicos de manera sistemática, con el fin de establecer de manera confiable correlaciones entre las unidades que afloran en las distintas sierras y que están separadas por cuencas sedimentarias. Hasta este momento la mayoría de esas correlaciones son litológicas, lo que en las rocas 
volcánicas resulta de una gran incertidumbre. Dado que la mayoría de las cuencas que separan sierras con afloramientos de rocas volcánicas son de origen tectónico, esos fechamientos servirán también para reconstruir la evolución de los sistemas estructurales y la historia tectónica.

- La migración del volcanismo durante el cenozoico hacia las márgenes de la $\mathrm{MC}$ ha sido documentado de manera muy general, pero los detalles de dicha migración, considerando edades, volúmenes de roca y estilos y composición del volcanismo, así como la deformación que migró conjuntamente con la actividad volcánica son aspectos que están pendientes por definirse.

- El papel que han jugado los grandes sistemas de fallas de la MC en los distintos eventos tectónicos que han tenido lugar durante el Cretácico y Cenozoico son aún oscuros. Su entendimiento requiere del estudio sistemático de esos sistemas estructurales mayores, así como de las rocas asociadas a ellos.

\section{Agradecimientos}

Este trabajo fue financiado por los proyectos PAPIIT IN102602 y CONACYT 41044-F. El modelo de elevación digital de la Figura 1 fue elaborado por Gabriel Origel. Se agradece a Luca Ferrari los numerosos comentarios y sugerencias sobre la tectónica y estratigrafía del occidente de México, así como la revisión del manuscrito; a Rafael Barboza-Gudiño su cuidadosa revisión y sugerencias, las cuales mejoraron sustancialmente este trabajo.

\section{Referencias}

Aguillón-Robles, A., Aranda-Gómez, J. J., Solorio-Munguía, J. G., 1994, Geología y tectónica de un conjunto de domos riolíticos del Oligoceno medio en el sur del estado de San Luis Potosí, México: Revista Mexicana de Ciencias Geológicas, 11, 29-42.

Aguirre-Díaz, G. J., McDowell, F., 1991, The volcanic section at Nazas, Durango, Mexico, the possibility of widespread Eocene volcanism in the Sierra Madre Occidental: Journal of Geophysical Research, 96, 13373-13388.

Aguirre-Díaz, G. J., McDowell, F. W., 1993, Nature and timing of faulting and synextensional magmatism in the southern Basin and Range, central-eastern Durango, Mexico: Geological Society of America Bulletin, 105, 1435-1444.

Aguirre-Díaz, G. J., Labarthe-Hernández, G., 2003, Fissure ignimbrites: fissure-source origin for voluminous ignimbrites of the Sierra Madre Occidental and its relationship with Basin and Range faulting: Geology, 31, 773-776.

Aguirre-Díaz, G. J., Nelson, S. A., Ferrari, L., López-Martínez, M., 1997, Ignimbrites of the central Mexican Volcanic Belt, Amealco and Huichapan Calderas (Querétaro-Hidalgo), en Aguirre-Díaz, G. J., Aranda-Gómez, J. J., Carrasco-Núñez, G., Ferrari, L. (eds.), Magmatism and tectonics of central and northwestern Mexico - A selection of the 1997 IAVCEI General Assembly excursions: México, D.F., Universidad Nacional Autónoma de México, Instituto de Geología, Excursión 1, 1-39.

Alaniz-Álvarez, S. A., Nieto-Samaniego, Á. F., 2005, El sistema de fallas Taxco-San Miguel de Allende y la Faja Volcánica Transmexicana, dos fronteras tectónicas del centro de México activas durante el Cenozoico: Boletín de la Sociedad Geológica Mexicana, 57(1), 65-82.

Alaniz-Álvarez, S. A., Nieto-Samaniego, Á. F., Reyes-Zaragoza, M. A., Orozco-Esquivel, M. T., Ojeda-García, Á. C., Vasallo-Morales, L. F., 2001, Estratigrafía y deformación de la región San Miguel de Allende-Querétaro: Revista Mexicana de Ciencias Geológicas, 18, 129-148.

Alaniz-Álvarez, S. A., Nieto-Samaniego, Á. F., Orozco-Esquivel, M. T., Vasallo-Morales, L. F., Xu, S. S., 2002, El sistema de Fallas TaxcoSan Miguel de Allende: implicaciones en la deformación postEocénica del centro de México: Boletín de la Sociedad Geológica Mexicana, 55(1), 12-29.

Albinson, T., 1985, Zoneamientos térmicos y su relación a la distribución mineral en algunos yacimientos epitermales en México, en XVI Convención Nacional, Memorias técnicas: Mazatlán, Sinaloa, Asociación de Ingenieros de Minas, Metalurgistas y Geólogos de México, $17 \mathrm{p}$.

Albinson, T., 1988, Geologic reconstruction of paleosurfaces in the Sombrerete, Colorada, and Fresnillo district, Zacatecas state, Mexico: Economic Geology, 83, 1647-1667.

Albinson, T., Norman, D. I., Cole, D., Chomiak, B., 2001, Controls on formation of low-sulfidation epithermal deposits in Mexico: constraints from fluid inclusion and stable isotope data, en Albinson, T., Nelson, C.E. (eds.), New mines and discoveries in Mexico and Central America. Littleton, Colorado, Society of Economic Geologists, Special Publication, 8, 1-32.

Alvarado-Méndez, H., Sánchez-Garrido, E., Pérez-Vargas, M. A., Caballero-Martínez, J. A., 1997, Carta geológico-minera Guanajuato F14-7, escala 1:250 000, segunda edición: Pachuca, Hidalgo, México, Consejo de Recursos Minerales, 1 mapa.

Aranda-Gómez, J. J., 1978, Metamorphism, mineral zoning, and paragenesis in the San Martín mine, Zacatecas, Mexico: Golden, Colorado, Colorado School of Mines, Tesis de maestría, 90 p.

Aranda-Gómez, J. J., 1993, Geotermometría y geobarometría en xenolitos del manto y de la base de la corteza en el estado de San Luis Potosí, México, en Xenolitos del manto y de la base de la corteza en el estado de San Luis Portosí, México: Universidad Nacional Autónoma de México, Boletín del Instituto de Geología, 106, parte 3, 37-61.

Aranda-Gómez, J. J., McDowell, F., 1998, Paleogene extension in the southern Basin and Range province of Mexico: syndepositional tilting of Eocene red beds and Oligocene volcanic rocks in the Guanajuato Mining District: International Geology Review, 40, 116-134.

Aranda-Gómez, J. J., Luhr, J. F., Nieto-Samaniego, Á. F., 1993a, Localidades recién descubiertas de xenolitos del manto y de la base de la corteza en el estado de San Luis Potosí, México, en Xenolitos del manto y de la base de la corteza en el estado de San Luis Potosí, México: Universidad Nacional Autónoma de México, Boletín del Instituto de Geología, 106, parte 2, 23-36.

Aranda-Gómez, J. J., Luhr, J. F., Pier, J. G., 1993b, Geología de los volcanes cuaternarios portadores de xenolitos del manto y de la base de la corteza en el estado de San Luis Potosí, México, en Xenolitos del manto y de la base de la corteza en el estado de San Luis Potosí, México: Universidad Nacional Autónoma de México, Boletín del Instituto de Geología, 106, parte 1, 1-22.

Aranda-Gómez, J. J., Henry, C.D., Luhr, J. F., McDowell, F. W., 1997, Cenozoic volcanism and tectonics in NW Mexico a transect across the Sierra Madre Occidental volcanic field and observations on extension related magmatism in southern Basin and Range and the Gulf of California tectonic provinces, en Aguirre-Díaz, G. J., ArandaGómez, J. J., Carrasco-Núñez, G., Ferrari, L., (eds.), Magmatism and tectonics in the central and the northwestern Mexico-A selection of the 19997 IAVCEI General Assembly excursions: México, D. F., Universidad Nacional Autónoma de México, Instituto de Geología, p. 41-84.

Aranda-Gómez. J. J., Henry, C. D., Luhr, J., 2000, Evolución tectonomagmática post-paleocénica de la Sierra Madre Occidental y de la porción meridional de la provincia tectónica de Cuencas y Sierras, México: Boletín de la Sociedad Geológica Mexicana, 
53(1), 59-71.

Aranda-Gómez. J. J., Henry, C. D., Luhr, J., McDowell, F. W., 2003, Cenozoic volcanic-tectonic development of northwestern Mexico - a transect across the Sierra Madre Occidental volcanic field and observations on extension-related magmatism in the southern Basin and Range and Gulf of California tectonic provinces, en Geologic transects across Cordilleran Mexico, Guidebook for field trips $99^{\text {th }}$ Annual Meeting of the Cordilleran Section of the Geological Society of America, México, D. F., March 25-30, 2003: Universidad Nacional Autónoma de México, Instituto de Geología, Centro de Geociencias, Publicación Especial 1, 71-121.

Aranda-Gómez, J. J., Housh, T. B., Luhr, J. F., Henry, C. D., Becker, T., Chávez-Cabello, G., 2005, Reactivation of the San Marcos fault during mid- to late Tertiary extension, Chihuahua, México, en Nourse, J. A., Anderson, T. H., McKee, J. W., Steiner, M. B. (eds.), The Mojave-Sonora megashear hypothesis: Development, assessment, and alternatives: Geological Society of America Special Paper, 393, 509-522.

Bacon, R. W., 1978, Geology of the northern Sierra de Catorce, San Luis Potosí, México: Arlington, Texas, University of Texas at Arlington, Tesis de maestría, $124 \mathrm{p}$.

Barboza-Gudiño, R., Tristán-González, M., Torres-Hernández, J. R., 1999, Tectonic setting of pre-Oxfordian units from central and northeastern Mexico: a review; en Bartolini, C., Wilson, J. L., Lawton, T. F. (eds.), Mesozoic sedimentary and tectonic history of north-central Mexico: Boulder, Colorado, Geological Society of America Special Paper, 340, 197-210.

Barboza-Gudiño, J. R., Hoppe, M., Gómez-Anguiano, M., MartínezMacías, P. R., 2004, Aportaciones para la interpretación estratigráfica y estructural de la porción noroccidental de la Sierra de Catorce, San Luis Potosí, México: Revista Mexicana de Ciencias Geológicas, 21, 299-319.

Bartolini, C., Lang, H., Stinnesbeck, W., 1999, Volcanic rock outcrops in Nuevo Leon, Tamaulipas and San Luis Potosí, Mexico: remnants of the Permian-early Triassic magmatic arc?; en Bartolini, C., Wilson, J. L., Lawton, T. F. (eds.), Mesozoic sedimentary and tectonic history of north-central Mexico: Boulder, Colorado, Geological Society of America Special Paper, 340, 347-355.

Bates, R. L., Jackson, J. A. (eds.), 1987, Glossary of geology, 3rd ed.: Alexandria, Va., American Geological Institute, 788 p.

Botsford, C. W., 1909, The Zacatecas district and its relation to Guanajuato and other camps: The Engineering and Mining Journal, 87, 12271228.

Bracho-Valle, F., 1960, Yacimientos de estaño en la Sierra de Chapultepec, Zac., La Ochoa, Dgo. y Cosío, Ags: Consejo de Recursos Naturales no Renovables, Boletín, 48, 116 p., 63 secciones plegadas, 31 láminas.

Buchanan, L. J., 1981. Precious metal deposits associated with volcanic environments in the Southwest, en Dickson, W. R., Payne, W. D. (eds.), Relations of tectonics to ore deposits in the southern Cordillera: Arizona Geological Society Digest, 14, 237-262.

Burckhardt, C., Scalia, S., 1906, Géologie des environs de Zacatecas, en $\mathrm{X}$ Internationale Géologique Congres, Guide excursion: México, Instituto Geológico de México, 1(16), 26 p.

Caballero-Martínez, J. A., Isabel-Blanci, J., Luévano-Pinedo, A., 1999, Carta geológico-minera Zacatecas F13-B58, escala 1:50 000: Pachuca, Hidalgo, México, Consejo de Recursos Minerales, 1 mapa.

Campos-Enriquez, J. O., Kerdan, T., Morán-Zenteno, D. J., UrrutiaFucugauchi, J., Sánchez-Castellanos, E., Alday-Cruz, R., 1992, Estructura de la litósfera superior a lo largo del Trópico de Cáncer: Geos, 12, 75-76.

Camprubí, A., Prol-Ledesma, R. M., Tritlla, J., 1998, Comments on "Metallogenic evolution of convergent margins: selected ore deposit models" by S. E. Kesler: Ore Geology Reviews 14, 71-76.

Camprubí, A., Ferrari, L., Cosca, M. A., Cardellach, E., Canals, A., 2003, Ages of epithermal deposits in Mexico: regional significance and links with the evolution of Tertiary volcanism: Economic Geology, 98, 1029-1038.

Camprubí, A., Albinson, T., en prensa, Los depósitos epitermales: revisión sobre el estado actual de su conocimiento, métodos de estudio y presencia en México: Boletín de la Sociedad Geológica Mexicana, 57(4).

Cantu-Chapa, C. M., 1969, Una nueva localidad Triásico Superior en México: Revista del Instituto del Petróleo, 1(2), 71-72.

Carranza-Castañeda, O., Petersen, M. S., Miller, W. E., 1994, Preliminary investigation of the Geology of northern San Miguel de Allende area, northeastern Guanajuato, Mexico: Brigham Young University, Geological Studies, 40, 1-9.

Carrasco-Núñez, G., Milán, M., Verma, S. P., 1989, Geología de Volcán El Zamorano, México: Revista del Instituto de Geología, 8, 194-201.

Carrillo-Bravo, J., 1971, La plataforma de Valles-San Luis Potosí: Boletín de la Asociación Mexicana de Geólogos Petroleros, 23, 110 p.

Centeno-García, E., Silva-Romo, G., 1997, Petrogenesis and tectonic evolution of central Mexico during Triassic-Jurassic time: Revista Mexicana de Ciencias Geológicas, 14, 244-260.

Chávez-Cabello, G., Aranda-Gómez, J. J., Molina-Garza, R. S., CossíoTorres, T. Arvizu-Gutiérrez, I. R., González-Naranjo, G., 2004, La Falla San Marcos: una estructura jurásica de basamento multireactivada del noreste de México: Boletín de la Sociedad Geológica Mexicana, 57(1), 27-52.

Chiodi, M., Monod, O., Busnardo, R., Gaspar, D., Sanchez, A., Yta, M., 1988, Une discordance ante Albienne datée par une faune d'ámmonites et de braquiopodes de type Téthysien au Mexique Central: Geobios, 21, 125-135.

Clark, K. F., Damon, P. E., Shafiquillah, M., Ponce, B. F., Cardenas, D., 1981, Sección geológica-estructural a través de la parte sur de la Sierra Madre Occidental, entre Fresnillo y la costa de Nayarit: Asociación Ingenieros Mineros, Metalúrgicos y Geólogos de México, Memoria Técnica, XIV, 69-99.

Clark, K. F., Foster, C. T., Damon, P. E., 1982, Cenozoic mineral deposits and subduction-related magmatic arcs in Mexico: Geological Society of America Bulletin, 93, 533-544.

Consejo de Recursos Minerales (Coremi), 1992, Monografía geológicominera del estado de Guanajuato: México, Secretaría de Energía, Minas e Industria Paraestatal, Consejo de Recursos Minerales, Publicación M-6e, 136 p., 4 láminas.

Consejo de Recursos Minerales (Coremi), 1996, Monografía geológicominera del estado de San Luis Potosí: México, Secretaria de Energía, Minas e Industria Paraestatal, Consejo de Recursos Minerales, Publicación M-7e, 217 p., 1 mapa, 2 láminas.

Córdoba-Méndez, D. A., 1988, Estratigrafía de las rocas volcánicas de la región entre Sierra de Gamón y Laguna de Santiaguillo, estado de Durango: Universidad Nacional Autónoma de México, Revista del Instituto de Geología, 7, 136-147.

Corona-Chávez, P., López-Picos, A., 1988, Análisis estratigráficoestructural de la secuencia volcánico-sedimentaria metamorfizada de la Sierra de Guanajuato, en IX Convención Geológica Nacional, Resúmenes: México, Sociedad Geológica Mexicana, 104.

Damon, P. E., Shafiqulla, M., Kenneth F., Clark, K. F., 1981, Evolución de los arcos magmáticos en México y su relación con la metalogénesis: Universidad Nacional Autónoma de México, Revista del Instituto de Geología, 6, 223-239.

Damon, P. E., Shafiqullah, M., Clark, K. F., 1983, Geochronology of the porphyry copper deposits and related mineralization of Mexico. Canadian Journal of Earth Sciences, 20, 1052-1071.

De Cserna, Z., 1976, Geology of the Fresnillo area, Zacatecas, Mexico: Geological Society of America Bulletin, 87, 1191-1199.

Edwards, J. D., 1955, Studies of some early Tertiary red conglomerates of Central Mexico: U. S. Geological Survey, Professional Paper, 264-H, 183 p.

Eguiluz-de Antuñano, S., 1984, Tectónica cenozoica del norte de México: Boletín de la Asociación Mexicana de Geólogos Petroleros, 36, 43-62.

Eguiluz-de Antuñano, S., Aranda-García, M., Marrett, R., 2000, Tectónica de la Sierra Madre Oriental, México: Boletín de la Sociedad Geológica Mexicana, 53, 1-26.

Fabregat-G., F. J., 1966, Los minerales mexicanos 3. Durantita: Universidad Nacional Autónoma de México, Boletín del Instituto de Geología, 77, 113 p. 
Farley, K. A., 2000, Helium diffusion from apatite: general behaviour as illustrated by Durango fluorapatite: Journal of Geophysical Research, 105(B2), 2903-2914.

Ferrari L., López-Martínez M., Rosas-Elguera J., 2002, Ignimbrite flare up and deformation in the southern Sierra Madre Occidental, western Mexico: implications for the late subduction history of the Farallon plate: Tectonics, 21(4), 17-1/24.

Ferrari, L., Valencia-Moreno, M., Bryan, S., 2005, Magmatismo y tectónica en la Sierra Madre Occidental y su relación con la evolución de la margen occidental de Norteamérica: Boletín de la Sociedad Geológica Mexicana, 57(3), 343-378.

Fix, J. E., 1975, The crust and upper mantle of central Mexico: Geophysical Journal of the Royal Astronomical Society, 43, 453-499.

Fournier, R. O., 1987, Conceptual models of brine evolution in magmatichydrothermal systems. en Decker, R.W., Wright, T.L., Stauffer, P.H. (eds.), Volcanism in Hawaii, vol. 2: U.S. Geological Survey, Professional Paper, 1350, 1487-1506.

Franco-Rubio, M., 1999, Geology of the basement below the decollement surface, Sierra de Catorce, San Luis Potosí, México, en Bartolini, C., Wilson, J. L., Lawton, T. F. (eds.), Mesozoic sedimentary and tectonic history of north-central Mexico: Boulder, Colorado, Geological Society of America Special Paper, 340, 211-227.

Freydier, C., Martinez- R., J., Lapierre, H., Tardy, M. Coulon, C., 1996, The early Cretaceous Arperos Basin (western Mexico), Geochemical evidence for an aseismic ridge formed near a spreading center: Tectonophysics, 259, 343-367.

Gemmell, J. B., Simmons, S. F., Zantop, H., 1988, The Santo Niño silver-lead-zinc vein, Fresnillo District, Zacatecas, Mexico; Part I. Structure, vein stratigraphy, and mineralogy: Economic Geology, $83,1597-1618$

Gilmer, A. L., Clark, K. F., Conde, J., Hernández, I., Figueroa, J. I., Porter, E. W., 1988, Sierra de Santa María, Velardeña mining district, Durango, Mexico: Economic Geology, 83, 1802-1829.

González-Reyna, J., 1956, Riqueza minera y yacimientos minerales de México, 3a edición: México, Banco de México, 497 p., 15 láminas.

González-Reyna, J., White, D. E., 1947, Los yacimientos de antimonio de San José, Sierra de Catorce, estado de San Luis Potosí: Comité Directivo para la Investigación de los Recursos Minerales de México, Boletín, 14, 36 p.

Gross, W. H., 1975, New ore discovery and source of silver-gold veins, Guanajuato, Mexico: Economic Geology, 70, 1175-1189.

Gunnesch, K. A., Torres del Ángel, C., Cuba Castro, C., Sáez, J., 1994. The $\mathrm{Cu}-(\mathrm{Au})$ skarn and $\mathrm{Ag}-\mathrm{Pb}-\mathrm{Zn}$ vein deposits of $\mathrm{La} \mathrm{Paz}$, northeastern Mexico: mineralogical, paragenetic, and fluid inclusion characteristics: Economic Geology, 89, 1640-1650.

Hayob, J. L., Essene, E. J., Ruiz, J., Ortega-Gutiérrez, F., Aranda-Gómez, J. J., 1989, Young high-temperature granulites from the base of the crust in central Mexico: Nature, 342, 265-268.

Hedenquist, J. W., 1986, Geothermal systems in the Taupo volcanic zone: their characteristics and relation to volcanism and mineralization, en Smith, I.E.M. (ed.), Late Cenozoic volcanism in New Zealand: Royal Society of New Zealand Bulletin, 23, 134-168.

Henry, C. D., Aranda-Gómez, J. J., 2000, Plate interactions control middlelate Miocene, proto-Gulf and Basin and Range extension in the southern Basin and Range: Tectonophysics, 318, 1-26.

Hernández-Laloth, N., 1991, Modelo conceptual de funcionamiento hidrodinámico del sistema acuífero del valle de León, Guanajuato: México, D. F.: Universidad Nacional Autónoma de México, Facultad de Ingeniería, Tesis profesional, $129 \mathrm{p}$.

Hernández-Sánchez-Mejorada, S., López Ramos, E., 1968, Carta Geológica de la República Mexicana escala 1:2 000 000: México, Comité de la Carta Geológica de México, Universidad nacional Autónoma de México, Instituto de Geología, 1 mapa.

Hoppe, M., Barboza-Gudiño, J. R., Schulz, H. M., 2002, Late Triassic submarine fan deposits in northwestern San Luis Potosí, Méxicolithology, facies and diagenesis: Neues Jahrbuch füer Geologie und Paläontogie, Monatshefte, 12, 705-724.

Huspeni, J. R., Kesler, S. E., Ruiz, J., Tuta, Z., Sutter, J. F., Jones, L. M., 1984, Petrology and geochemistry of rhyolites associated with tin mineralization in northern Mexico: Economic Geology, 79, 87-105.

Imlay, R. W., 1938, Studies of the mexican geosyncline: Bulletin of the Geological Society of America, 49, 1651-1694.

Instituto Nacional de Estadística, Geografía e Informática (INEGI), 2004, Mapa digital de México: México, Instituto Nacional de Estadística, Geografía e Informática, Sistemas Nacionales Estadístico y de Información Geográfica, acceso libre en <http://galileo.inegi.gob.mx/website/mexico/viewer.htm?c=423>

Iriondo, A., Kunk, M. J., Winick, J. A., Coremi, 2003, 40Ar/39Ar dating studies of minerals and rocks in various areas in Mexico: USGS/ Coremi scientific collaboration (Part I): U. St. Geological Survey, Open-File Report, (03-020), 79 p. on-line edition, <http://pubs.usgs.gov/of/2003/ofr-03-020/>

Jiménez-Nava, F. J., 1993, Aportes a la estratigrafía de Aguascalientes mediante la exploración geohidrológica a profundidad, en Simposio sobre la geología del Centro de México, resúmenes y guía de excursión: Universidad de Guanajuato, Facultad de Minas, Metalurgia y Geología, Extensión Minera, 1, 93.

Johnson, B., Montante, A., Kearvell, G., Janzen, J., Scammell, R., 1999, Geology and exploration of the San Nicolás polymetallic $(\mathrm{Zn}-\mathrm{Cu}-$ $\mathrm{Au}-\mathrm{Ag}$ ) volcanogenic massive sulphide deposit, en Ambor, J. L. (ed.), VMS and carbonate-hosted polymetallic deposits of Central Mexico: Vancouver, B.C.: British Columbia and Yukon Chamber of Mines, Cordillera Roundup, Special Volume, 45-54.

Kerdan, T. P., 1992, Estructura de la corteza y manto superior en el norte de México (a lo largo del Trópico de Cáncer desde Baja California hasta el Golfo de México): México, Universidad Nacional Autónoma de México, Colegio de Ciencias y Humanidades, Unidad Académica de los Ciclos Profesionales y de Posgrado, Tesis de maestría, 347 p.

Labarthe-Hernández, G., Jiménez-López, L. S., 1992, Características físicas y estructura de lavas e ignimbritas riolíticas en la Sierra de San Miguelito, S. L. P.: Universidad Autónoma de San Luis Potosí, Instituto Geología, Folleto Técnico, 114, 31 p., 4 láminas.

Labarthe-Hernández, G., Jiménez-López, L. S., 1993, Geología del domo Cerro Grande, Sierra de San Miguelito, S. L. P.: Universidad Autónoma de San Luis Potosí, Instituto Geología, Folleto Técnico, 117, 22 p., 3 láminas.

Labarthe-Hernández, G., Jiménez-López, L. S., 1994, Geología de la porción sureste de la Sierra de San Miguelito, S. L. P.: Universidad Autónoma de San Luis Potosí, Instituto Geología, Folleto Técnico, 120, 34 p., 2 mapas.

Labarthe-Hernández, G., Tristán-González, M., 1980, Cartografía geológica hoja Santa María del Río, San Luis Potosí: Universidad Autónoma de San Luis Potosí, Instituto de Geología y Metalurgia, Folleto Técnico, 67, $32 \mathrm{p}$.

Labarthe-Hernández, G., Tristán-González, M., Aranda-Gómez, J. J., 1982, Revisión estratigráfica del Cenozoico de la parte central del estado de San Luis Potosí: Universidad Autónoma de San Luis Potosí, Instituto de Geología, Folleto Técnico, 85, 208 p., 1 mapa, 2 secciones.

Labarthe-H., G., Tristán-G., M., Aguillón-R., A., Jiménez-L., L. S., Romero, A., 1989, Cartografía geológica 1:50 000 de las hojas El Refugio y Mineral El Realito, estados de San Luis Potosí y Guanajuato: Universidad Autónoma de San Luis Potosí, Instituto de Geología, Folleto Técnico, 112, 76 p., 4 láminas.

Lang, B., Steinitz, G., Sawkins, F. J., Simmons, S. F., 1988, K-Ar age studies in the Fresnillo silver district, Zacatecas, Mexico: Economic Geology, 83, 1642-1646.

Lapierre, H., Ortiz, L. E., Abouchami, W., Monod, O., Coulon, Ch., Zimmermann, J. L., 1992, A crustal section of an intra-oceanic island arc: the late Jurassicc-early Cretaceous Guanajuato magmatic sequence, central México: Earth and Planetary Sciences Letters, 108, 61-77.

Levresse, G., González-Partida, E., Tritlla, J., Camprubí, A., CienfuegosAlvarado, E., Morales-Puente, P., 2003, Fluid characteristics of the world-class, carbonate-hosted Las Cuevas fluorite deposit (San Luis Potosí, Mexico): Journal of Geochemical Exploration, 78-79, 537-543.

López-Doncel, R., 2003, La Formación Tamabra del Cretácico medio en la porción central del margen occidental de la Plataforma Valles- 
San Luis Potosí, centro-noreste de México: Revista Mexicana de Ciencias Geológicas, 20(1), 1-19.

López-Infanzón, M., 1986, Estudio petrogenético de las rocas ígneas en las formaciones Hizachal y Nazas: Boletín de la Sociedad Geológica Mexicana, 47, 1-42.

López- Monroy, P., 1888, Las minas de Guanajuato, Anales del Ministerio de Fomento (México), 10, México, 69 p.

Loza-Aguirre, I., 2005, Estudio estructural de la actividad cenozoica del sistema de fallas San Luis-Tepehuanes de la región Zacatecas-San José de Gracia: Cd. Madero, Tamaulipas, Instituto Tecnológico de Ciudad Madero, Ingeniería en Geociencias, Tesis profesional, 96 p., 1 mapa.

Lugo-Hubp, J., 1989, Diccionario geomorfológico: México, D.F., Universidad Nacional Autónoma de México, Instituto de Geografía, $337 \mathrm{p}$.

Luhr, J. F., Pier, J. G., Aranda-Gomez, J. J., Podosek, F. A., 1995, Crustal contamination in early Basin-and-Range hawaiites of the Los Encinos Volcanic Field, central Mexico: Contributions to Mineralogy and Petrology, 118(4), 321-339.

Lyons, J.I., 1988, Volcanogenic iron oxide deposits, Cerro de Mercado and vicinity, Durango, Mexico: Economic Geology, 83, 1886-1906.

Magonthier, M. C., 1988, Distinctive rhyolite suites in the mid-Tertiary ignimbritic complex of the Sierra Madre Occidental, western Mexico: Bulletin de la Societe Geologique de France, Huitieme Serie, 4(1), 57-68.

Mango, H., Zantop, H., Oreskes, N., 1991, A fluid inclusion and isotope study of the Rayas Ag-Au-Cu-Pb-Zn mine, Guanajuato, Mexico: Economic Geology, 86, 1554-1561.

Martínez-Reyes, J., 1992, Mapa geológico de la Sierra de Guanajuato con resumen de la geología de la Sierra de Guanajuato: Universidad Nacional Autónoma de México, Instituto de Geología, Cartas Geológicas y Mineras, 8, 1 mapa con resumen de la geología.

Martínez-Ruiz, J., Cuellar-González, G., 1978, Correlación de superficie y subsuelo de la cuenca geohidrológica de San Luis Potosí, S. L. P.: Universidad Autónoma de San Luis Potosí, Instituto Geología, y Metalurgia, Folleto Técnico, 65, 25 p., 1 mapa.

McDowell, F. W., Keizer, R. P., 1977, Timing of mid-Tertiary volcanism in the Sierra Madre Occidental between Durango City and Mazatlan, Mexico: Geological Society of America Bulletin, 88, 1479-1487.

McGehee, R., 1976, Las rocas metamórficas del arroyo de La Pimienta, Zacatecas, Zac.: Boletín de la Sociedad Geológica Mexicana, 37, $1-10$.

Megaw, P. K. M., 1999, The high-temperature, Ag-Pb-Zn- $(\mathrm{Cu})$ carbonate replacement deposits of Central Mexico, en: Ambor, J. L. (ed.), VMS and carbonate-hosted polymetallic deposits of Central Mexico: Vancouver, B.C.: British Columbia and Yukon Chamber of Mines, Cordillera Roundup, Special Volume, 25-44.

Megaw, P. K. M., Ruiz, J., Titley, S. R., 1988, High-temperature, carbonatehosted Ag-Pb- $\mathrm{Zn}(\mathrm{Cu})$ deposits of Northern Mexico: Economic Geology, 83, 1856-1885.

Meyer, R. P., Steinhart, J. S., Woolard, G. P., 1958, Seismic determination of crustal structure in the central plateau of Mexico: Transanctionsm American Geophysical Union, 39, 525.

Miranda-Gasca, M. A., 2000. The metallic ore deposits of the Guerrero terrane, western Mexico: an overview. Journal of South American Earth Sciences, 13, 403-413.

Mitchell, A. H. G., Balce, G. R., 1990, Geological features of some epithermal gold systems, Philippines, en Hedenquist, J.W., White, N.C., Siddeley, G. (eds.), Epithermal gold mineralization of the Circum-Pacific: geology, geochemistry, origin and exploration, I: Journal of Geochemical Exploration, 35, 241-296.

Monod, O., Calvet, P. H., 1991, Structural and Stratigraphic reinterpretation of the Triassic units near Zacatecas (Zac.), Central Mexico: Evidence of Laramide nappe pile: Zentralblatt für Geologie und Paläontologie, Teil 1, 1533-1544.

Montellano-Ballesteros, M., 1992, Una edad del Irvingtoniano al Rancholabreano para la fauna Cedazo del estado de Aguascalientes: Universidad Nacional Autónoma de México, Revista del Instituto de Geología, 9, 195-203.

Moore, G., Marone, C., Carmichael, I. S. E., Renne, P., 1994, Basaltic volcanism and extension near the intersection of the Sierra Madre volcanic province and the Mexican Volcanic Belt: Geological Society of America Bulletin, 106, p. 383-394.

Morán-Zenteno, D.J., Caballero-Miranda, C.I., Silva-Romo, G., OrtegaGuerrero, B., González-Torres, E., 1993, Jurassic-Cretaceous paleogeographic evolution of the northern Mixteca terrane, southern Mexico: Geofisica Internacional, 32, 453-473.

Morán-Zenteno, D. J., Martiny, B., Tolson, G., Solis-Pichardo, G., AlbaAldave, L., Hernández-Bernal, M. S., Macías-Romo, C., MartínezSerrano, R., Schaaf, P., Silva-Romo, G., 2000, Geocronología y características geoquímicas de las rocas magmáticas terciarias de la Sierra Madre del Sur: Boletín de la Sociedad Geológica Mexicana, 53, 27-58.

Moreira-Rivera, F., Flores-Aguillón, G., Martínez-Rodríguez, L., PalaciosGarcía, R., Chiapa-García, R., Olvera-Campos, A., Pérez-Benavidez, A., González-Monsivais, P., 1998, Carta geológico-minera San Luis Potosí F14-4, escala 1:250 000: Pachuca, Hidalgo, México, Consejo de Recursos Minerales, 1 mapa.

Mortensen, J. K., Hall, B. V., Bissig, T., Friedman, R. M., Danielson, T., Oliver, J., Rhys, D. A., and Ross, K. V., 2003, U-Pb zircon age and $\mathrm{Pb}$ isotopic constrains on the age and origin of volcanogenic massive sulfide deposits in the Guerrero terrane of central Mexico, en: 99th Annual Meeting Cordilleran Section: Geological Society of America, Abstracts with Programs, 35, 61-62.

Mujica-Mondragón, M. R., Jacobo-Albarrán, J., 1983, Estudio petrogenético de las rocas ígneas y metamórficas del Altiplano Mexicano: México, Instituto Mexicano del Petróleo, Proyecto C-1156, 78 p.

Munguía-Rojas, P., García-Padilla, J. L., Armenta-Román, R., Camacho, J. M., 2000, Carta geológico-minera Santiago Papasquiaro G13-8, Durango, escala 1:250 000: Pachuca, Hidalgo, México, Consejo de Recursos Minerales, 1 mapa.

Muñoz, F., 1993, Modelo genético de los depósitos de oro del proyecto San Martín, Querétaro, en: XX Convención Nacional, Memorias técnicas: México, Asociación de Ingenieros de Minas, Metalurgistas y Geólogos de México, 20, 246-260.

Murillo-Muñetón, G., Torres-Vargas, R., 1987, Mapa petrogenético y radiométrico de la República Mexicana: Instituto Mexicano del Petróleo, Subdirección de Tecnología de Exploración, informe del proyecto C-2010, 78 p., inédito

Nesbitt, B. E., 1990. Fluid flow and chemical evolution in the genesis of hydrothermal ore deposits, en Nesbitt, B.E. (ed.), Short Course on Fluids in Tectonically Active Regimes of the Continental Crust, Shorth Course Handbook: Toronto, Ontariom Mineralogical Association of Canada, 18, 261-297.

Nieto-Samaniego, Á. F., 1990(1992), Fallamiento y estratigrafía cenozoicos en la porción sudoriental de la Sierra de Guanajuato: universidad Nacional Autónoma de México, Revista del Instituto de Geología, 9, 146-155.

Nieto-Samaniego, Á. F., Macías-Romo Consuelo, Alaniz-Álvarez, S. A., 1996, Nuevas edades isotópicas de la cubierta volcánica cenozoica de la parte meridional de la Mesa Central, México: Revista Mexicana de Ciencias Geológicas, 13, 117-122.

Nieto-Samaniego, Á. F., Alaniz-lvarez, S. A., Labarthe-Hernández, G., 1997, La deformación cenozoica poslaramídica en la parte meridional de la Mesa Central, México: Revista Mexicana de Ciencias Geológicas, 14, 13-25.

Nieto-Samaniego, Á. F., Ferrari, L., Alaniz-Álvarez, S. A., LabartheHernández, G., Rosas-Elguera, J., 1999, Variation of Cenozoic extension and volcanism across the southern Sierra Madre Occidental volcanic province, Mexico: Geological Society of America Bulletin, 111, 347-363.

Ojeda-García, Á. C., 2004, Cartografía Geológica 1:50 000 del límite El Bajío-Mesa Central, Porción Salamanca-Irapuato, estado De Guanajuato, Mexico: Hermosillo, Sonora, Centro de Estudios Superiores del Estado de Sonora, Unidad Académica Hermosillo, Carrera de Ingeniero en Geociencias, Tesis profesional, 86 p., 1 mapa.

Olvera-Carranza, K., Centeno, E., Camprubí, A., 2001, Deformation and distribution of massive sulphide deposits in Zacatecas, Mexico, en: Pietrzynsi, A., et al. (eds.), Mineral deposits at the beginning of the 
21st century: Lisse, Swets \& Zeitlinger Publishers, 313-316.

Orozco-Esquivel, M. T., Nieto-Samaniego, Á. F., Alaniz-Álvarez, S. A., 2002, Origin of rhyolitic lavas in the Mesa Central, Mexico, by crustal melting related to extension: Journal of Volcanology and Geothermal Research 118, 37-56.

Ortega-Gutiérrez, F., Mitre-Salazar, L. M., Roldán-Quintana, J., Aranda-Gómez, J. J., Morán-Zenteno, D.J., Alaniz-Álvarez, S.A., Nieto-Samaniego, Á.F., 1992, Carta geológica de la República Mexicana, quinta Edición, escala 1:2 000 000: México, D. F., Universidad Nacional Autónoma de México, Instituto de Geología; Secretaría de Energía, Minas e Industria Paraestatal, Consejo de Recuros Minerales, 1 mapa.

Pantoja-Alor, J., 1963, Hoja San Pedro del Gallo, estado de Durango, escala 1:100 000: México, D.F., Universidad Nacional Autónoma de México, Instituto de Geología, Carta Geológica de México, 1 mapa.

Pasquarè, G., Ferrari, L., Garduño, V. H., Tibaldi, A., Vezzoli, L., 1991, Geologic map of the central sector of the Mexican Volcanic belt, States of Guanajuato and Michoacán: Geological Society of America Map and Chart series MCH072, 1 mapa con texto explicativo, $20 \mathrm{p}$.

Pearson, M. F., Clark, K. F., Porter, E. W., 1988, Mineralogy, fluid characteristics, and silver distribution at Real de Ángeles, Zacatecas, Mexico: Economic Geology, 83, 1737-1759.

Pérez-Venzor, J. A., Aranda-Gómez, J. J., McDowell, F., Solorio-Munguía, J. G., 1996, Geología del volcán Palo Huérfano, Guanajuato, México: Revista Mexicana de Ciencias Geológicas, 13, 174-183.

Petersen, M. A., Della Libera, M., Jannas, R.R., Maynard, S.R., 2001, Geology of the Cerro San Pedro porphyry-related gold-silver deposit, San Luis Potosí, Mexico, en Albinson, T., Nelson, C.E. (eds.), New mines and discoveries in Mexico and Central America: Littleton, Colorado, Society of Economic Geologists, Special Publication, $8,217-241$.

Petruk, W., Owens, D., 1974, Some mineralogical characteristics of the silver deposits in the Guanajuato mining district, Mexico: Economic Geology, 69, 1078-1085.

Pollard, P. J., 2000, Evidence of a magmatic fluid and metal source for Fe-oxide Cu-Au mineralization, en Porter, T.M. (ed.), Hydrothermal iron oxide copper-gold \& related deposits: a global perspective: Glenside, South Australia, Australia, Australian Mineral Foundation, $1,27-41$

Ponce, B. F., Clark, K. F., 1988, The Zacatecas Mining District: A tertiary caldera complex associated with precious and base metal mineralization: Economic Geology, 83, 1668-1682.

Ponce, D. A., Glen, J. M. G., 2002, Relationship of epithermal gold deposits to large-scale fractures in Northern Nevada: Economic Geology, 97, 3-9.

Quintero-Legorreta, O., 1992, Geología de la región de Comanja, estados de Guanajuato y Jalisco: Universidad Nacional Autónoma de México, Revista del Instituto de Geología, 10, 6-25.

Raisz, E., 1959, Landforms of Mexico, scale ca. 1:3 000 000: Cambridge, Massachussetts, U. S. Office of Naval Research, Geography Branch, 1 mapa.

Randall, J. A., Saldaña, E., Clark, K.F., 1994, Exploration in a vulcanoplutonic center at Guanajuato, Mexico: Economic Geology, 89, $1722-1754$

Rangin, C., 1977, Sobre la presencia de Jurásico Superior con amonitas en Sonora septentrional: Universidad Nacional Autónoma de México, Revista del Instituto de Geología, 1, 1-14.

Ranson, W. A., Fernández, L. A., Simmons, W. B., Enciso-de la Vega, S., 1982, Petrology of the metamorphic rocks of Zacatecas, Mexico: Boletín de la Sociedad Geológica Mexicana, 41, 37-59.

Rivera J., Ponce L., 1986, Estructura de la corteza al oriente de la Sierra Madre Occidental, México, basada en la velocidad del grupo de las ondas Rayleigh: Gofísica Internacional, 25, 383-402.

Rivera, R., 1993, Cocientes metálicos e inclusiones fluidas del distrito minero de Real de Asientos, Aguascalientes, en XX Convención Nacional, Memorias técnicas: México, Asociación de Ingenieros de Minas, Metalurgistas y Geólogos de México, 310-325.

Roldán-Quintana, J., 1968, Estudio geológico de reconocimiento de la región de Peñón Blanco, estado de Durango: Boletín de la Sociedad
Geológica Mexicana, 31, 79-105.

Rubin, J. N., Kyle, J. R., 1988, Mineralogy and geochemistry of the San Martín skarn deposit, Zacatecas, Mexico: Economic Geology, 83, 1782-1801.

Ruiz, J., Kesler, S. E., Jones, L. M., Sutter, J. F., 1980, Geology and geochemistry of the Las Cuevas fluorite deposit, San Luis Potosí, Mexico: Economic Geology, 75, 1200-1209.

Ruvalcaba-Ruiz, D.C., Thompson, T.B., 1988, Ore deposits at the Fresnillo mine, Zacatecas, Mexico: Economic Geology, 83, 1583-1596.

Salas, G. P., 1975, Carta y provincias metalogenéticas de la República Mexicana: México, Consejo de Recursos Minerales, Publicación, 21E, 242 p., 1 mapa.

Sánchez-Zavala, J. L., Centeno-García, E., Ortega-Gutiérrez, F., 1999, Review of Paleozoic stratigraphy of Mexico and its role in the Gondwana-Laurentia connections, en Ramos, V. A., Keppie, J. D. (eds.), Laurentia-Gondwana connections before Pangea: Boulder, Colorado, Geological Society of America Special Paper, 336, 211-226.

Silva-Romo, G., 1996, Estudio de la estratigrafía y estructuras tectónicas de la Sierra de Salinas, Edos. de S. L. P. y Zac.: Universidad Nacional Autónoma de México, Facultad de Ciencias, División de Estudios de Posgrado, Tesis de Maestría, 139 p.

Silva-Romo, G., Arellano-Gil, J., Mendoza-Rosales, C., Nieto-Obregón, J., 2000, A submarine fan in the Mesa Central Mexico: Journal of South American Earth Sciences, 13, 429-442.

Simmons, S. F., 1991, Hydrologic implications of alteration and fluid inclusion studies in the Fresnillo District, Mexico. Evidence for a brine reservoir and a descending water table during the formation of hydrothermal $\mathrm{Ag}-\mathrm{Pb}-\mathrm{Zn}$ ore bodies: Economic Geology, 86, 1579-1601.

Simmons, S. F., Gemmell, J.B., Sawkins, F.J., 1988, The Santo Niño silver-lead-zinc vein, Fresnillo District, Zacatecas, Mexico; part II. Physical and chemical nature of ore-forming solutions: Economic Geology, 83, 1619-1641.

Smith, L., 1995, Evolución dinámica y ocurrencia de mineralización, veta El Herrero, en XXI Convención Nacional, Memorias técnicas: México, Asociación de Ingenieros de Minas y Metalurgistas de México, 21, $13 \mathrm{p}$.

Staude, J. M. G., 1993, Gold, silver, and base metal epithermal mineral deposits around the Gulf of California, Mexico: relationship between mineralization and mayor structures, en Scott, R.W. Jr., Detra, P.S., Berger, B.S. (eds.), Advances related to United States and international mineral resources: developing frameworks and exploration technologies: U.S.Geological Survey, Bulletin, (2039), 69-78.

Swanson, E. R., 1989, A new type of maar volcano from the State of Durango-the El Jagüey-La Breña complex reinterpreted: Universidad Nacional Autónoma de México, Revista del Instituto de Geología, 8, 243-248.

Swanson, E. R., Keizer, R. P., Lyons, J. I., Clabaugh, S. E., 1978, Tertiary volcanism and caldera development near Durango City, Sierra Madre Occidental, Mexico: Geological Society of America Bulletin, 89, 1000-1012.

Tardy M., Maury R., 1973, Sobre la presencia de elementos de origen volcánico en las areniscas de los flyschs de edad Cretácica superior de los estados de Coahuila y Zacatecas: Boletín de la Sociedad Geológica Mexicana, 34, 5-12.

Tristán-González, M., 1986, Estratigrafía y tectónica del graben de Villa de Reyes en los estados de San Luis Potosí y Guanajuato, México: Universidad Autónoma de San Luis Potosí, Instituto de Geología, Folleto Técnico, 107, $91 \mathrm{p}$.

Tristán-González, M., 1987, Cartografía geológica Hoja Tierra Nueva, San Luis Potosí: Universidad Autónona de San Luis Potosí, Instituto de Geología y Metalurgia, Folleto Técnico, 109, 103 p.

Trujillo-Candelaria, J. A., 1985, Origen del fallamiento, en Flores-Núñez, J., (ed.), Fallamiento de terrenos en Celaya: Celaya, Guanajuato, Sociedad Mexicana de Mecánica de Suelos, 3-9.

Tuta, Z. H., Sutter, J. F., Kesler, S. E., Ruiz, J., 1988, Geochronology of mercury, tin, and fluorite mineralization in northern Mexico, Economic Geology, 83(8), 1931-1942. 
van der Lee, S., Nolet, G., 1997, Seismic image of the subducted trailing fragments of the Farallon plate: Nature, 386, 266-269.

Verma, S. P., Carrasco-Núñez, G., 2003, Reappraisal of the geology and geochemistry of Volcán Zamorano, Central Mexico: implications for the discrimination of the Sierra Madre Occidental and Mexican Volcanic Belt province: International Geology Review, 45, 724752.

Webber, K. L., Fernández, L. A., Simmons, B., 1994, Geochemistry and mineralogy of the Eocene-Oligocene volcanic sequence, southern Sierra Madre Occidental, Juchipila, Zacatecas, México: Geofísica Internacional, 33, 77-89.

White, N. C., Hedenquist, J.W., 1990, Epithermal environments and styles of mineralization: variations and their causes, and guidelines for exploration, en Hedenquist, J.W., White, N.C., Siddeley, G. (eds.), Epithermal gold mineralization of the Circum-Pacific: geology, geochemistry, origin and exploration, II. Journal of Geochemical Exploration, 36, 445-474.

Xu, S. S., Nieto-Samaniego, Á.F., Alaniz-Álvarez, S. A., 2004, Vertical shear mechanism of faulting and estimation of strain in the Sierra de San Miguelito, Mesa Central, Mexico: Geological Acta, 2, 189-201.
Yamamoto, J., 1993, Actividad microsísmica en el área de Canatlán, Durango y su relación con la geología regional: Geofísica Internacional 32, 501-510.

Young, E. J., Myers, A. T., Munson, E.L., Conklin, N.M., 1969, Mineralogy and geochemistry of fluorapatite from Cerro de Mercado, Durango, Mexico: U.S. Geological Survey, Professional Paper, (650-D), D84-D93.

Zárate-del Valle, P. F., 1982, Geología y análisis metalogénico de la Sierra de Catorce: Boletín de la Sociedad Geológica Mexicana,.43, 1-21.

Manuscrito recibido: Febrero 4, 2005

Manuscrito corregido recibido: Octubre 10, 2005

Manuscrito aceptado: Octubre 12, 2005 